\title{
Invasive Species Curriculum ${ }^{1}$
}

\author{
Charles Jacoby, Nanette Holland, and Debbi Berger ${ }^{2}$
}

\section{UF | FLORIDIDA IFAS Extension}

The Institute of Food and Agricultural Sciences (IFAS) is an Equal

Opportunity Institution authorized to provide research, educational information and other services only to individuals and institutions that function with nondiscrimination with respect to race, creed, color, religion, age, disability, sex, sexual orientation, marital status, national origin, political opinions or affiliations. For more information on obtaining other extension publications, contact your county Cooperative Extension service.

U.S. Department of Agriculture, Cooperative Extension Service, University of Florida, IFAS, Florida A. \& M. University Cooperative Extension Program, and Boards of County Commissioners Cooperating. Larry Arrington, Dean.

\section{Copyright Information}

This document is copyrighted by the University of Florida, Institute of Food and Agricultural Sciences (UF/IFAS) for the people of the State of Florida. UF/IFAS retains all rights under all conventions, but permits free reproduction by all agents and offices of the Cooperative Extension Service and the people of the State of Florida. Permission is granted to others to use these materials in part or in full for educational purposes, provided that full credit is given to the UF/IFAS, citing the publication, its source, and date of publication.

\footnotetext{
${ }^{1}$ This document is CIR1496, an Invasive Species Curriculum comprising 12 activities that also are available separately (CIR1501-CIR1512). This document is reprinted by permission of the Tampa Bay Estuary Program and The Florida Aquarium. Original EDIS publication date: January, 2007. It was supported by the Tampa Bay Estuary Program, the Florida Aquarium, the Department of Fisheries and Aquatic Sciences of the University of Florida, and the National Sea Grant College Program of the National Oceanic and Atmospheric Administration (NOAA), U.S. Department of Commerce, under NOAA Grant No. NA 16RG2195. Visit the EDIS Web Site at http://edis.ifas.ufl.edu.

${ }^{2}$ Charles Jacoby, Assistant Professor, Department of Fisheries and Aquatic Sciences, Cooperative Extension Service, Institute of Food and Agricultural Sciences, University of Florida, Gainesville, 32611; Nanette Holland, Public Outreach Coordinator, Tampa Bay Estuary Program, 100 8th Avenue S.E., MS I-1 / NEP, St. Petersburg, FL 33701; Debbi Berger, Vice President of Education, The Florida Aquarium, Inc., 701 Channelside Drive, Tampa, Florida, 33602.
} 
This page was intentionally left blank. 
Invasive Species

Series
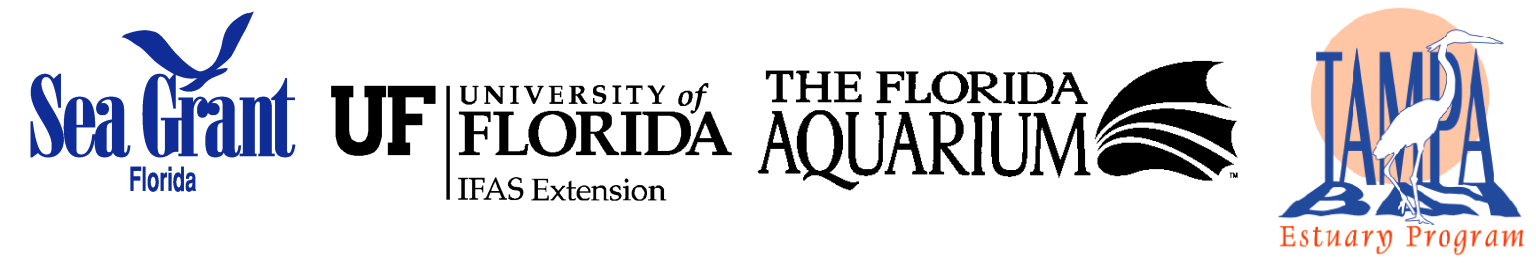

\section{Invasive Species Curriculum}

\section{Contents}

- Acknowledgments and Introduction

- Vocabulary Master List

- Suggested W eb Sites

- Activities:
- A Dichotomous W hat?
- By Land, By Sea, By Air...
- Classroom Takeover!
- How Many Are REALLY O ut There!???
- How W ell Do You Know Your N eighbors?
- Invaders Galore!
- Lionfish... Could They Invade O ur W aters?
- Made For Eating!
- O ne Mean W eed!
- The Race For Space!
- Ssssneaky, Pesssky, Ssspeciesss!
- The Green Machine

- Species Fact Sheets 
This page was intentionally left blank. 
Invasive Species

Series

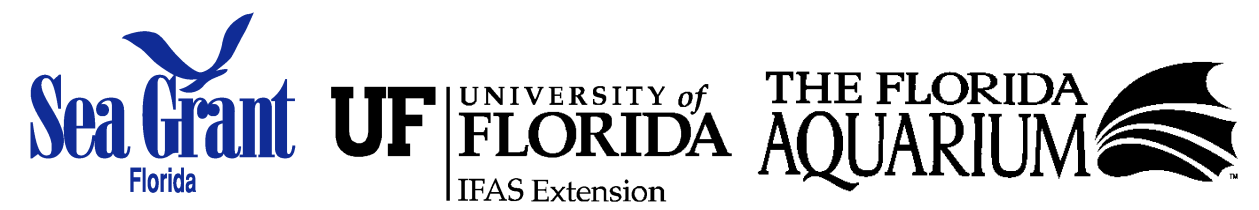

\section{Invasive Species Curriculum}

Revised February 2006

This curriculum contributes to education about invasive species. We hope students and teachers use it to improve their awareness and understanding of these issues so that they can make better decisions and help prevent plant and animal invasions. Please use these activities, let us know what you think, and check for updates by going to:

http://www.tbep.org/eyesonthebay.html\#1

http://www.flseagrant.org/program_areas/ecosystem_health/ecohealth_cp.htm\#invasive

\section{Acknowledgments}

Curriculum Development:

The Florida Aquarium

Tampa Bay Estuary Program

Funding:

Tampa Bay Estuary Program

Florida Sea Grant

Advisors:

Southwest Florida Water Management District Florida Sea Grant

Indian River Lagoon National Estuary Program

Rookery Bay National Estuarine Research Reserve
Florida Sea Grant

UF/IFAS Cooperative Extension Service

UF/IFAS Cooperative Extension Service

Florida Fish and Wildlife Research Institute St Johns River Water Management District Guana-Tolomato-Matanzas National Estuarine Research Reserve 


\section{Introduction}

Invasive species have been introduced into an area that is not part of their natural range, and they cause harm to the economy, the environment or human health. We should all be concerned about invasive species and the harm they cause. First, we want to avoid harmful consequences from introductions. Second, our actions or activities can spread invasive species, so we are responsible for managing both introductions and consequences. Managing invasive species is not simply a matter of banning all introductions, because all of us benefit from some introductions. In addition, many introductions are accidental or unintentional making bans difficult to enforce.

People began introducing species when they began traveling. For example, Europeans transported Old World species to their new settlements in the Western Hemisphere and elsewhere. The cargo manifests from Columbus' second and subsequent voyages indicate deliberate transport of species regarded as potential crops and livestock. Humans continue to disperse species today, and the worldwide increase in plant, animal, and microbial introductions roughly tracks the increase in human transport and commerce. In particular, the meteoric growth of global commerce in the past 200 to 500 years has produced numerous opportunities for biotic invasions.

Introduced species often do not survive and reproduce. Therefore, they seldom establish themselves and become invasive. Introducing species without management can be viewed as a game of chance. We 'take a chance' by moving species beyond their natural ranges and introducing them into new ranges. We risk having the introduced species become established, spread and cause harm. As in any game of chance, the outcome of a given round is uncertain. We may introduce numerous species or one species numerous times and suffer on significant consequences, or we may introduce a single species once and generate considerable harm.

Management of invasive species occurs at the international, national and state levels. Management plans at all levels typically recognize prevention or control of introductions as the key to success. Once a species establishes and spreads, eradication or control become costly and often difficult or impossible. Surveillance for non-native species and rapid removal before they establish and spread is the second best defense. Management plans also recognize the need for research, education and outreach. Gathering and disseminating better information can help us manage invasive species. For example, informed decision-makers should make better choices about large-scale, intentional introductions, and an informed public can modify its behavior to prevent small-scale intentional or accidental introductions. 


\section{Invasive Species \\ Series

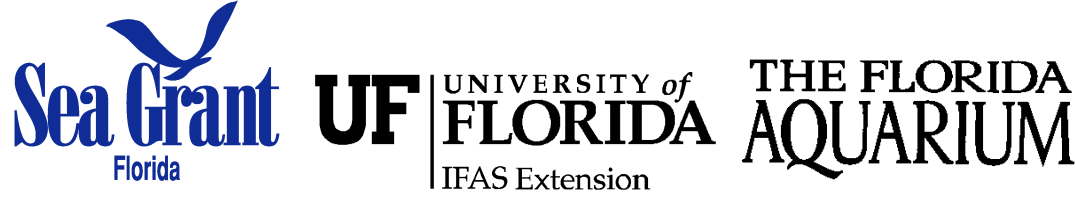

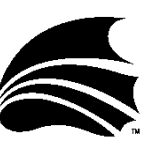

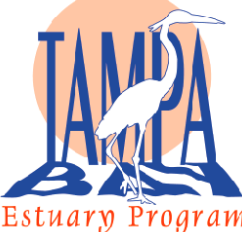

\section{Vocabulary Master List}

Anatomy - The study of the parts of an organism in order to ascertain their position, relationship, structure and function.

Aquatic - Living or growing in, on, or near water.

Ballast - W ater or other heavy material placed in the hold of a ship for stability.

Biodiversity - The variety of plant and animal species present in an ecosystem.

Camoufiage - Colors and patterns that help an object blend in with its surroundings.

Compete - The process of two or more organisms demanding limited environmental resources, such as nutrients, living space or light.

Compressiform - Body flat from side to side and tall and thin when viewed from the front.

Depressiform - Body flattened from top to bottom and wide and thin when viewed from the front.

Dichotomous - Divided or dividing into two parts or classifications.

Dichotomous key - A series of questions that leads to the identification of a species.

Disperser - An organism that spreads or distributes fruits and/or seeds from a stationary parent plant.

Emarginate - H aving a notched margin.

Eradicate - Eliminate, exterminate, remove.

Filiform - Long, skinny, tube-shaped body.

Forked - Having two or more branches or points.

Fusiform - Streamlined oval-shaped body.

Invader/Invasive species - A plant or animal that is not native and causes harm, including disrupting natural ecosystems. 
Invasion rate - How quickly invasive species are being established in a geographic region. A rate is a change in something over time.

Lunate - Shaped like a crescent or quarter-moon.

Morphology - The study of organisms' structure or form.

Native species - A plant or animal that originated in a certain place. A species occurring in its natural range. Species that were present in Florida at the time the first Spanish settlers arrived.

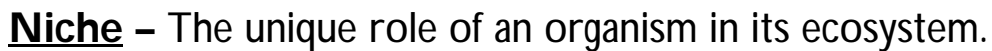

Nitrogen - A nutrient required in large amounts as an essential component of proteins, nucleic acids and other cellular constituents.

Nitrogen fixation - 0 rganisms cannot use nitrogen gas $\left(\mathrm{N}_{2}\right)$, but the gas can be "fixed" or converted into ammonia by bacteria.

Non-native species - A species introduced to a region intentionally or accidentally.

Pathway - The means by which a species is moved from place to place and introduced.

Perennial - A plant that is lasting or active through the year or many years.

Plankton - Small, aquatic plants or animals that cannot swim strongly, so they drift with currents.

Point transect - A series of points surveyed along a tape measure anchored at a random point and stretched to a predetermined length.

Predator - An organism that feeds on another organism.

Quadrats - Survey grids of a fixed size and shape.

Rounded - C urved or shaped like part of a circle.

Species - A basic taxonomic group that subdivides a genus; it comprises individuals of common ancestry that strongly resemble each other physiologically and interbreed to produce fertile offspring.

Taxonomy - The science of classifying organisms into groups or taxa.

Truncate - Short and square or slightly rounded. 


\section{Invasive Species \\ Series
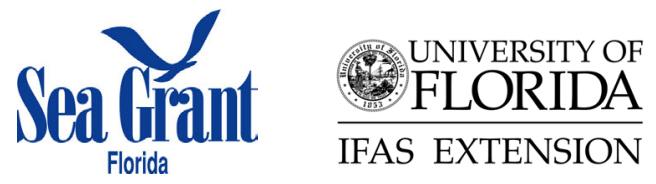

\section{Suggested Web Site List}

\section{Compiled March 2005}

\section{Educational:}

http://www.invasivespecies.org/resources/

Educational resources about invasive species

http://www.iisgcp.org/edk-12/escape/escape.htm

Exotic Species Compendium of Activities to Protect the Ecosystem (ESCAPE) for teachers and students

http://www.sgnis.org/kids/index.html

$\mathrm{Nab}$ the Aquatic Invader (a site for youth)

http://www.nps.gov/invspcurr/alienhome.htm

A middle school curriculum about invasive weeds, particularly in national parks

\section{Florida and the Gulf of Mexico:}

http://www.dep.state.fl.us/lands/invaspec/index.htm

Florida Department of Environmental Protection Bureau of Invasive Plant

Management

http://research.myfwc.com/features/category main.asp?id=1952

http://floridafisheries.com/Fishes/non-native.html

Information on invasive species from the Florida Fish and Wildlife Conservation

Commission

http://fleppc.org/websites.htm

Florida Exotic Pest Plant Council's web links

http://www.epa.gov/gmpo/nonindig.html

Information on invasive species, especially in the Gulf of Mexico region

http://nis.gsmfc.org/

Non-native aquatic species in the Gulf of Mexico and south Atlantic regions

http://aquat1.ifas.ufl.edu/

Center for Aquatic and Invasive Plants; University of Florida Institute of Food and Agricultural Sciences

http://plants.ifas.ufl.edu/seagrant/aquinv.html

Non-native and invasive aquatic wetland plants

http://www.tbep.org/eyesonthebay.html\#1

Eyes on the Bay from the Tampa Bay Estuary Program, includes publications and video lending library 


\section{National:}

http://www.invasivespecies.gov/

Federal programs related to the Executive Order on Invasive Species, with links to the Invasive Species Council and the National Invasive Species Management Plan

http://www.wws.princeton.edu/ ota/disk1/1993/9325_n.html

Invasive species in the US Office of Technology Assessment Report 1993

http://www.nps.gov/plants/alien/index.htm

Weeds Gone Wild: Alien Plant Invaders of Natural Areas

http://www.aphis.usda.gov/

Animal and Plant Health Inspection Service

http://ceris.purdue.edu/napis/

National Agricultural Pest Information System (NAPIS)

http://spfnic.fs.fed.us/exfor/

Exotic Forest Pest Information System for North America

http://www.nbii.gov/

National Biological Information Infrastructure will yield information on invasive species

http://www.sgnis.org/

National Sea Grant nonindigenous species site

http://www.aquaticinvaders.org/nan_ld.cfm

National Sea Grant aquatic nuisance species clearinghouse

http://nas.er.usgs.gov/

United States Geologic Survey site on nonindigenous aquatic species

http://www.serc.si.edu/labs/marine_invasions/

Smithsonian Environmental Research Center marine invasions program

http://www.anstaskforce.gov/

National Aquatic Nuisance Species Task Force homepage

http://habitatattitude.net

Site for aquarium hobbyists, backyard pond owners, water gardeners and others who are concerned about aquatic resource conservation

$\underline{\text { http://protectyourwaters.net }}$

Site for recreational users who want to help stop aquatic nuisance species

\section{Other regions:}

http://www.northeastans.org/

Northeast Aquatic Nuisance Species Panel under the Aquatic Nuisance Species Task Force

http://www.iisgcp.org/EXOTICSP/

Information on exotic species, especially in the Great Lakes region

http://www.glc.org/ans/

Great Lakes Aquatic Nuisance Species Panel under the Aquatic Nuisance Species

Task Force

http://www.dnr.state.wi.us/org/land/er/invasive/index.htm

Wisconsin Department of Natural Resources; Ecologically Invasive Species

http://vnps.org/invasive.html

The Virginia Native Plant Society with information on invasive alien plant species 
http://www.state.va.us/ dcr/dnh/invlist.htm

Invasive Alien Plant Species of Virginia

http://invader.dbs.umt.edu/

Invaders Database System at the University of Montana

http://endeavor.des.ucdavis.edu/weeds/

California Noxious Weed Control Projects Inventory

http://tncweeds.ucdavis.edu/index.html

weed control handbook from the University of California, Davis

http://ballast-outreach-ucsgep.ucdavis.edu/

Outreach dealing with ballast water on the west coast

http://www.swrcb.ca.gov/ rwqcb9/programs/caulerpa/caulerpa.html

Information on Caulerpa taxifolia in California

http://www.sbg.ac.at/ipk/avstudio/pierofun/ct/caulerpa.htm

Information on Caulerpa taxifolia and its invasion of the Mediterranean

http://farrer.riv.csu.edu.au/ASGAP/APOL16/dec99-2.html

Weeds - The Silent Invaders: Australian Plants Online

\section{Identification:}

http://plants.usda.gov/

Plants Database; can search by common or scientific name

http://florawww.eeb.uconn.edu/

Ecology \& Evolutionary Biology Conservatory; Family Index Menu

http://bonap.org/

The Biota of North America Program (North Carolina Botanical Garden, University of North Carolina)

http://www.fleppc.org/ID_book.htm

Identification and Biology of Non-Native Plants in Florida's Natural Areas

\section{General:}

http://web.uflib.ufl.edu/msl/invspecies.html

University of Florida Libraries Subject Guide on Invasive Species; many useful links

http://invasions.bio.utk.edu/

Institute of Invasions; various species featured

http://www.inhs.uiuc.edu/edu/VMG/VMG.html

Vegetation Management Guideline 
This page was intentionally left blank. 


\section{Invasive Species \\ Series

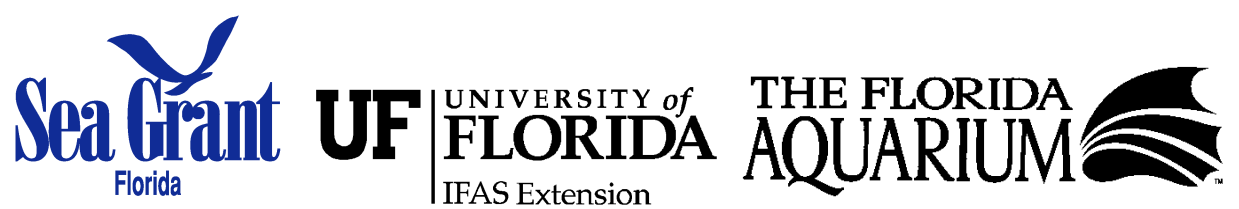

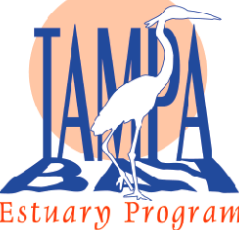

\section{A Dichotomous What?}

\begin{abstract}
Sneak PeeK
Students will be introduced to

concepts and issues surrounding

invasive species. Florida has a

large number of invaders, and

some are harder to identify

than others. Students will learn

about different invaders and

ways they can distinguish the $m$

from native species. This

activity incorporates a

dichotomous key and

environmental investigations.
\end{abstract}

Aligned with the following

$S$ unshine State $S$ tandards and

$\mathcal{F C A T}$ Benchmarks for grades

$6-8:$

$S$ C.D.1.3.3 CS

$S$ C.D.1.3.4 $\mathcal{A A}$

SC.F.2.3.3 CS

S C.F.1.3.1 AA

$S C . G .1 .3 .2 C S$

SC.F.1.3.7 CS

$\mathcal{A} \mathcal{A}=$ annually assessed

$C S=$ content sampled

\section{Objectives:}

Students will...

- Learn how to use a dichotomous key.

- Collect information on specific Florida invasive species.

- Demonstrate an understanding of how to use a dichotomous key.

- Be able to identify different Florida invaders.

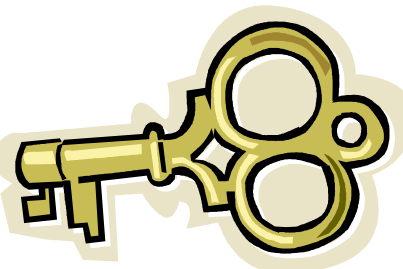

\section{Materials:}

- Internet access, books or articles on invasive species of Florida.

- Copies of Florida A quarium species fact sheets.

- Examples of plant and animal dichotomous keys.

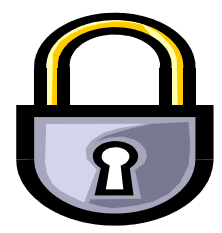

Background:

\section{What is an invader?}

An invasive species, or invader, is a plant or animal that is not native to a particular area. It causes harm, including disrupting natural ecosystems. Today, there are many invasive species thriving in Florida. Invasive species may compete with native species for food and living space. A successful invader can take over space in which a native species would normally live. Eventually, invasive species may cause a loss of biodiversity by reducing the number of species found in a given area. 


\section{H ow can you distinguish invaders from native species?}

At times, it can be difficult to tell different animals or plants apart so scientists have developed a method to identify different species. Scientists use taxonomy to classify different organisms into groups or taxa. A dichotomous key uses a series of questions about visible characteristics to help scientists identify species of plants or animals. By using yes and no questions about the characteristics of an item, you can identify exactly what that item is. In order to understand how a dichotomous key works, complete the attached shoe activity.

\section{Procedure:}

1. To gain an understanding of how a key like this works, follow the instructions for using the Dichotomous Key of Shoes.

2. In groups, have the students choose one or two invasive species from a list of Florida invasive species.

3. Using the Internet, books and other resources, have students gather information about the invaders they chose.

4. After researching different invaders, have the students create their own dichotomous key for the invaders they chose. Make sure to stress the importance of asking yes or no questions and using specific characteristics of that species. Hand out the attached example keys.

5. Have the students provide a short presentation about the main characteristics they used to identify their invader. Allow the students to exchange their dichotomous keys to see if they can identify different species.

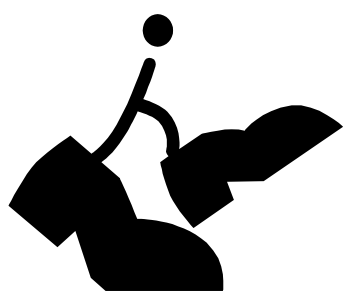




\section{Example of Dichotomous Key for Plants}

1. Ne edles in 6undles/groups. (go to \#2)

1. $\mathcal{N}$ e edles single or flattened ersaly. (go to \#6)

2. Needles in clusters. Tamarack

2. Needles 2.5 per 6 undle. (go to \#3)

3. Five needles per bundle. White Pine

3. Needles in pairs. (go to \# 4)

4. Needles 3 - 4 inches long. Red or Norway Pine

4. Needles under 2 inches. (go to \#5)

5. Bark darkgray. Iack Pine

5. Bark orange-6rown. Scots Pine

6. Ne edles square, round or scaly. (go to \# 7)

6. Ne edles flat. (go to \# 9)

7. Needles scaly, flattened. orthern White Cedar

7. Needles square or round. (go to \#8)

8. Ne edles 1/3-3/4 inchlong, twigs hairless. White Spruce

8. Needles 1/4-3/4, new twigs with hair. BlackSpruce

9. Shrub. Canada Yew

9. Tree. (go to \# 10)

10. Needles $1 / 2$ inch long with short ste m. Eastern He mlock

10. Needles 3/4 -1 1/4 inches long, no stem. Balsam Fir 


\section{Example of a Dichotomous Key for Animals}

1a. This organism has an exoskeleton (go to question 2)

1b. This organism has an endoskeleton or no skeleton (go to question 3)

2a. This organism has thin black body and a red stripe on its abdomen (go to question 4a.)

$2 b$. This organism has a thick black body and large grey/brown abdomen (go to question $4 b$ ).

3a. O rganism dwells on land (go to question 5)

3b. O rganism dwells in the ocean (go to question 6)

4a. O rganism is Latrodectus hasselti (black widow spider)

4b. O rganism is Atrax infensus (funnel-web spider)

5a. O rganism is totally covered in smooth scale-like skin (go to question 7)

5b. O rganism has a textured coat or covering (go to question 8)

6a. O rganism has 8 thick legs or tentacles (go to question 9a.)

6b. Has many string-like legs or tentacles (go to question 9b.)

7a. Scale-like skin is patterned in horizontal stripes over the body (go to question 10a.)

7b. Scale-like skin has one block color over most of its body (go to question 10b.)

8a. Has fine fur-like covering (go to question 11)

8b. Has feather-like covering over most of its body (go to question 12)

9a. O rganism is Hapalochlaena lunulata (blue-ringed octopus)

9b. O rganism is Chironex flecken (sea wasp)

10a. O rganism is Psuedonaja texilis (tiger snake)

10b. O rganism is Pseudechis porphyricus (red-bellied black snake)

11a. Has two opposing thumbs on the front paws (go to question 13a.)

11b. Has no opposing thumb on the front paws (go to question 13b.)

12a. Has large bone-like structure on a bald, blue-skinned head (go to question 14a.)

12b. Has feather-like covering over head with no bone-like structure (go to question 14b.)

13a. O rganism is Phascolatarctos cinerus (koala)

13b. 0 rganism is Vombatus ursinus (wombat)

14a. $O$ rganism is Casuarius casuarius (cassowary)

14b. 0 rganism is Dromaius novaebollandiae (emu) 


\section{Dichotomous Key of Shoes}

\section{Procedure:}

1. Arrange chairs in a circle.

2. Instructor takes off one shoe (can also be done with shoe laces or watches) and places it in the middle of the circle.

3. Each student will take off one shoe and place it in the circle.

4. The students now have to divide the shoes into two piles. The piles do not have to be equal but everyone must agree on an obvious characteristic to distinguish the two piles. (e.g. all the shoes in one pile have laces or all the shoes are brown)

5. Record the two characteristics on the board.

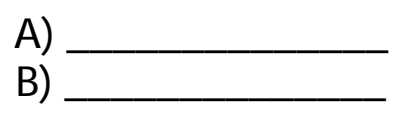

FIG. 1

6. Return to the pile of shoes. Push one pile aside for the moment and divide the other pile of shoes into two distinct piles. Remember there must be one agreed characteristic distinguishing the two new piles. Record on the board.

C)

A)

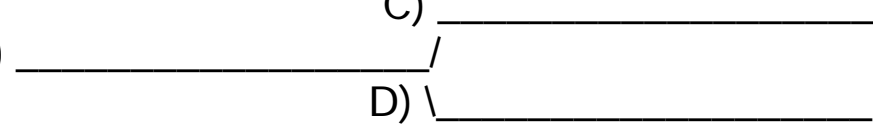

FIG. 2

7. Continue dividing the shoes into two distinct piles and adding the information to the sketch until there is only one shoe with the identifying characteristics. That one shoe can then be identified and the owner's name is added to the sketch.

E)

C)

A)

D)

F)

FIG. 3

8. Divide the second pile of shoes in the same manner as the first pile until all of the shoes have been identified. 


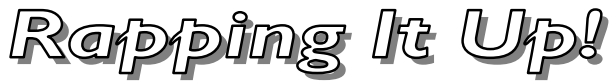

1. W hat are some of the main characteristics of the invasive species you chose to research at the beginning of this activity?

2. O ut of the whole class, which invasive species did you find most interesting? W hy?

3. W hat is a dichotomous key? W hy are they important to have?

4. W hat simple characteristics did you use to begin your dichotomous key?

5. W as it difficult to come up with characteristics? W hy or why not? 


\section{Glossany:}

Biodiversity - The variety of plant and animal species present in an ecosystem.

Dichotomous - D ivided or dividing into two parts or classifications.

Dichotomous key - A series of questions that leads to the identification of a species.

Invader/Invasive species - A plant or animal that is not native and causes harm, including disrupting natural ecosystems.

Native species - A plant or animal species that originated in a certain place. A species occurring in its natural range. Species that were present in Florida at the time the first Spanish settlers arrived.

Non-native species - A species introduced to a region intentionally or accidentally.

Species - A basic taxonomic group that subdivides a genus; it comprises individuals of common ancestry that strongly resemble each other physiologically and that interbreed to produce fertile offspring.

Taxonomy - The science of classifying organisms into groups or taxa. 
This page was intentionally left blank. 


\section{Invasive Species}

Series
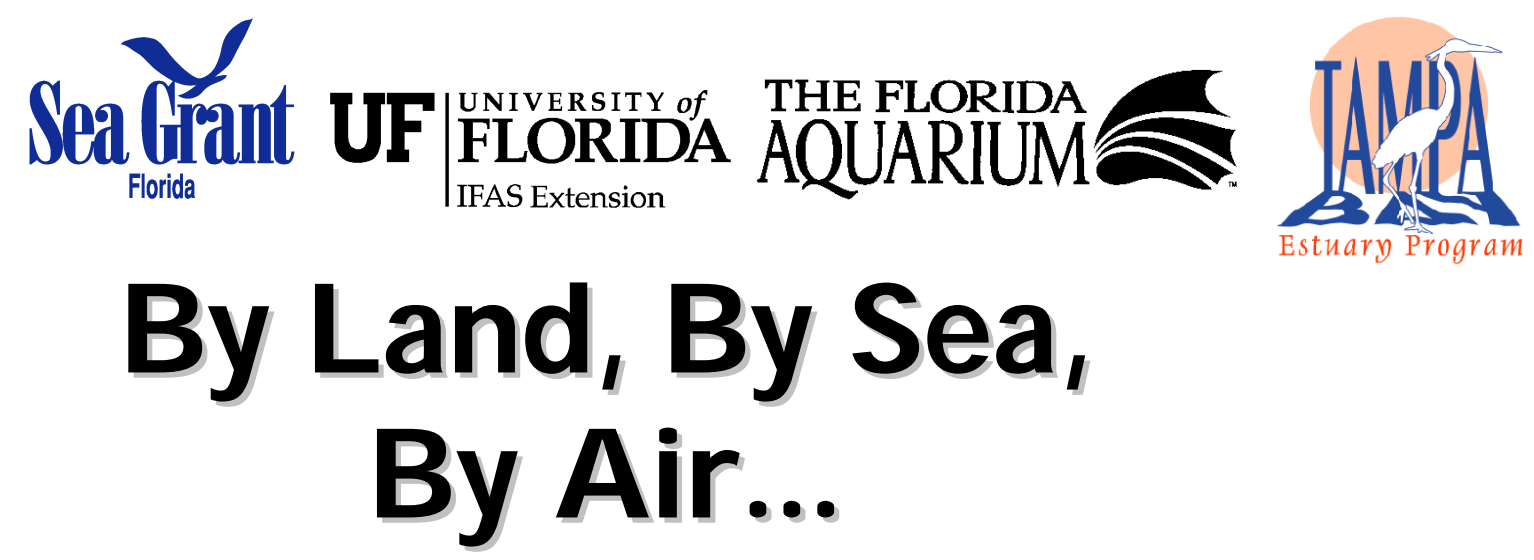

Sneak Pe eK

Students will be introduced to concepts and issues surrounding invasive and non-native

species. Students will explore how invasive species arrive in Florida. They will research the origin of a specific species and create a storyline outlining the arrival of the first individual.

This activity incorporates

information gathering, creative writing, and presentation skills.

Aligned with the following $S$ unstine State $S$ tandards and $\mathcal{F C A T}$ Benchmarks for grades $6-8:$

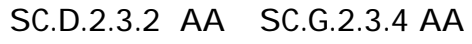

$S C . F .1 .3 .7 \quad \mathcal{C S} \quad S \mathcal{S} . \mathcal{H} .2 .2 .1 \mathrm{CS}$

SC.G.2.3.3 CS

$\mathcal{A} \mathcal{A}=$ annually assessed

CS = content sampled

\section{Objectives:}

Students will:

- Identify the pathways by which non-native species are transported.

- Collect information on a specific invasive species in Florida.

- Demonstrate an understanding of how pathways transport non-native species by creating a fictitious story of the first individual's arrival.

\section{Materials:}

- Internet access, books or resource articles on invasive species.

- Copies of Florida A quarium species fact sheets.

- Variety of costumes (not required) and craft supplies for role-play.

\section{Background:}

\section{How did they get here?}

N on-native species arrive in Florida several different ways. A pathway is the means by which a species is transported from one location and introduced into another location where it was not present. So me species are deliberately introduced by humans. The plant Kudzu was introduced to control soil erosion. N on-native ornamental plants, such as Brazilian pepper, have been used in landscaping around homes and businesses. U nusual pets, including aquatic species, have been released by owners into Florida's wild lands and waterways. 
$\mathrm{N}$ on-native species also arrive in Florida as the unintentional consequence of human activities. Ballast water can carry organisms across the world.

The process of importing fruits and vegetables can carry pests to a new location. Even the international movement of people can bring diseases or viruses wherever they may travel!

The intentional and unintentional pathways described above are enhanced or created by human activity. Species also make use of natural pathways, including wind and currents. Please visit www.invasivespecies.gov for more information.

\section{Procedure:}

1. Divide the class into groups of three. Distribute one of the Florida Aquarium species fact sheets to each group. You can also decide to let each group choose their invasive species.

2. After each group has a specific invader species, instruct them to research how the invader is thought to have arrived in Florida. If this information is not known, lead the group to speculate based on how similar species arrived.

3. O nce the class has gathered this information, instruct them to create a specific story outlining the way the original individual arrived. This should include an introduction of the human characters including their jobs or role in the story, a depiction of the trip and a description of the arrival in Florida.

4. O nce they have written the script for the presentation, they can use craft supplies or costumes to "dress up" as their characters.

5. Each group will present their "play" to the class. 


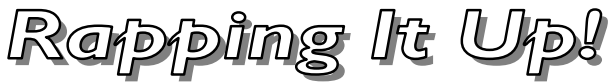

1. The non-native species in this activity all had pathways.

W as your species introduced intentionally? Describe why you think the introduction was intentional or non-intentional.

2. Non-native species are not necessarily invasive. D efine the difference between invasive and non-native.

3. You have created the arrival of the first individual of your species. W hat are ways the introduction of this species could have been prevented?

4. C an you think of any other pathways that might bring a species to Florida that you haven't heard about in this class? 


\section{Glossary:}

Ballast- W ater or other heavy material placed in the hold of a ship for stability.

Invader/Invasive species - A plant or animal that is not native and causes harm, including disrupting natural ecosystems.

Native species - A plant or animal species that originated in a certain place. A species occurring in its natural range. Species that were present in Florida at the time the first Spanish settlers arrived.

Non-native species - A species introduced to a region intentionally or accidentally.

Pathway - The means by which a species is moved from place to place and introduced. 


\section{Invasive Species \\ Series
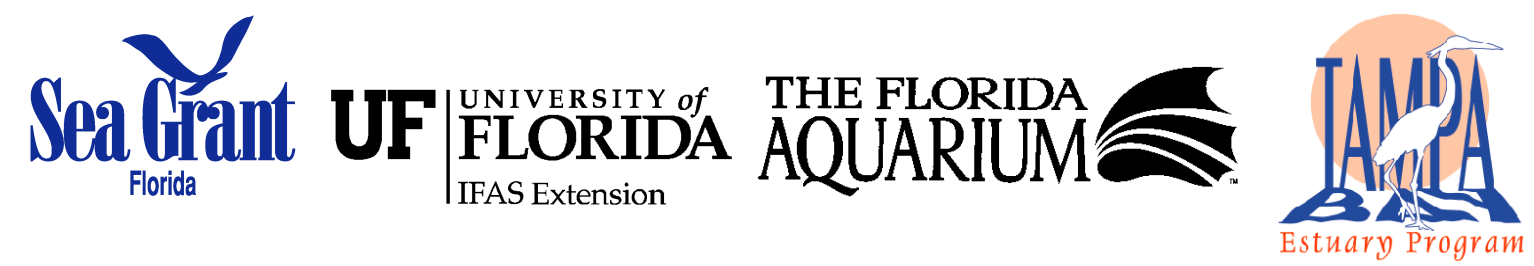 \\ Classroom Takeover!}

\section{Objectives:}

Sne ak Pe eK

Students will be introduced to concepts and is ues surrounding invasive species. Students will explore the differences

between non-native and invasive species bycreating one of their own. They will see how the ir classroom environment changes with the introduction of the ir species. This activity incorporates making connections, drawing conclusions, and thinking critically.

Aligned with the following

$S$ unsfine State Standards and

$\mathcal{F C A T}$ Benchmarks for grades $6-8:$

$S$ C.F.1.2.2 CS SC.G.1.2.7 CS

$S$ C.F.1.2.3 AA $S C . G .2 .2 .2 C S$

$S$ C.F.2.2.1 CS $S$ C.G.2.2.3 CS

$S$ C.G.1.2.2 $\mathcal{A A}$ $S$ C.H.1.2.3 $\mathcal{A} \mathcal{A}$

$S$ C.H.1.2.5 CS S C.H.2.2.1 CS

S C.H.3.2.4 $\mathcal{A} \mathcal{A}$

$\mathcal{A} \mathcal{A}=$ annually assessed

CS $=$ content sampled
Students will:

- Identify growth and survival characteristics that make invasive species survive and thrive.

- Demonstrate several impacts invasive species have on the environment.

\section{Materials:}

- Colored pencils or markers.

- Five to ten unique items such as a toilet paper roll, small foam football, water bottle, etc.

- $\quad 0$ verhead projector and pens.

- Internet access or resource articles on invasive species (recommended, not required).

\section{Background:}

An invasive species is defined as a species that is 1) non-native(or alien) to the ecosystem under consideration and 2) causes harm to the economy, the environment or human health. Invasive species may compete with native species for food and living space. A successful invader will take over space in which a native species normally lives. Eventually, invaders can reduce the variety of species in an area, which is called a loss of biodiversity.

An invasive species usually thrives in an environment for two main reasons. First, it has the ability to reproduce rapidly. This means that it either has many offspring that survive and flourish and/or the individuals grow quickly and produce offspring of their own relatively soon. A second reason for success is that the invader can often survive in a wider range of conditions than the native species surrounding it. Changes in temperature or amounts of food, water, or nutrients may not adversely affect the invasive species as 
much as the native species. In their introduced range, invasive species may also escape from predators, diseases or other natural controls.

A species may be non-native but not have the negative effects of an invasive species. A non-native species is a species introduced to a region intentionally or accidentally.

Florida has more than 2,000 non-native species, which makes it second only to Hawaii. There are several state laws restricting the cultivation of specific non-native species of weeds and aquatic plants. You can find a listing of these laws at www.invasivespecies.gov.

\section{Procedure:}

1. Divide the class into groups of three. Distribute one of the unique objects representing a fictitious invasive or non-native species to each group.

2. Explain to the students that the classroom is the local environment supporting the native species, teachers and students. Right now, the environment is balanced and functioning well. This environment allows the students to learn and the teachers to teach each day.

3. U sing their knowledge of invasive and non-native species, as well as any additional resource materials, ask each group to decide if their species will be invasive or non-native.

4. Instruct each group to decide how the classroom would change as their species reproduces. They should list potential impacts their species may have on the environment. (e.g. their species eats chalk so eventually the teacher wouldn't be able to write on the board.)

5. Ask students to create a name for their species and list at least four characteristics critical for the species' survival (e.g. it eats pencils, needs to be in the dark for twenty hours of the day, etc.).

6. Have students present their information on an overhead. 


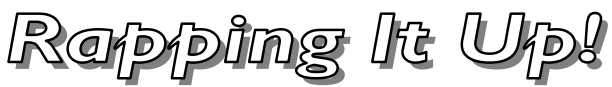

1. W hat are the characteristics of your species that make it able to be categorized as invasive or non-native?

2. W hat makes the invasive species harmful to the environment?

3. If your species was introduced to your schools' environment, how could you stop from spreading and/or causing harm?

4. Do you think there are laws that could be adopted to protect native species in Florida? 


\section{Glossary:}

Biodiversity - The variety of plant and animal species present in an ecosystem.

Invader/Invasive species-A plant or animal that is not native and causes harm, including disrupting natural ecosystems.

Native species - A plant or animal species that originated in a certain place. A species occurring in its natural range. Species that were present in Florida at the time the first Spanish settlers arrived.

Non-native species - A species introduced to a region intentionally or accidentally. 


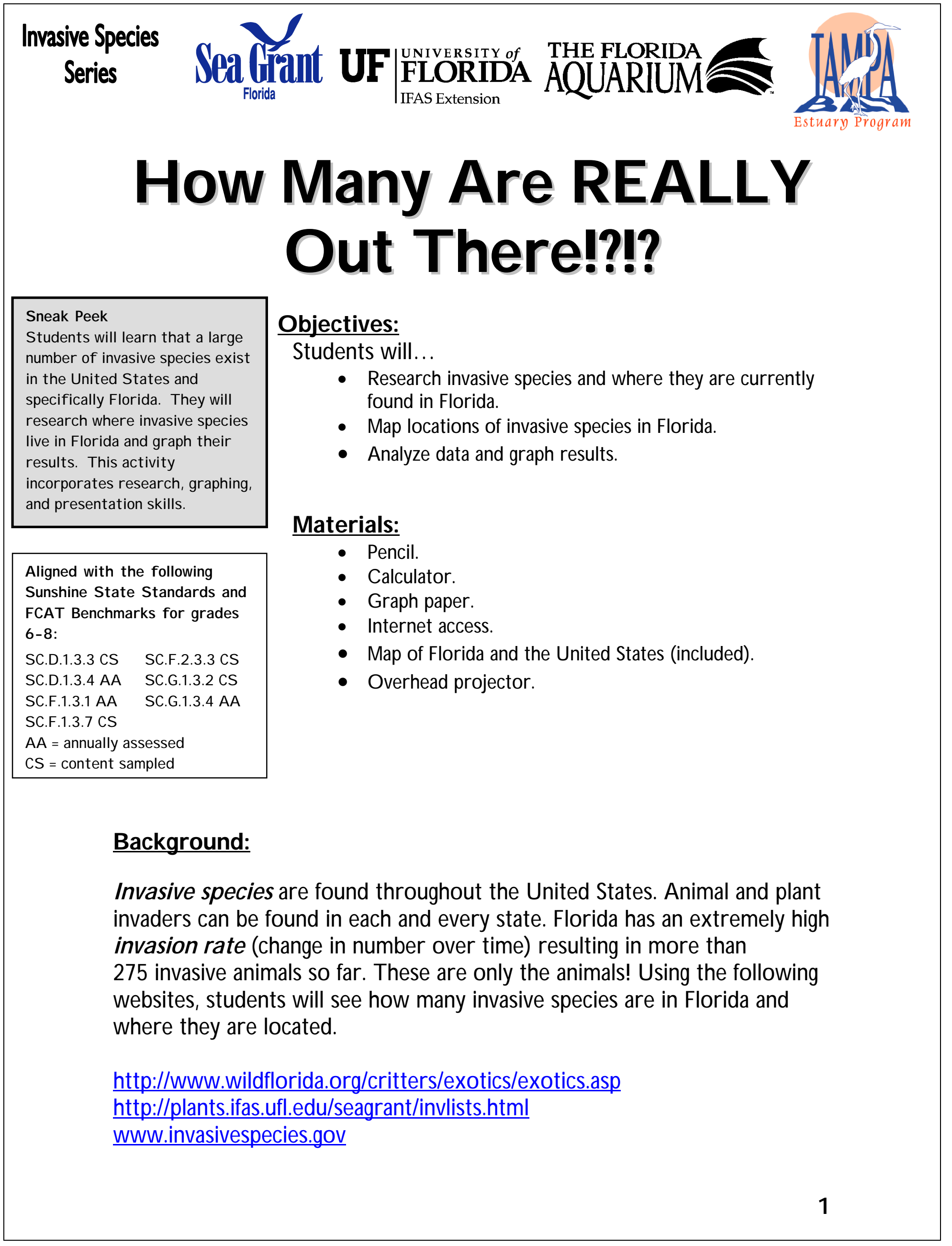




\section{Procedure:}

1. Copy U.S. map onto overhead transparency, using the one provided, or substituting one of your choosing.

2. Lead a discussion asking students what states have invasive species, citing common names of specific examples (see website list for sites that provide information on national invasive species). After soliciting answers, place the names of each invasive on the blank map of the United States on the overhead. All the states should be covered. Florida alone has more than 350 known invasive species (including plants).

3. Distribute the map of Florida and assign geographic regions (depending on class size) with several counties per group.

4. Groups should then research their counties in an attempt to name as many invasive species currently living in that area as possible.

5. Groups should now create a bar graph of the number of species in each county using the chart provided.

6. Have groups report on the invasive species they found in their geographic region, including how many are animals and how many are plants. 


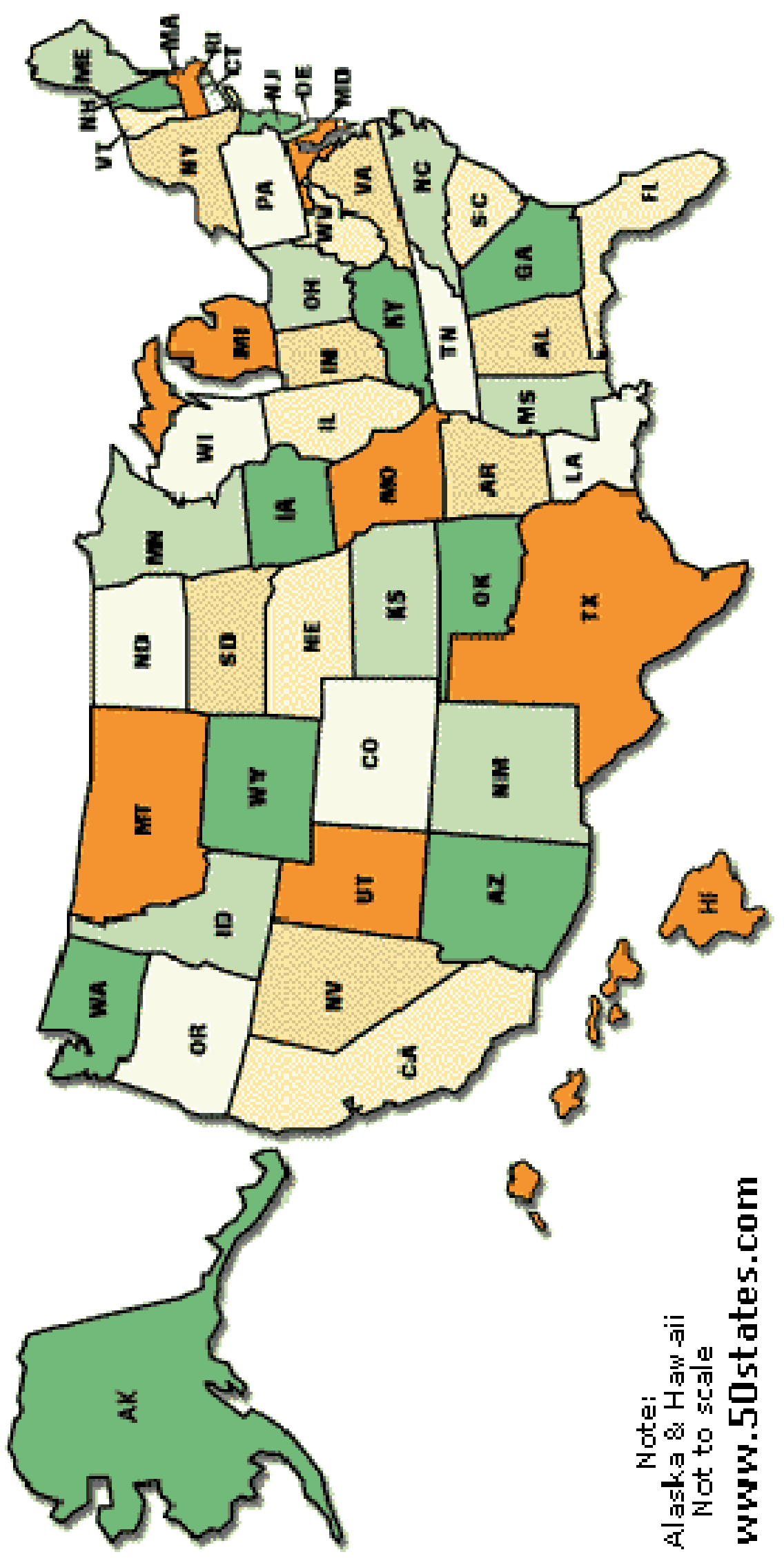




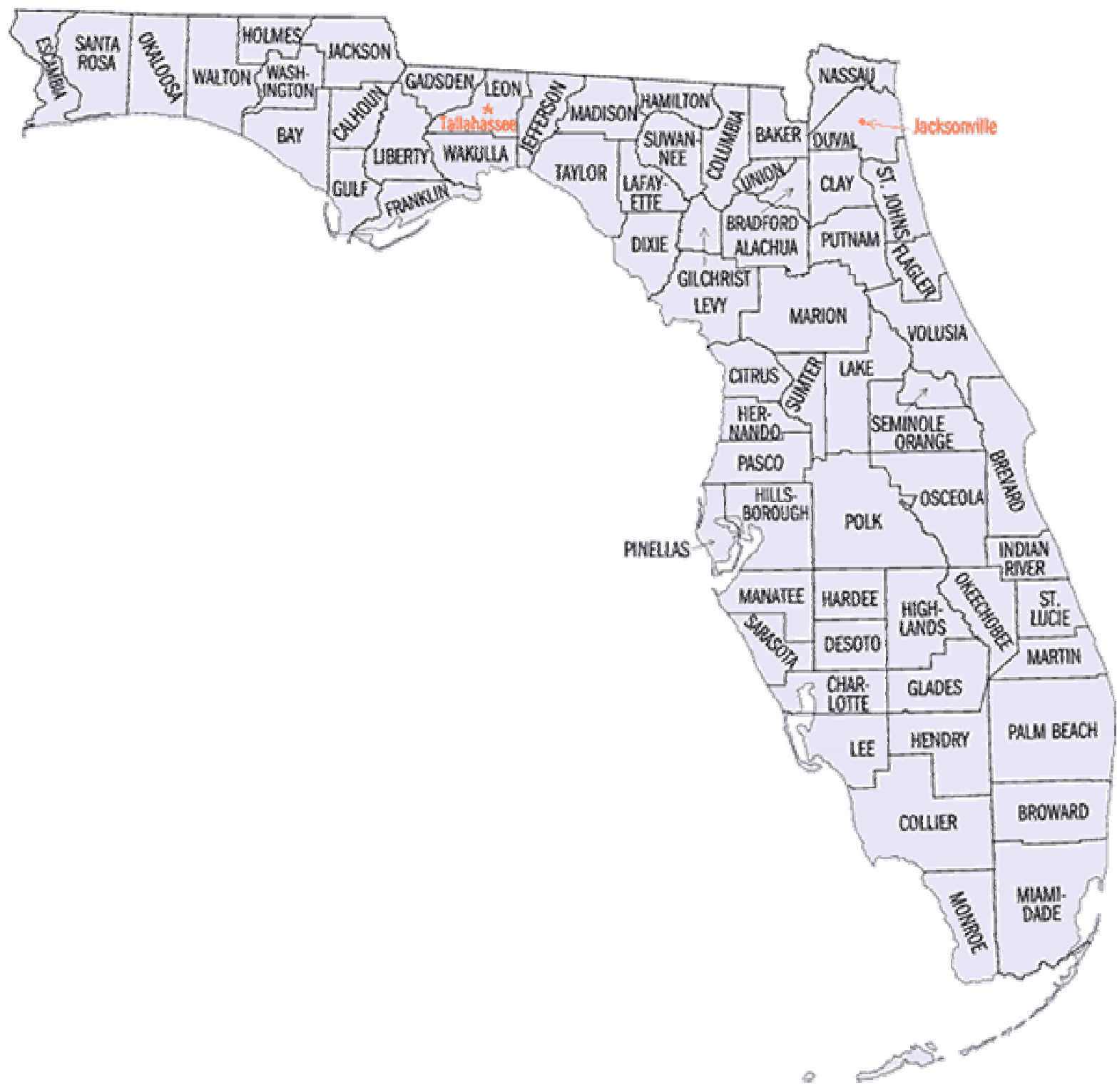

Map provided by digital-topo-maps.com at: http://county-map.digital-topo-maps.com/florida.shtml 


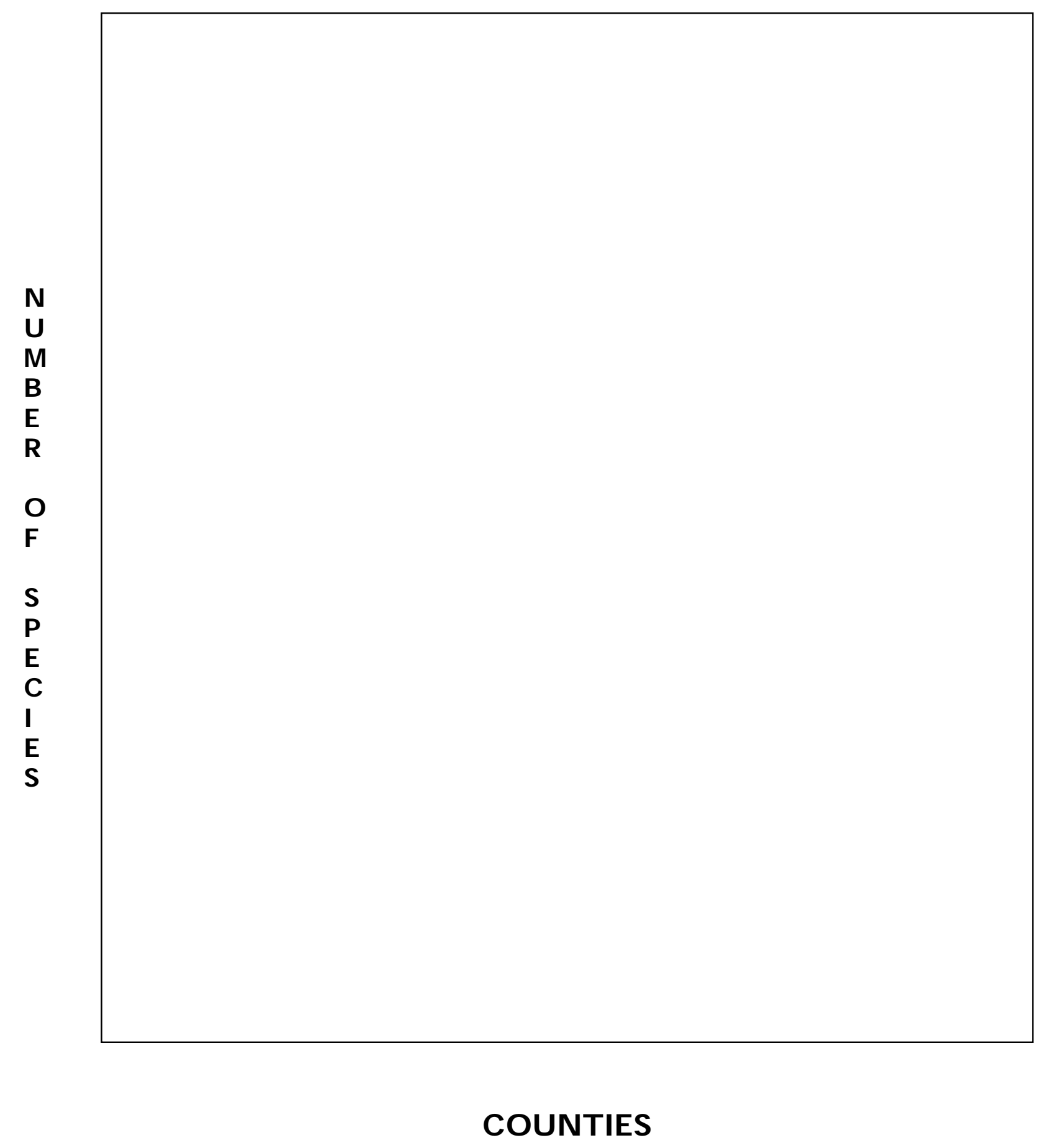




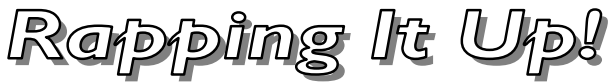

1. Before this activity, how many states did you think currently have invasive species living there? Do you think this number is increasing or decreasing and why?

2. Did you find more invasive plants or animals? Why do think this was the case?

3. W hich counties had the most invaders? W hy do you think this is? 


\section{Glossary:}

Invader/Invasive species - A plant or animal that is not native and causes harm, including disrupting natural ecosystems.

Invasion rate - How quickly invasive species are being established in a geographic region. A rate is a change in something over time. 
This page was intentionally left blank. 


\section{Invasive Species \\ Series
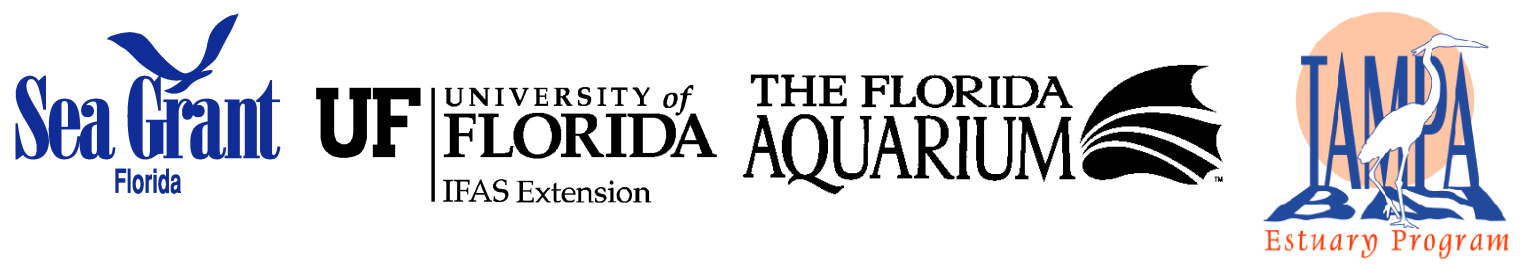 \\ How Well Do You Know \\ Your Neighbors?}

\begin{abstract}
Sne ak Pe e K
Students will be introduced to

the concepts and issues

surrounding invasive species.

The $y$ will be able to identify

different pathways that

allow invaders to expand.

The y will also le arn about

invaders in different areas of

the world and think about ways

to prevent the expansion of

invaders in the future. This

activity incorporates mapping,

environmental investigations, and

research methods.
\end{abstract}

Aligned with the following

$S$ unshine State $S$ tandards and

$\mathcal{F C A T}$ Benchmarks for grades

$6 \cdot 8:$

$S$ C.D.1.3.3 CS

$S$ C.D.1.3.4 $\mathcal{A A}$

$S$ C.F.1.3.1 AA

SC.F.1.3.7 CS

$\mathcal{A} \mathcal{A}=$ annually assessed

CS = content sampled

\section{Objectives:}

Students will...

- Identify pathways involved in the transport of non-native species.

- Collect information on specific Florida invasive species.

- Gather information about invaders throughout the world.

- Compare invaders in similar climates.

- Think critically about how to prevent the influx of more invaders.

\section{Materials:}

- Internet access, books or articles on invasive species.

- Copies of Florida Aquarium species fact sheets.

- W orld map

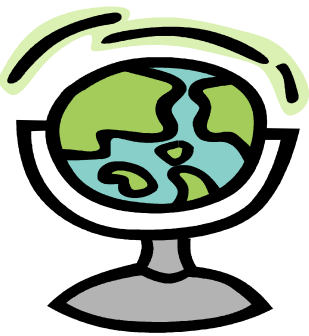

How did they get here?

N on-native species arrive in Florida in several different ways. A pathway is the means, or transport mechanism, by which a species is moved from one location to another and introduced into a new area Some species are deliberately introduced by humans. The plant Kudzu was introduced to control soil erosion. N on-native ornamental plants, such as Brazilian Pepper, are used in landscaping around homes and businesses. Unusual pets, including aquatic species, have been released by owners into Florida's wild lands and waterways. 
$\mathrm{N}$ on-native species also arrive in Florida as the unintentional consequence of human activities. Ballast water can carry organisms around the world. Importing fruits and vegetables can introduce plant pests to a new location. Even the international movement of people can carry diseases or viruses wherever they may travel! The success of an invader depends on many environmental factors including temperature, rain and wind. A nother important influence on the success of an invader is how quickly it can reproduce. The faster the better for the invader! An invader that thrives often has a high reproductive rate.

The intentional and unintentional pathways described above are enhanced or created by human activity. H umans are active throughout the world, so that probably means invaders are everywhere as well.

Please visit www.invasivespecies.gov for more information on pathways.

\section{Procedure:}

1. Have students work together in groups of three or four. Each group should be asked to research three to four Florida invasive species. Find out how they arrived in Florida, the climate they prefer, their reproductive rate, etc.

2. W arm up! Have groups of students go around the school trying to identify different invasive species using The Florida A quarium species fact sheets and the research they have done.

3. Map the locations around the school in which you found invaders.

4. In the original groups, have students research areas with climates similar to Florida. D o they also have invasive species? W hat kind of invasive species do they have? How do you think they got there?

5. Have students hypothesize how invaders got to other locations. D iscuss ways to prevent the spread of invaders from places with similar climates to Florida. 


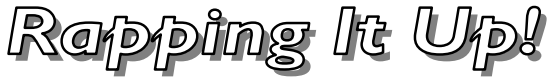

1. List three different pathways for invasive species.

2. Name three Florida invaders. Name three invaders outside of Florida, if you found some during your research.

3. W hich of the invaders that you researched traveled the farthest to get to Florida?

4. What do you think can be done to control the spread and introduction of more invasive species?

5. Name three reasons why invasive species are harmful to native species. 


\section{Glossany:}

Ballast - W ater or other heavy material placed in the hold of a ship for stability.

Invader/Invasive species - A plant or animal that is not native and causes harm, including disrupting natural ecosystems.

Native species - A plant or animal species that originated in a certain place. A species occurring in its natural range. Species that were present in Florida at the time the first Spanish settlers arrived.

Non-native species - A species introduced to a region intentionally or accidentally.

Pathway - The means by which a species is moved from place to place and introduced. 


\section{Invasive Species Series}

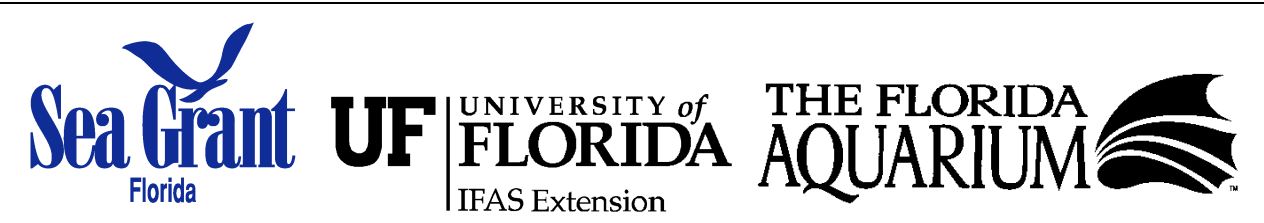

\section{Invaders Galore!}

Sneak Peek

Students will be introduced to

the concepts and is $s$ ues

surrounding invasive species.

Some specific invaders are

Kudzu, Australian Pine, Brown

Anole and Asian Green Mussel.

$S$ tudents will actively simulate

the fluctuations in invasive

populations. They will also learn

factors that lead to the

increase of invasive populations.

This activity incorporates

graphing, dat a analys is, and

environmental investigations.

Aligned with the following

$S$ unstine State Standards and

$\mathcal{F C A T}$ Benchmarks for grades

$6 \cdot 8:$

SC.D.1.3.3 CS SC.F.2.3.3 CS

$S C . D .1 .3 .4$ AA $\quad S C . G .1 .3 .2 \mathrm{CS}$

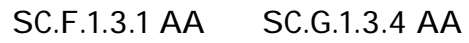

$S$ C.F.1.3.7 CS

$\mathcal{A} \mathcal{A}=$ annually assessed

$C S=$ content sampled

\section{Objectives:}

Students will...

- Recognize that fluctuations in wildlife populations are natural.

- Understand factors that increase or decrease numbers of invaders.

- A nalyze data and graph results.

\section{Materials:}

- Pencil.

- Graph paper.

- $5 \times 7$ note cards.

- Space.

\section{Background:}

Invasive species are plants or animals that are not native to a particular area and cause harm, often by disrupting natural ecosystems. Today, there are many invasive species thriving in Florida. Invasive species compete with native species for the fundamental requirements for survival, that is food, water, shelter and living space. A successful invader will take over space in which a native species would normally live. Eventually, invaders can reduce the variety of species in an area, which is called a loss of biodiversity.

A variety of factors affects the ability of invaders to successfully increase their populations over time. Some factors that allow populations to expand are available space, rapid reproduction, stable temperature, and durability of the species. All living things, invaders and natives alike, need food, water and shelter to survive. Certain factors, such as extreme weather patterns, pollution and a sudden decrease of available food, may cause a population 
to decrease over time. Those able to best cope with a negative change in these factors are more likely to survive.

Some natural factors or human activities may limit the reproduction of native wildlife populations and may enhance the survival and reproduction of nonnative species. Competition for limiting factors may threaten, endanger, or eliminate native species, which opens the door for invaders to spread!

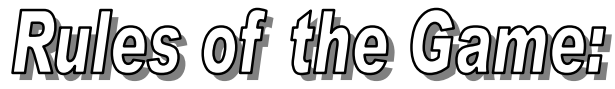

1. Have the students choose one of the following four invaders.

- Kudzu

- Australian Pine

- Brown Anole

- Asian Green Mussel

2. Discuss, in class, the factors that increase or decrease the populations of your chosen invader.

3. Each student should receive two note cards. O n one note card, each student should write one reason for the expansion of the chosen invader, and on the other note card, they should list one reason why the population of that particular invader might decrease. Divide the note cards into two piles (a pile of positive factors and a pile of negative factors).

4. Designate one student to keep track of the number of invaders on the attached chart. Keep track of the numbers of invaders, elements, and influences in each group using the attached table.

5. Separate the remainder of the class into three groups. 0 ne group represents the invaders, another group represents the elements (e.g food, water, and shelter), and the last group represents the positive and negative influences on invaders. Try to keep the ratio for the groups at six invaders, six positive/negative influences, and ten elements. Elements can repeat.

6. Everyone in class must agree upon hand signals that will be used to represent food, water and shelter. It is very important to remember these hand signals! 
7. Have the three groups spread out in the allotted space with invaders on one side and elements on the other. The positive and negative influences will be in the middle of these two other groups.

8. Pass out the positive and negative cards to the assigned students in a ratio of 1 positive to 3 negatives.

9. O nce the students and cards are in place, have the elements and invaders turn so that their backs are to each other, leaving the positive and negative influences in the middle. At this time, the elements decide individually what they want to be (e.g. food, water or shelter). The invaders will also decide individually which element they need. 0 nce everyone has decided, have the students turn around, face one another and display the hand signal for their chosen element.

10. The invaders now have a choice!

a. They can go directly to an element that matches their hand signal. If the hand signal matches, the element becomes an invader. If there is no match, the invader becomes an element.

b. The second option would be to take a chance at picking an influence card. If the invader chooses a positive card, it then must find an element that matches its signal. If it succeeds in getting a positive card and the correct element, all three students become invaders. If the invader chooses a negative card, it automatically becomes a positive or negative influence.

11. After each round, record the new numbers for invaders, elements and influences based on the changes that occurred in the preceding round.

12. Continue the game until the teams are too unbalanced to continue! 


\section{UNVA DER PROGRESS}

\begin{tabular}{|l|l|l|l|}
\hline & INVADERS & ELEMENTS & $(+-)$ INFLUENCES \\
\hline ROUND 1 & & & \\
\hline ROUND 2 & & & \\
\hline ROUND 3 & & & \\
\hline ROUND 4 & & & \\
\hline ROUND 5 & & & \\
\hline ROUND 6 & & & \\
\hline ROUND 7 & & & \\
\hline ROUND 8 & & & \\
\hline ROUND 9 & & & \\
\hline ROUND 10 & & & \\
\hline
\end{tabular}




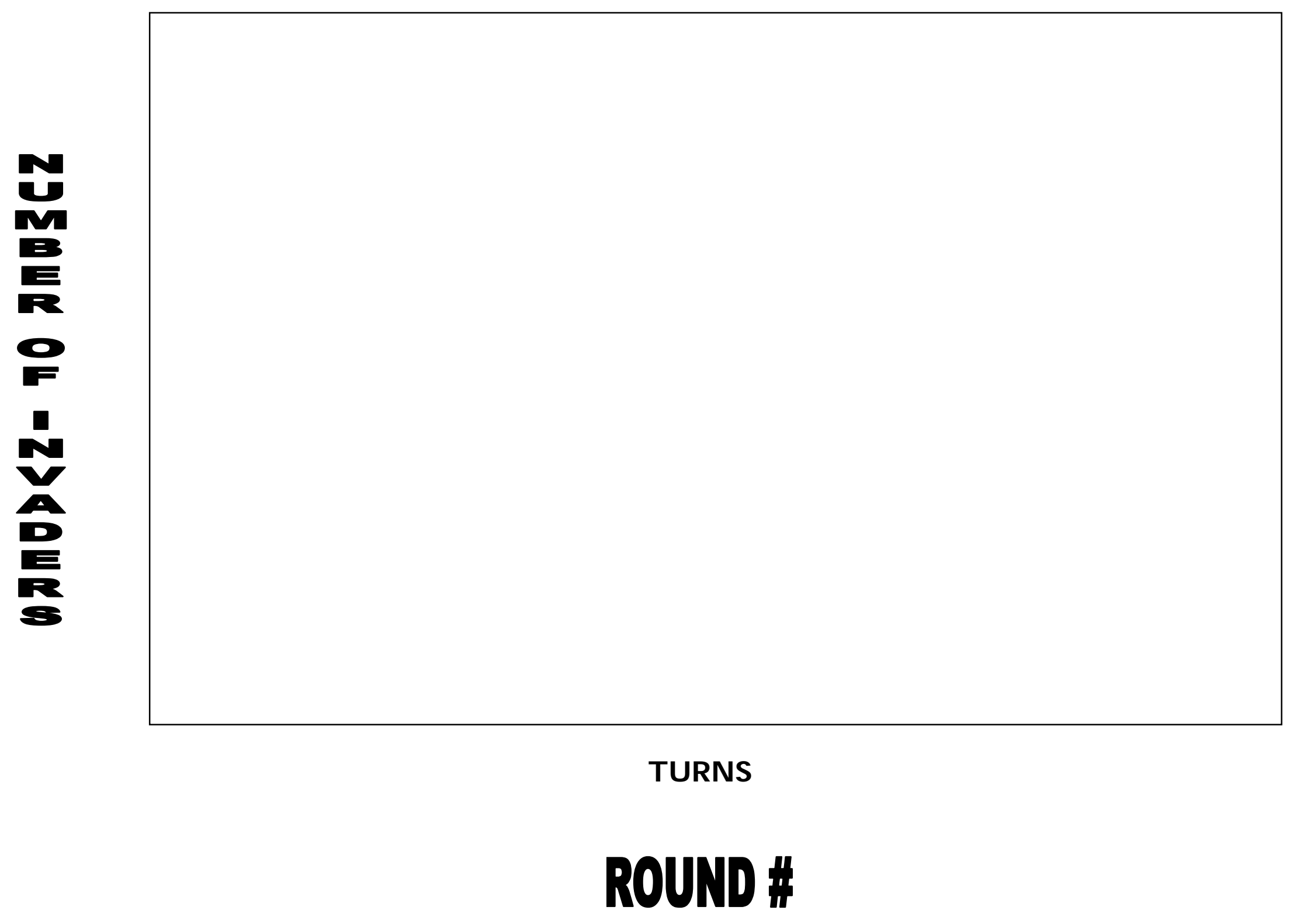




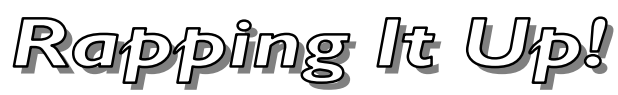

1. List three ways in which invaders can spread.

2. All species require food, water and shelter in order to survive. Is there evidence in your results to suggest that the invaders used up a lot of resources?

3. Using the results from the charts, graph the "N umber of Invaders" on the $\mathrm{Y}$-axis and the number of rounds on the $\mathrm{X}$-axis. D o you see a pattern?

4. How might this activity relate specifically to the state of Florida?

5. What are some ways to control or reduce the number of invaders in an area? 


\section{Glossary:}

Biodiversity - The variety of plant and animal species present in an ecosystem.

Compete - The process of two or more organisms demanding limited environmental resources, such as nutrients, living space or light.

Invader/Invasive species - A plant or animal that is not native and causes harm, including disrupting natural ecosystems.

Native species - A plant or animal species that originated in a certain place. A species occurring in its natural range. Species that were present in Florida at the time the first Spanish settlers arrived.

Non-native species - A species introduced to a region intentionally or accidentally. 
This page was intentionally left blank. 


\section{Invasive Species \\ Series

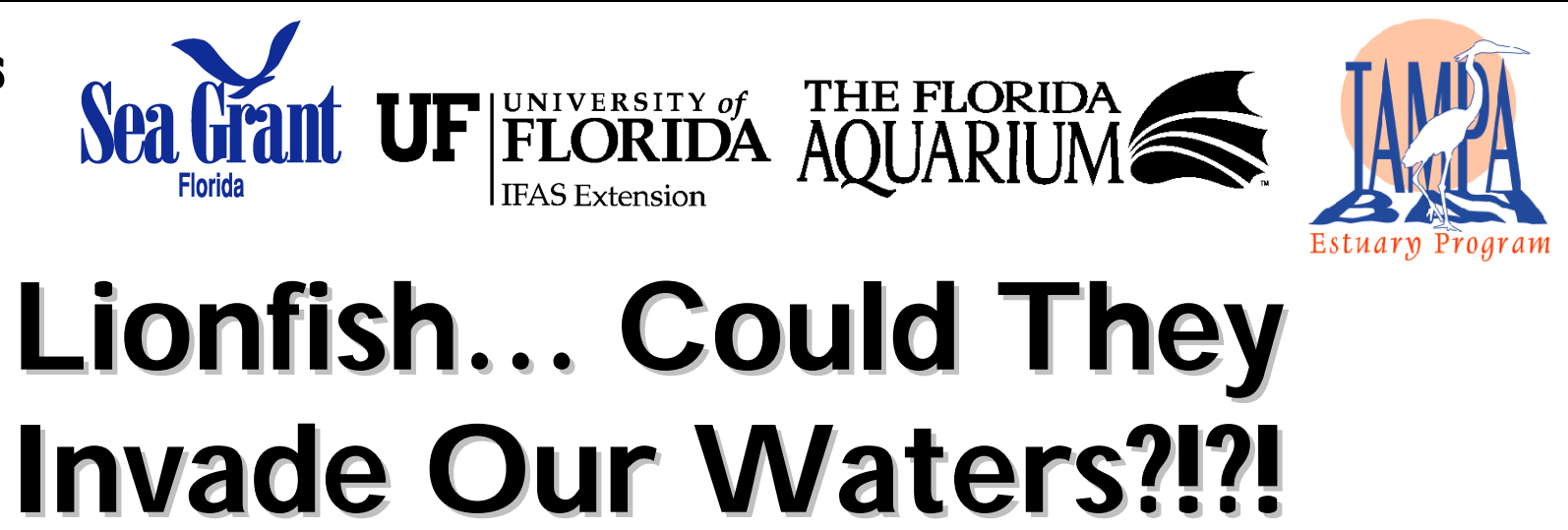

Sne ak Pe eK

Students will be introduced to concepts and issues surrounding invasive species. A new nonnative species in Florida is the lionfish Pterois volitans.

$S$ tudents will explore how this fascinating fish from the Indian and Pacific Oceans could harm Florida reef systems. This activity incorporates information gathering, critical thinking, predicting, and persuasive writing/illustrations.

\section{Objectives:}

Students will...

- Identify adaptations that contribute to a species' success.

- Gather information in order to create a compelling argument about the harm an invasive species can cause.

- D emonstrate understanding of people's roles in spreading invasive species.

- D emonstrate critical thinking skills by predicting what might happen when a new species is introduced into an ecosystem.
Aligned with the following

$S$ unshine State $S$ tandards and

$\mathcal{F C A} \mathcal{T}$ Benchmarks for grades

$6-8:$

$S C . D .1 .3 .3$ CS S SC.G.2.3.3 CS

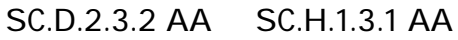

$S$ C.F.2.3.4 CS SC.H.2.3.1 CS

$S$ C.G.1.3.2 CS

$\mathcal{A} \mathcal{A}=$ annually assessed

CS = content sampled

\section{Materials:}

- Copies of the following: St. Petersburg Times article, KW L chart, Florida A quarium fact sheet and Assessment Action worksheet.

- $\quad 0$ verhead projector and KW L* transparency (optional). $* \mathrm{KW} L=\mathrm{Knnow}, \mathrm{W}$ ant to Know, Learned.

- Student research materials (books, Internet access, journals, etc.).

- Poster supplies:

Poster board.

Markers, colored pencils, paint, etc.

Magazines/books for ideas (optional).

Sample posters for models (optional).

\section{Background:}

Invasive species are plants or animals that are not native to a particular area and cause harm, often by disrupting natural ecosystems. Invasive species may compete with native species for food and living space. A 
successful invasive species will take over space in which a native species would normally live. It is often difficult to determine exactly what harm a potential invader may cause until it is to 0 late. Case studies have often shown that once an invasive species is established it is virtually impossible to eradicate.

\section{Lionfish... will they take over?}

The introduction of a plant or animal does not necessarily mean it will thrive in that environment. The success of an aquatic invader depends on many factors including water temperature, water chemistry, available food sources, presence of predators, etc.

In the coral reefs of the Pacific and Indian 0 ceans, the lionfish species Pterois volitans has been adapting over time within its natural habitat. The population of this highly venomous fish has been kept in balance because lionfish are a natural part of the ecosystem. They typically prey upon fish, shrimp and crabs. W hile there is very little information known about their predators, some lionfish species are thought to be preyed upon by sharks and cornetfish. 0 ver time, lionfish have developed a unique niche and a balance with other species in the Pacific and Indian 0 ceans. If they were to become an established part of Atlantic 0 cean food webs, they would do so without their natural predators or prey. Researchers can attempt to predict what the consequences may be, but only time can tell whether these fish will cause severe ecological damage. 0 ver the past several years, lionfish have been seen along the east coast of Florida and as far north as $\mathrm{N}$ ew York. They have likely been released from aquaria, including home aquaria.

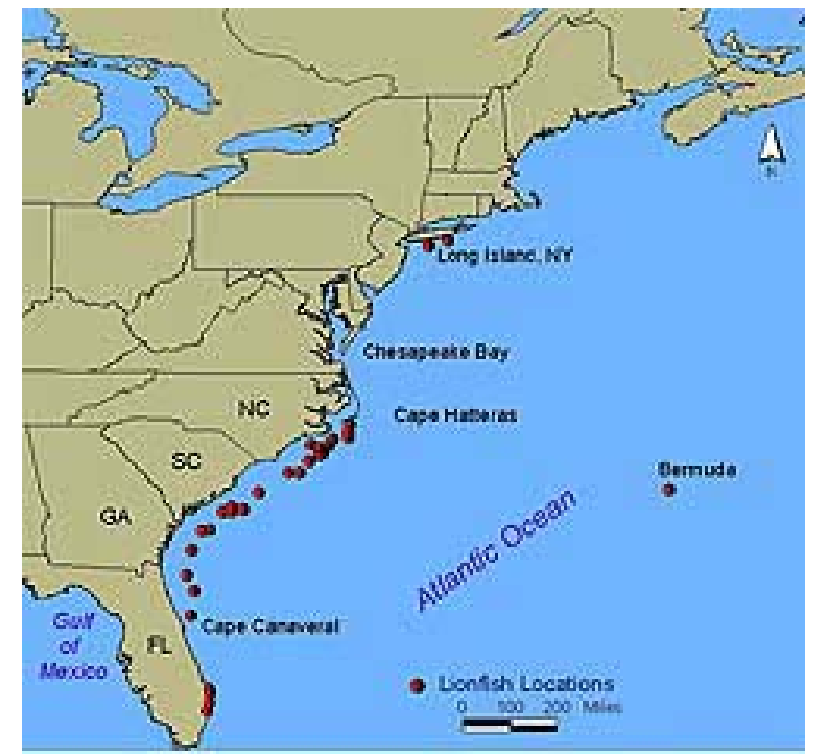

Sightings of lionfish along the east coast of the U nited States. (image from the $\mathrm{N}$ ational $\mathrm{O}$ ceanographic and Atmo spheric Administration) 


\section{Procedure:}

1. Distribute the attached article from The St. Petersburg Times. Allow time for students to read the article, and emphasize that this article relates to a current Florida environmental issue.

2. As a class, complete a KW L chart, beginning with the $K$ and the $W$. Draw the grid on the board or an overhead, or copy and distribute the one provided at the end of this activity. Discuss what students feel they know about lionfish, as well as what they would like to learn. The $L$ portion of the chart should be left blank at this time.

3. O ver the course of one to two classroom sessions, allow students to research information about the species Pterois volitans. Instruct students to locate information that includes appearance, adaptations, distribution, feeding habits, behavior and predators. Students should also note anything else they find interesting or that matches what is listed in their $\mathrm{W}$ column of the chart. U tilize newspaper articles, books, the Internet, journal articles, etc.

4. Complete the $L$ portion of the chart as a class, adding information that was learned. Correct any misinformation in the $\mathrm{K}$ section of the chart.

5. Refer back to the St. Petersburg Times article. Review with students the fact that the species they have studied may be starting to inhabit Florida reef systems.

6. Divide the students into pairs or small groups. Review the idea that lionfish introductions are likely the result of aquarium introductions before moving to the next step.

7. Explain to students that the task at hand is for each group to design an educational poster to be displayed at local aquarium and pet stores that sell aquatic species. D istribute and review the Assessment Action worksheet that explains in more detail how students should design this poster.

8. W hen students have completed their posters, have each pair/team unveil it to the rest of the class.

9. If time allows, discuss each poster and its content. Is it visually appealing? D oes it succeed in its intent? 


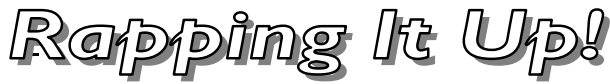

1. W hy is it often difficult to predict how an introduced species may impact its new ecosystem?

2. Invasive species compete with native species for food and living space. Why is it important for native species to survive in their natural ecosystems?

3. W hat factors would make introduced lionfish difficult to eradicate from Florida reefs?

4. What did you learn from this activity about life in Florida waters overall? 


\section{Glossary:}

Aquatic - Living or growing in, on, or near water.

Eradicate - Eliminate, exterminate, remove.

Invader/Invasive species - A plant or animal that is not native and causes harm, including disrupting natural ecosystems.

Native species - A plant or animal species that originated in a certain place. A species occurring in its natural range. Species that were present in Florida at the time the first Spanish settlers arrived.

Niche - The unique role of an organism in its ecosystem.

Predator - An organism that feeds on another organism. 
This page was intentionally left blank. 


\title{
St. Detershurg Times \\ Poisonous fish cluster off coast; [SOUTH PI NELLAS Edition]
}

CRAIG PITTMAN. St. Petersburg Times. St. Petersburg, Fla.: Feb 16, 2002. pg. 5.B

\begin{abstract}
Document Summary)
Although Florida ranks second only to Hawaii in the number of exotic species that have invaded the state, the lionfish is a rarity among exotics, said [Dan Roberts] of the Florida Marine Research Institute. Virtually all of the others that have been found in Florida have been plants, animals or freshwater fish. The lionfish is one of the first saltwater species to relocate to the Sunshine State.

The Florida Marine Research Institute's experts do not know how the lionfish could have spread throughout Florida's offshore waters, but one theory blames Hurricane Andrew and the tropical fish industry. Miami is a central shipping point for the nation's tropical fish trade, Roberts said, so perhaps the 1992 hurricane that hit South Florida damaged a shipping company, allowing the lionfish to escape and start breeding.

State wildlife officials first heard reports of lionfish being seen near Key Biscayne, Boca Raton and West Palm Beach, but nothing could be confirmed. Last summer, there were lionfish sightings off North Carolina, suggesting the Gulf Stream current had swept them north, Roberts said.
\end{abstract}

Full Text (702 words)

Copyright Times Publishing Co. Feb 16, 2002

David Brown heard the stories. Somewhere off Florida's east coast, divers had seen an exotic creature with bright stripes and long, fanlike fins.

So Brown, who teaches marine biology at Wilson Senior High School in Jacksonville, told a friend that if he saw one, he should try to bring it back.

Two days later the friend, commercial spearfisherman David Hagan, saw six of the exotic fish. Hagan swam up close enough to capture a small one in a bag - taking care not to get stuck by its dangerous, venomous fins.

"I hated to mess with that fish," Hagan said, adding, "They're pretty."

Brown shipped the bag to the Florida Marine Research Institute, where this week experts confirmed two years of rumors: It was a lionfish, native to Australia and Malaysia - not Florida. 
On Friday, the institute issued a public warning to all divers who might venture into deep waters anywhere off Florida's east coast: Watch out for the lionfish.

One prick from its fins can cause pain, numbness, paralysis, respiratory illness and, in rare cases, death.

"The dorsal, anal and pelvic fins have spines that are attached to glands that secrete this toxin," said Dan Roberts, a research scientist at the institute's St. Petersburg lab. "It's easy to get nailed by them. The points of these things are like hypodermic needles."

A California woman who sued a pet store for selling her a lionfish without warning her about the fins described its sting this way: "I immediately felt intense pain in my right hand. The pain was indescribable. It was as though one was taking a hammer and slamming at full strength the hammer upon my right thumb. It was excruciating. Then, the pain worsened. It was too terrible to think about."

Despite the risk, lionfish are extremely popular with tropical fish collectors, selling for anywhere from $\$ 50$ to $\$ 100$, according to Frank Sinatra - yes, that's his real name who owns Aquarium Professionals in St. Petersburg.

"They have a little bit of a mystique to them, a little danger," he said.

In fact, the curious-minded can get a closeup view of lionfish at St. Petersburg's Pier Aquarium.

Although Florida ranks second only to Hawaii in the number of exotic species that have invaded the state, the lionfish is a rarity among exotics, said Roberts of the Florida Marine Research Institute. Virtually all of the others that have been found in Florida have been plants, animals or freshwater fish. The lionfish is one of the first saltwater species to relocate to the Sunshine State.

The Florida Marine Research Institute's experts do not know how the lionfish could have spread throughout Florida's offshore waters, but one theory blames Hurricane Andrew and the tropical fish industry. Miami is a central shipping point for the nation's tropical fish trade, Roberts said, so perhaps the 1992 hurricane that hit South Florida damaged a shipping company, allowing the lionfish to escape and start breeding.

"They're everywhere out there," said Hagan, who began spearfishing for lobster in 1973. "I 've been seeing them for about the last year, year and a half. They usually start in about 120 feet of water and you see them out to about 200 feet."

State wildlife officials first heard reports of lionfish being seen near Key Biscayne, Boca Raton and West Palm Beach, but nothing could be confirmed. Last summer, there were lionfish sightings off North Carolina, suggesting the Gulf Stream current had swept them north, Roberts said. 
In J une sport divers swimming in 120 feet of water about 35 miles offshore from St. Simons Island, Ga., killed a 9-inch red lionfish with a speargun. Then, last month, Hagan found the 6-inch one that went to the Florida Marine Research Institute.

Now that the lab has confirmed the lionfish rumors, the institute will step up its investigation, Roberts said. However, once word gets out about where to find free lionfish, there may not be as many available.

"As soon as the tropical fish collectors recognize them, they'll probably go out and start collecting them," he joked.

- Times researcher Caryn Baird contributed to this report.

\section{[ I llustration]}

Caption: A lionfish at St. Petersburg's Pier Aquarium spreads its fins.; Photo: PHOTO, LARA CERRI

Reproduced with permission of the copyright owner. Further reproduction or distribution is prohibited without permission.

People: Brown, David, Hagan, David, Roberts, Dan

Text Word Count 702

Document URL: 
This page was intentionally left blank. 


\section{Lionfish... Could They Invade Our W aters???}

\begin{tabular}{|l|c|c|}
\hline \multicolumn{1}{|c|}{ W } & \multicolumn{1}{c|}{$\mathbf{L}$} \\
\hline \hline What I feel I know... & What I would like to know... & What I fave learned... \\
\hline & & \\
& & \\
& & \\
\hline
\end{tabular}


This page was intentionally left blank. 


\section{Lionfish}

Pterois sp.

Order: Scorpaeniformes

Family: Scorpaenidae

Size:

May reach 14-17 inches.

Description: Lionfish are easily recognized by their elongated, venomous dorsal spines and bright stripe patterns. Appendages on the head and around the eyes mask the mouth and eyes. Lionfish appear to hover in the water column. They have been observed hanging motionless at the crest of a reef or ledge waiting for prey items to approach.

Range and Habitat: Temperate and tropical Indo-pacific Ocean. Commonly seen in openings of coral or around pilings in harbors and bays

Wild Diet: $\quad$ Crustaceans, worms, smaller fish. Usually prefer live prey.

\section{Notes:}

- The Florida Aquarium will house 3 species of lionfish: Pterois volitans, P. radiata, and $P$. antennata. There are currently over 300 species in the Scorpaenidae family.

- Due to their striking appearance, lionfish are also known as dragonfish, turkeyfish, zebrafish, scorpionfish and firefish.

- Lionfish are primarily nocturnal hunters. If hungry, these voracious feeders will try to swallow anything that they can get into their mouths.

- Lionfish often use their large pectoral fins to trap and corner smaller fish. When feeding on benthic (bottom-dwelling) prey, these fins spread like a net to trap prey.

- The venomous dorsal spines of lionfish are used as a defense mechanism. Lionfish will often point these spines toward a predator.

- The sting of a lionfish can be painful for long periods of time, but it is rarely fatal to humans unless multiple stings are inflicted and help is not sought immediately. For immediate treatment, apply very hot water to the afflicted area. 
This page was intentionally left blank. 


\section{Assessment Action! \\ Lionfish... Could They Invade Our Waters??!}

\section{Background:}

A local university's aquatic research department needs your help! They need to spread the word about the possible effects that lionfish may have on Florida reefs. Little is known about how this invasive species might negatively affect local aquatic habitats, so it is up to you to educate others.

\section{Task:}

Your task is to create a visually appealing poster that conveys accurate information. Your poster should express how Pteris vditans may harm Florida reef systems. The poster should include information about both lionfish and Florida reefs in order to show the relationships between this potential invasive species and its "new" habitat.

\section{Audience:}

Consumers that visit aquarium and pet shops are the audience for your work. Many of these people own and maintain their own tanks of aquatic species.

\section{Purpose:}

The purpose of your poster is two-fold. The main purpose of the poster is to spread awareness of how lionfish (non-native species potentially becoming invasive) could harm Florida reefs. The second purpose of your poster is to share the fact that lionfish may have arrived on Florida reefs through release from aquaria, so your target audience's actions play a part in the health of local ecosystems.

\section{Procedure:}

1. G ather as much information as possible about lionfish species Pterisvditans

2. As a group, list the top five adaptations that you think make these fish excellent "survivors." What do they have/ use/ do to hunt and stay alive?

3. Conduct a fact-finding investigation of Florida reefs. What lives on a Florida reef? What are the typical predator/ prey relationships?

4. Mentally place lionfish into a Florida reef system. Review your top five lionfish adaptations and brainstorm the ways that these fish may harm Florida reefs.

5. As a team, decide how your poster will illustrate the negative effects that lionfish could have on reefs and why they happen, as well as the role that people may have played in introducing this predator into a new habitat.

6. Sketch ideas for your poster, keeping in mind that the poster should contain accurate information while being appealing enough to catch the attention of store customers.

7. Using the materials provided, create your final poster that will be displayed at stores. Be sure to adhere to the timelines set by your teacher. 
This page was intentionally left blank. 


\section{Invasive Species \\ Series
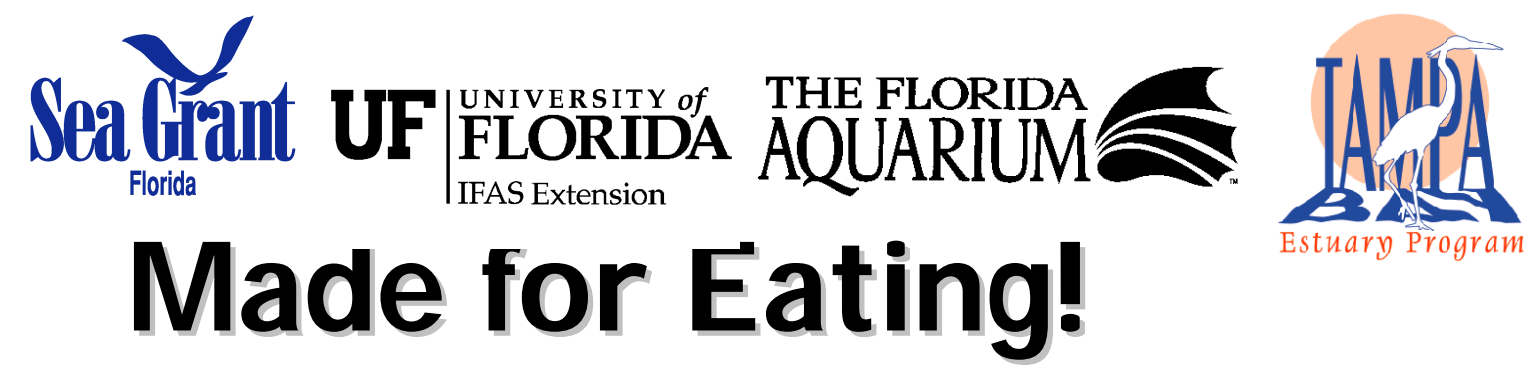

Sne ak Peek

Students will study the parts of

a fish to develop the

understanding that the shape,

form and structure of a fish's

parts influence its lifestyle and

behavior. The Flathe ad Catfish

is a Florida invader, which is

extremely successful in part

due to its voracious appetite.

$S$ tudents will identity the

morphology of this fish and find

out how this helps its success.

This activity incorporates data

analys is, writing skills, graphic

arts, and critic al thinking.

Aligned with the following

$S$ unshine State Standards and

FCAT Benchmarks for grades

$6 \cdot 8:$

SC.D.2.3.2 $\mathcal{A} \mathcal{A} \quad$ SC.G.2.3.4 AA

SC.F.1.3.7 CS SC.H.2.2.1 CS

SC.G.2.3.3 CS

$\mathcal{A} \mathcal{A}=$ annually assessed

CS = content sampled

\section{Objectives:}

Students will:

- Identify the various parts of a fish.

- Investigate the concept of fish morphology.

- Relate shape, form and structure of a fish's parts to their functions.

- Draw inferences about where and how a fish might live based on its morphology.

- Understand why the morphology of the Flathead Catfish, Pylodictis olivaris, makes it such a successful predator.

\section{Materials:}

- Rubber fish models (can be purchased from N ASC 0 1-800-558-9595) or several different kinds of whole frozen fish that demonstrate different shapes (flounder, skate or ray, an eel, a perch, sea bass, angel fish, tuna or mackerel) obtained from your local fish market, supermarket or from a nearby marine research facility. 0 nce obtained, fish can be frozen and reused at your discretion.

- Tempera paint.

- Paint brushes.

- Colored markers.

- N ewsprint paper, or other kind of craft paper.

- Newspaper.

- Fish anatomy diagram and fish morphology chart (included).

- Q uestions W orksheet.

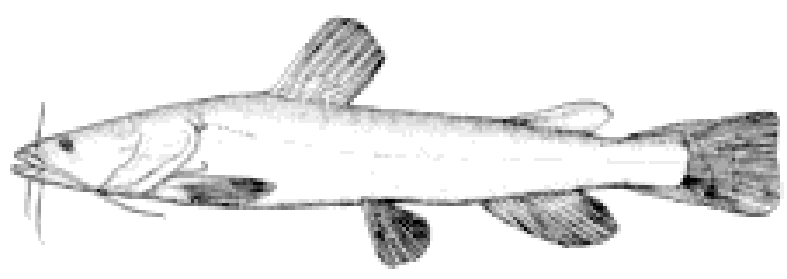

Flathead catfish illustration from $\mathrm{C}$ anadian Museum of $\mathrm{N}$ ature 


\section{Background:}

Invasive species are plants or animals that are not native to a particular area and cause ecological or economic harm. A nimal invaders can out-compete native species by avoiding predators better or finding or capturing prey better. The bodies of animals provide clues about their competitive abilities, and fish provide several excellent examples.

Fish shape and anatomy helps us discover information about how a fish moves, where and how the fish lives, and how it has adapted to its environment. Morphology is the study of the structure and form of living things. Body shape, mouth location and size, tail shape and body color give us clues as to how animals live.

Body shape is a good indicator of how a fish moves and where it lives. Fish that are flat or depressiform, like a skate, flap their fins up and down to swim through the water in the same way a bird flaps its wings.

Flounder normally live on the bottom of the sea floor. Meanwhile, fish that are long and skinny, or filiform, like an eel, slither through the water like a snake. Fish that are streamlined and have an oval or fusiform cross-section, like a tuna or striped bass, are fast swimmers and usually live in open water. A compressiform shape like that of angelfish looks thin when viewed from the front. This body shape is well designed for making quick turns and quick bursts of speed over short distances. Compressiform fish commonly live where there are many places to hide such as among plants in lakes or on coral reefs.

The shape of a fish's tail also indicates how the fish moves and lives.

Rounded, truncated or emarginate tails, like that of a killifish or minnow, are increasingly better for maneuverability and short bursts of speed with less drag. A forked tail, like that of a striped bass, is good for maneuverability and speed over longer distances. Lunate, or crescent shaped tails, like those found on a swordfish are not good for maneuvering but allow for great speed over long distances and are usually found on fish that live in the open ocean.

The size and location of the mouth tells us a lot about where a fish finds its food, what food it eats, and where it may live. Fish with a large mouth generally eat large pieces of food. Fish with a small mouth generally eat small items of food, such as plankton. If the mouth is oriented upwards, it is a surface feeder (or it feeds on prey above it) like a stargazer or stonefish. If the mouth is located in the middle front of the head, like a tuna, 
we can assume that the fish feeds on prey directly in front of it. If the mouth is oriented downwards, it is a bottom feeder, like the catfish. Some fish have elongated tube-like mouths to reach into crevices. An example of this type is a butterfly fish. 


\section{Procedure:}

1. Review fish anatomy and explain that all fish have the same basic body parts. However, those parts may look different. Have students hypothesize why different body parts are shaped differently. Introduce the concept of fish morphology or how the form and shape of a fish and its parts influence function.

2. Students will spend approximately $10-30$ minutes doing G yotaku (Jee-oh-tăk-00), the ancient Japanese art of fish printing using rubber models or real fish. If real fish are used, wash, blot dry and, if frozen, thaw slightly before printing. Lay fish flat on top of newspaper. Brush a thin layer of paint on the exposed side of the fish.

3. The best prints result from the least amount of paint while still attaining full coverage. C arefully lay a sheet of paper on top of the painted fish, and gently press paper down onto all parts of the fish to help pick up details. Slowly lift the paper to reveal the print and place aside to dry. 0 ften a fresh coat of paint is not necessary before the next print.

4. Have students label the external anatomy of the fish and use the fish morphology charts to label the body shape of their fish and the fish's tail on their prints.

5. Have students compare and contrast the morphology of their fish and those in the prints that were made from other species of fish. Have students write a paragraph about their fish's possible behavior and habitat based on its shape and anatomy.

6. Have students review pictures of the Flathead $\mathrm{C}$ atfish. Have students describe the body shape and tail shape. Lead a discussion on why these voracious eaters are so successful in large part due to their morphology. Instruct students to draw a picture of the Flathead C atfish on scrap paper.

7. Lead a discussion about how the morphology of other invasive species in Florida might contribute to their success. 
Body Shape

\begin{tabular}{|l|l|l|l|}
\hline Cross section & \multicolumn{1}{|c|}{ Shape } & Locomotion \\
\hline & Fusiform & $\begin{array}{l}\text { Fast-swimming in } \\
\text { open water }\end{array}$ \\
\hline & Compressiform & $\begin{array}{l}\text { Capable of quick } \\
\text { bursts of speed } \\
\text { over short } \\
\text { distances }\end{array}$ \\
\hline Skate/Ray & $\begin{array}{l}\text { Swimming often } \\
\text { resembles a } \\
\text { bird's wings in } \\
\text { motion }\end{array}$ \\
\hline & Depressiform & $\begin{array}{l}\text { Undulates } \\
\text { though the water } \\
\text { in a snake-like } \\
\text { manner }\end{array}$ \\
\hline
\end{tabular}

Caudal Fin (Tail) Shape

\begin{tabular}{|l|l|}
\hline Shape & Function \\
\hline Rounded & $\begin{array}{l}\text { Large surface area for acceleration } \\
\text { and maneuvering, but creates drag } \\
\text { that causes fatigue }\end{array}$ \\
\hline Less drag than rounded tail, effective \\
acceleration and maneuvering
\end{tabular}




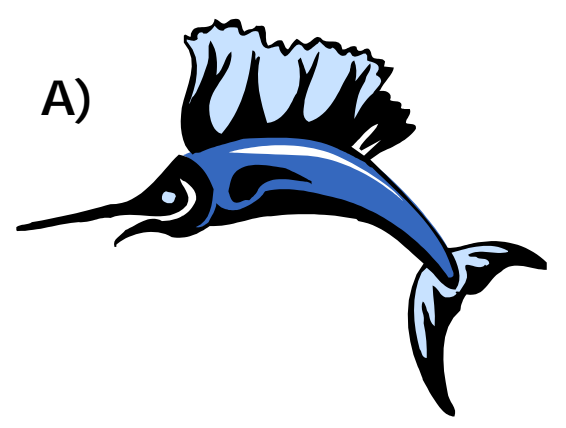

B)

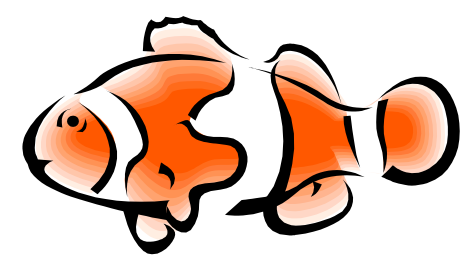

C)

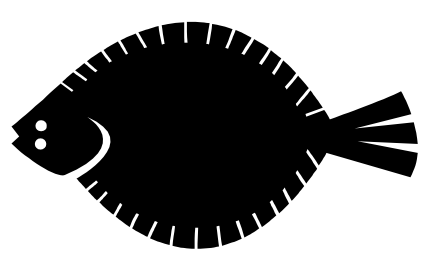

D)

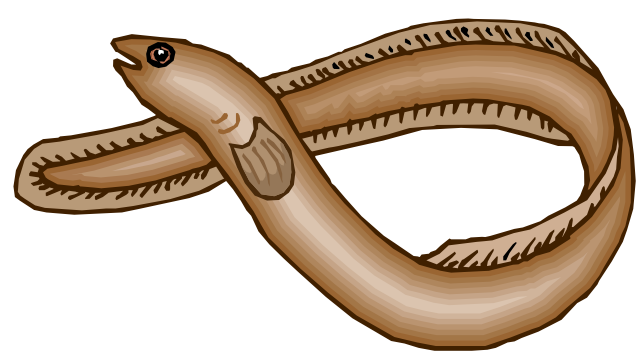

\section{Using the information on the previous page, answer the following questions:}

1. W hich of the fish above swims the fastest in open water?

2. W hich fish can make sharp turns?

3. W hich fish is a great sprinter but not fit for a long distance marathon?

4. W hich fish swims like a flying bird?

5. W hich fish slithers through the water like a snake?

6. W hich fish lives on the sea floor? 


\section{Glossary:}

Anatomy - The study of the parts of an organism in order to ascertain their position, relationship, structure and function.

Compressiform - Body flat from side to side and tall and thin when viewed from the front.

Depressiform - Body flattened from top to bottom and wide and thin when viewed from the front.

Emarginate - Having a notched margin.

Filiform - Long, skinny tube-shaped body.

Forked - H aving two or more branches or points.

Fusiform - Streamlined oval-shaped body.

Lunate - shaped like a crescent or quarter-moon.

Morphology - The study of organisms' structure or form.

Plankton - Small plants or animals that cannot swim strongly, so they drift with currents.

Rounded - C urved or shaped like part of a circle.

Truncate - Short and square or slightly rounded. 
This page was intentionally left blank. 


\section{Invasive Species}

Series

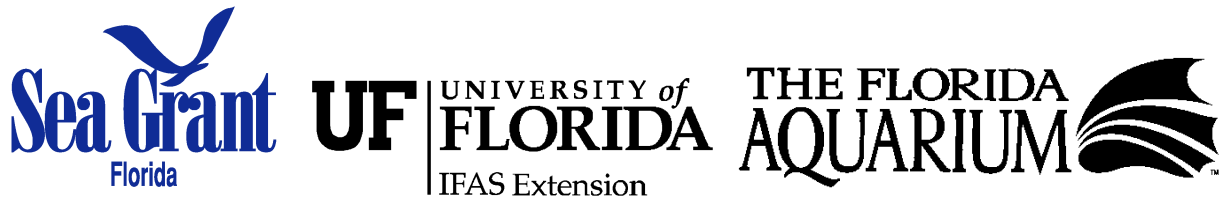 \\ One Mean Weed!}

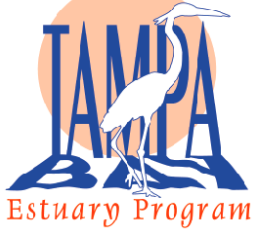

Sne a K Pe eK

$S$ tudents will be introduced to plant dispersal. Students will explore the Autumn Olive bush and specifically the fruits and roots of the plant. They will also be introduced to the process of nitrogen fixation and how the root system of plants help this process. This activity incorporates observation skills, math skills, and critic al thinking.

\section{Objectives:}

Students will:

- Become familiar with the reproductive ability of an aggressive plant.

- Demonstrate understanding of the concept that roots help a plant to compete better.

\section{Materials:}

- Specimen of A utumn 0 live, Elaeagnus umbellata, including fruits (this can be obtained by collecting or ordering from the Internet - just look up "order autumn olive"). Remember not to let seeds or plants get into the environment.

- Cups in which to collect fruit.

- Scale to weigh fruit.

- Surface on which to crush fruit.

- Hand lens.

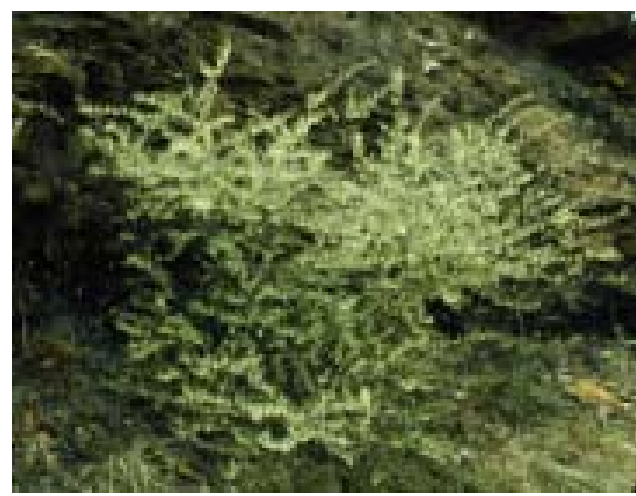

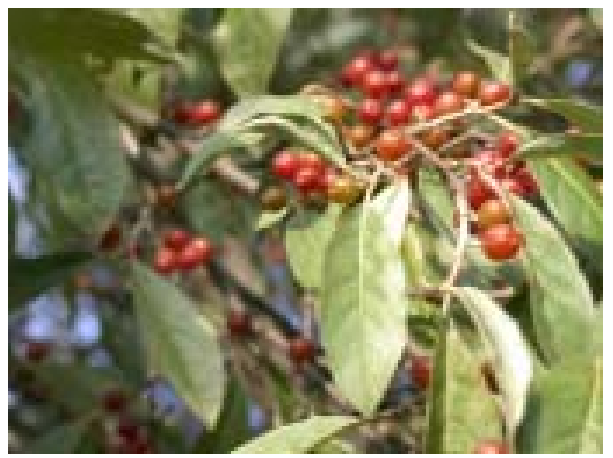

photographs from The Florida Aquarium

\section{Background:}

\section{How does a fruit-bearing plant spread?}

A disperser is an organism that spreads or distributes fruits and/or seeds from a stationary parent plant by eating the fruit and excreting the seeds in another location. 
Autumn $O$ live (Elaeagnus umbellate) shrubs have berries that many animals eat. This is a perennial shrub (grows year-round) that can grow to twenty feet. The more berries that are eaten, the more widely the shrub will be dispersed.

\section{H ow do the roots of a plant help it grow?}

$\mathbf{N}$ itrogen is a nutrient required in large amounts as an essential component of proteins, nucleic acids and other cellular constituents. Some plants have bacteria in nodules on their roots that fix nitrogen. By this nitrogen fixation process, plants convert nitrogen gas into ammonia. The ammonia can be used for plant growth. Autumn 0 lives have roots that allow a lot of nitrogen to be collected.

\section{Procedure:}

1. Each student should be given 20 fruits in a cup. The students should weigh each cup of fruit and determine the weight of an individual berry by dividing the total weight by 20 .

2. Have students determine how many fruits must be collected to weigh 8 pounds, which is how much fruit one plant can produce.

3. O nce the fruits have been weighed, the students should squash the berries and determine how many seeds are in each fruit. Have the students think about how many seeds there would be in 8 pounds of fruit and the consequences of that many seeds being dispersed in the landscape.

4. Divide the students into groups of three and have them observe Autumn 0 live roots with a hand lens. The instructor should prepare the students by describing the form of root nodules and then allow the groups to locate the nodules on their samples. W hile studying the root samples, the students should also observe whether Autumn 0 live has one long root or many short fibrous roots, because nutrient absorption will be affected by the form of roots. 


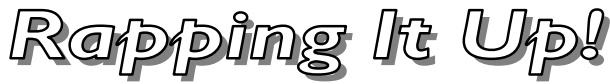

1. What type of animals do you think like to eat Autumn 0 live berries? (Think about how big the berries are and what animals could reach them.)

2. Did your Autumn 0 live have one long root, or many short fibrous roots? Knowing that Autumn O live "fix" nitrogen very well, which root structure do you think helps this process?

3. W hy do you think Autumn O live bushes spread easily in the environment? 


\section{Glossany:}

Disperser - An organism that spreads or distributes fruits and/or seeds from a stationary parent plant.

Nitrogen - A nutrient required in large amounts as an essential component of proteins, nucleic acids and other cellular constituents.

Nitrogen fixation - 0 rganisms cannot use nitrogen gas $\left(\mathrm{N}_{2}\right)$, but nitrogen gas can be "fixed" or converted into ammonia by bacteria.

Perennial - A plant that is lasting or active through the year or many years. 


\section{Invasive Species \\ Series

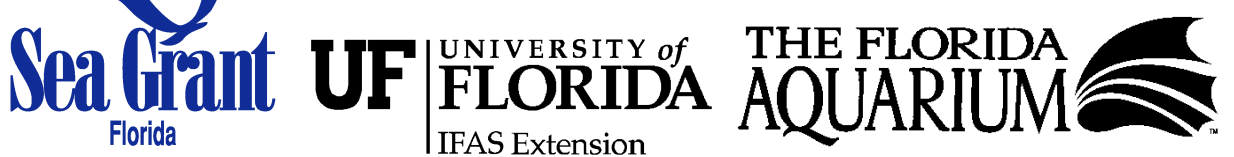

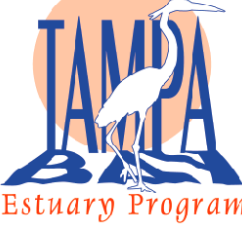 \\ The Race for Space!}

Sne ak Peek

Students will be introduced to concepts and issues

surrounding invasive species.

One specific invader in Tampa

Bay is the Asian Green

Mussel. Students will compare

how fast green mussels invade

living space normally occupied

by native species. This

activity incorporates

mathe matical calculations,

graphing, data analysis, and

environme ntal investigations.

Aligned with the following

$S$ unsfine State $S$ tandards and

$\mathcal{F C A T}$ Benchmarks for grades

$6 \cdot 8$.

$S \mathcal{C} \cdot \mathcal{D} \cdot 1.3 .3 \mathcal{C S}$

SC.F.2.3.3 CS

$S \mathcal{S C} \cdot \mathcal{D} \cdot 1.3 .4 \mathcal{A A}$

$S C . G .1 .3 .2 C S$

$S \mathcal{C} \cdot \mathcal{F} .1 .3 .1 \mathcal{A A}$

SC.G.1.3.4 $\mathcal{A A}$

$S$ C.F.1.3 7 CS

$\mathcal{A} \mathcal{A}=$ annually assessed

CS = content sampled

\section{Objectives:}

Students will...

- Calculate exponential growth.

- Formulate data to display species growth in limited living space.

- Analyze data and graph results.

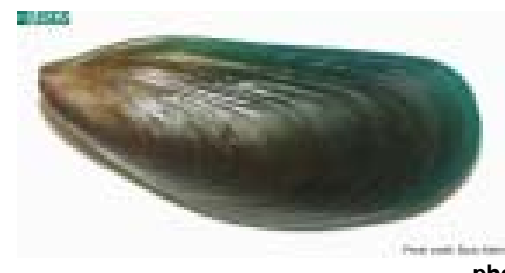

photographs from USGS

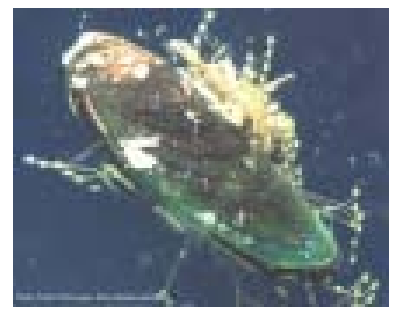

\section{Materials:}

- Pencil.

- Calculator.

- Graph paper.

- 200 blue M\&Ms, 200 red M\&Ms, and 200 yellow M\&Ms per group (other small items may be substituted, such as colored toothpicks, buttons, pipe cleaners, craft beads, etc.).

- 10 cups per group.

- 1 die per group.

\section{Background:}

Invasive species are plants or animals that are not native to a particular area and cause harm, often by disrupting natural ecosystems. There are many invasive species thriving in Florida. Invasive species may compete with native species for food and living space. A successful invader will take over space in which a native species would normally live. Eventually, invasive species may cause a loss of biodiversity by reducing the number of species found in a given area. 


\section{M ussel Explosion!}

The introduction of a plant or animal does not necessarily mean it will thrive in that environment. The success of an aquatic invader depends on many factors including water temperature, $\mathrm{pH}$, currents and water level. $O$ ne important factor is reproductive rate. A thriving invader typically has a high reproductive rate. The A sian Green Mussel is an invasive species with a high reproductive rate. It was first discovered in Tampa Bay clogging the insides of cooling water intake pipes at a power plant during the summer of 1999. The A sian G reen Mussel's current known distribution includes Tampa Bay, the west coast of Florida south to the Everglades, the Panhandle, and northeast Florida to southern Georgia. These mussels may limit biodiversity in the Tampa Bay area and elsewhere.

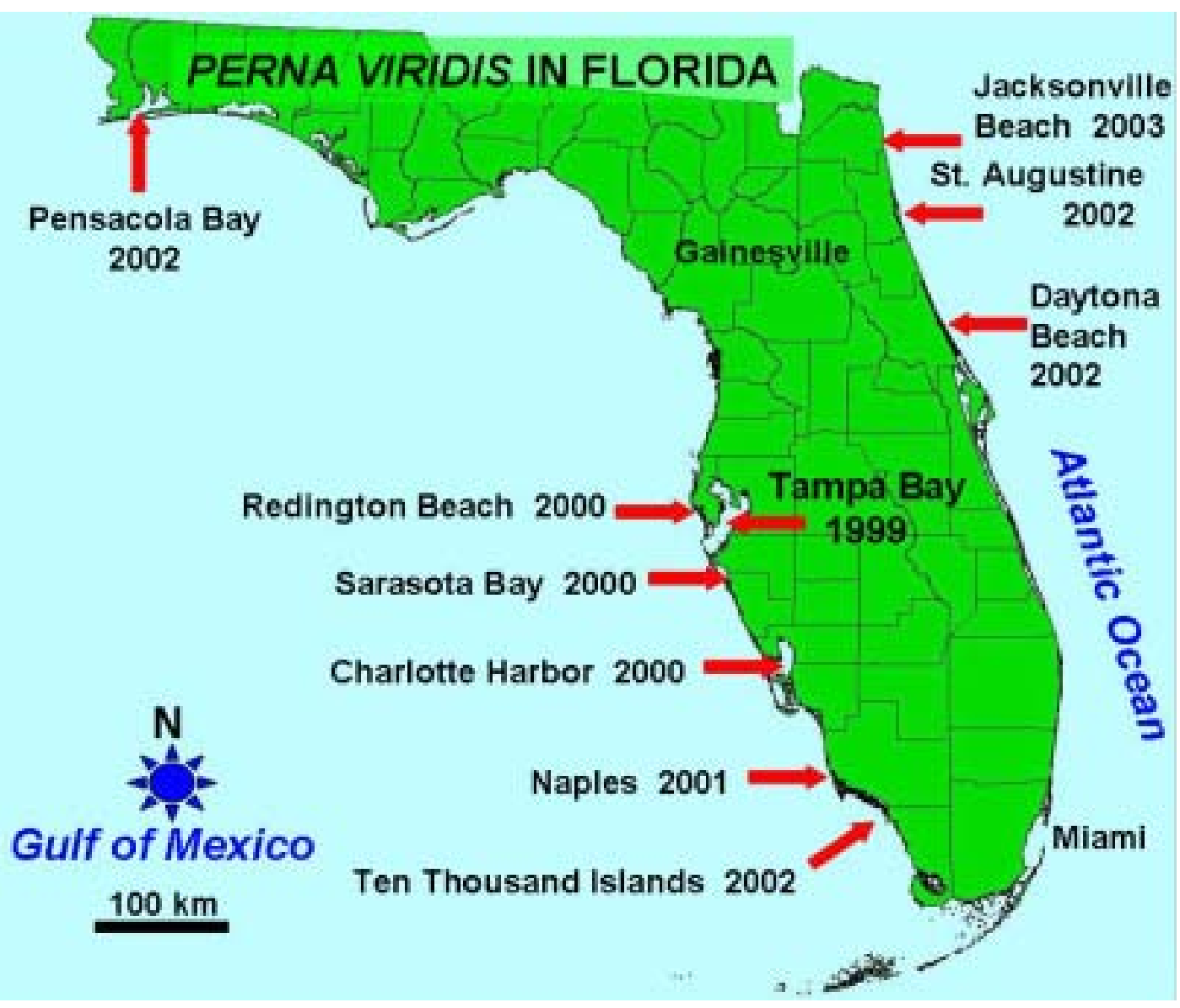

\section{Change in the distribution of Asian Green Mussel (Perna viridis) over time.}

Note: As of December 2006, the report from Pensacola Bay is not considered valid. It appears to have been a misidentification. This update provides evidence of the need for further valid information on invasive species. 


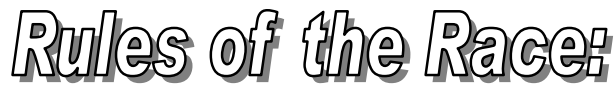

1. Separate the class into groups of three or six. Each group should form three teams representing three different species. Each team should have 200 of the same colored M\&Ms or other substituted object. Place ten cups in front of each group.

2. Team one has a survival factor of 1.25

Team two has a survival factor of 1.0

Team three has a survival factor of 0.75

*The survival factor is the ability of each species to reproduce successfully.

Team one represents Asian Green M ussels. Team two and Team three are native species. Students can pick a native bivalve species such as the Bay Scallop or Eastem Oyster.

3. Each team takes turns rolling the die. This number represents how favorable the environment is for their species, with one being least favorable and six being most favorable.

*The number on the die represents variable changes in the environment, such as changes in $\mathrm{pH}$, temperature, food availability, etc.

4. Each team has one representative from their species to start. After a member of the team rolls the die, multiply that number by the survival factor and the result by the number of individuals reproducing. For the first roll, the number of individuals reproducing is one.

5. After a team calculates the final number, round up to the nearest whole number and place that many $M \& M s$ in any cup. The cup represents living space. Only $\mathbf{2 0}$ individuals of any species can live in one cup! When a cup has 20 M\&Ms in it, the team must move to another cup.

Example:

Team one rolls a 4 on their first turn. Multiply $4 x$ $1.25 \times 1=5$. Team one then places $5 \mathcal{M e} M$ s in any cup or cups. Team one will have 5 individuals reproducing in the next round. 


\section{The next time team one rolls, they get a 2 . Multiply}

$2 \times 1.25 \times 5=12.5$ (13). Thus, team one places

13 M\&Ms in any cup or cups. *Remember only 20 M \&M s per cup!

6. Record all numbers in the attached table.

7. Once the re are $20 \mathcal{M}$ OMs in every cup, the race is over! The living space is gone! 


\section{\# OF REPRODUCING INDIVIDUALS x SURVIVAL FACTOR x ENVIRONMENTAL FAVORABLENESS}

\begin{tabular}{|c|c|c|c|}
\hline & TEAM 1 & TEAM 2 & TEAM 3 \\
\hline \# of reproducing individuals for Round 1 & 1 & 1 & 1 \\
\hline Survival factor & 1.25 & 1.0 & 0.75 \\
\hline \multicolumn{4}{|l|}{ Environmental favorableness (off die) } \\
\hline \multicolumn{4}{|l|}{ \# of individuals for cups } \\
\hline \multicolumn{4}{|l|}{ \# of reproducing individuals for Round 2} \\
\hline Survival factor & 1.25 & 1.0 & 0.75 \\
\hline \multicolumn{4}{|l|}{ Environmental favorableness (off die) } \\
\hline \multicolumn{4}{|l|}{ \# of individuals for cups } \\
\hline \multicolumn{4}{|l|}{ \# of reproducing individuals for Round 3} \\
\hline Survival factor & 1.25 & 1.0 & 0.75 \\
\hline \multicolumn{4}{|l|}{ Environmental favorableness (off die) } \\
\hline \multicolumn{4}{|l|}{ \# of individuals for cups } \\
\hline \multicolumn{4}{|l|}{ \# of reproducing individuals for Round 4} \\
\hline Survival factor & 1.25 & 1.0 & 0.75 \\
\hline \multicolumn{4}{|l|}{ Environmental favorableness (off die) } \\
\hline \multicolumn{4}{|l|}{ \# of individuals for cups } \\
\hline \multicolumn{4}{|l|}{ \# of reproducing individuals for Round 5} \\
\hline Survival factor & 1.25 & 1.0 & 0.75 \\
\hline \multicolumn{4}{|l|}{ Environmental favorableness (off die) } \\
\hline \multicolumn{4}{|l|}{ \# of individuals for cups } \\
\hline \multicolumn{4}{|l|}{ \# of reproducing individuals for Round 6} \\
\hline Survival factor & 1.25 & 1.0 & 0.75 \\
\hline \multicolumn{4}{|l|}{ Environmental favorableness (off die) } \\
\hline \multicolumn{4}{|l|}{ \# of individuals for cups } \\
\hline \multicolumn{4}{|l|}{ \# of reproducing individuals for Round 7} \\
\hline Survival factor & 1.25 & 1.0 & 0.75 \\
\hline \multicolumn{4}{|l|}{ Environmental favorableness (off die) } \\
\hline \# of individuals for cups & o & & \\
\hline \multicolumn{4}{|l|}{ \# of reproducing individuals for Round 8} \\
\hline Survival factor & 1.25 & 1.0 & 0.75 \\
\hline \multicolumn{4}{|l|}{ Environmental favorableness (off die) } \\
\hline \# of individuals for cups & & & \\
\hline
\end{tabular}

\# of reproducing individuals for each round = number of individuals placed in cups after the preceding round 
GRAP舟的

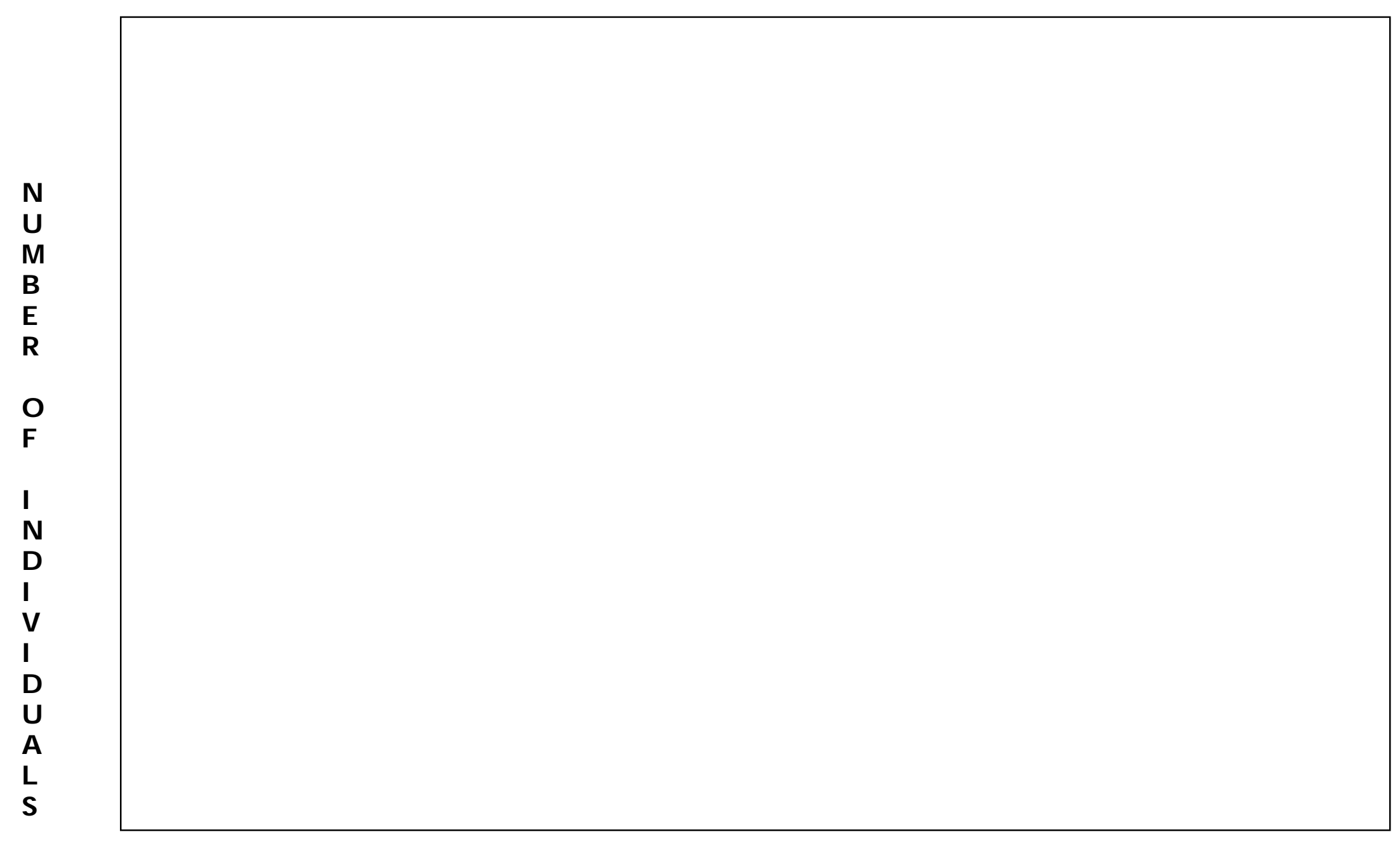

RO ULDS 


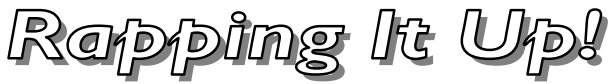

1. W hich species occupied the most living space? W hy?

2. Invasive species compete with native species for food and living space. Is there evidence in your results to suggest the Asian G reen Mussels did this? Hint: If there were no Asian Green M ussels how would your results have changed?

3. Graph the number of individuals you had for your species for each turn. Does your graph differ from the graphs of your opposing teams? How?

4. W hat are the connections between this activity and life in Tampa Bay?

5. W hat existing environmental factors may cause the invasive A sian Green Mussels to reproduce more successfully than similar native species? 


\section{Glossary:}

Aquatic- Living or growing in, on or near water.

Biodiversity - The variety of plant and animal species present in an ecosystem.

Invader/Invasive species - A plant or animal that is not native and causes harm, including disrupting natural ecosystems.

Native species - A plant or animal species that originated in a certain place. A species occurring in its natural range. Species that were present in Florida at the time the first Spanish settlers arrived. 


\section{Invasive Species \\ Series
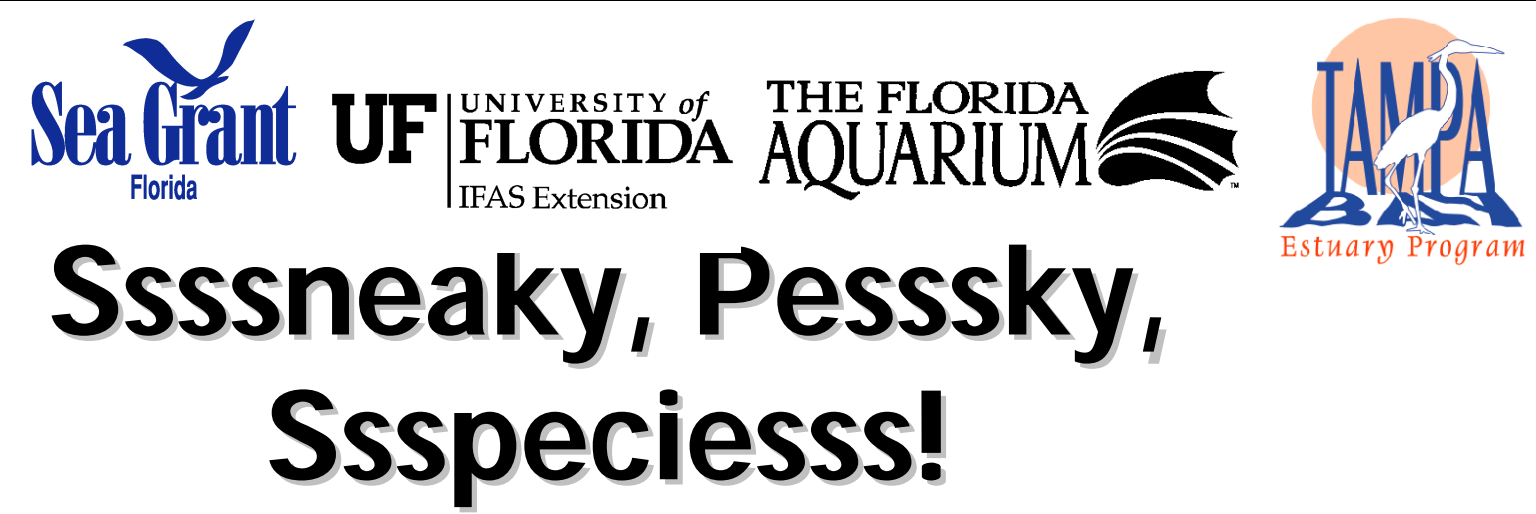

Sne ak Pe eK

Students will be introduced to the concepts and issues surrounding invasive species. $\mathcal{A}$ potential Florida invader is the Brown Tree Snake, Boiga irregularis. Students will explore how this resourceful snake wiped out many native species on Guam and the potential harm it could cause here in Florida. This activity incorporates critical thinking, predicting, and math skills.

\section{Objectives:}

Students will...

- Identify the damage an invasive species can inflict on an environment.

- D emonstrate understanding of the spread of an invasive species in a particular area.

- Model the effects the Brown Tree Snake can have on native species.

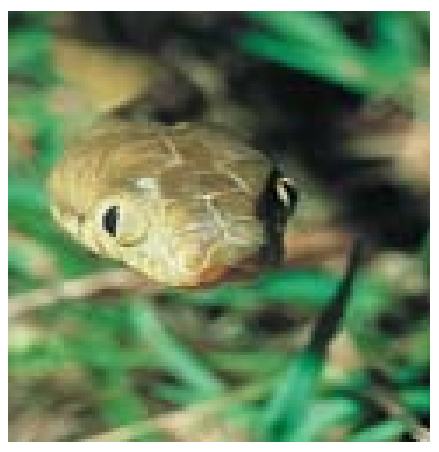

\section{Materials:}

\section{Picture source: NASA}

- 50 snake cut-outs (or $1 / 2$ index cards) per group.

- 200 bird cut-outs (or one-inch squares of paper) per group.

- D ata table (included).

- Graph paper.

\section{Background:}

Invasive species are plants or animals that are not native to a particular area and cause harm by disrupting natural ecosystems. Invasive species may compete with native species for food and living space. A successful invasive species will take over space in which a native species would normally live. It is often difficult to determine exactly what harm a potential invader may 
cause until it is too late. C ase studies have often shown that once an invasive species is established it is virtually impossible to eradicate.

The brown tree snake (Boiga irregularis) is an introduced species on Guam.

The first sightings were in the early 1950s. These snakes became conspicuous throughout central Guam by the 1960 s.

The brown tree snake has become a serious threat due to the absence of natural population controls and availability of vulnerable prey on Guam. The snakes are now causing major ecological and economic problems on the island.

The brown tree snake has virtually wiped out the native forest birds of Guam. Twelve species of birds, some found nowhere else, have disappeared from the island, and several others are close to extinction.

The snakes feed on a wide variety of animals including lizards, birds, and small mammals, as well as bird and reptile eggs. Snakes frequently invade poultry houses, homes and yards to consume domestic poultry, eggs, pet birds and small mammals associated with residential areas. Up to 13,000 snakes per square mile may occur in some forested areas of Guam.

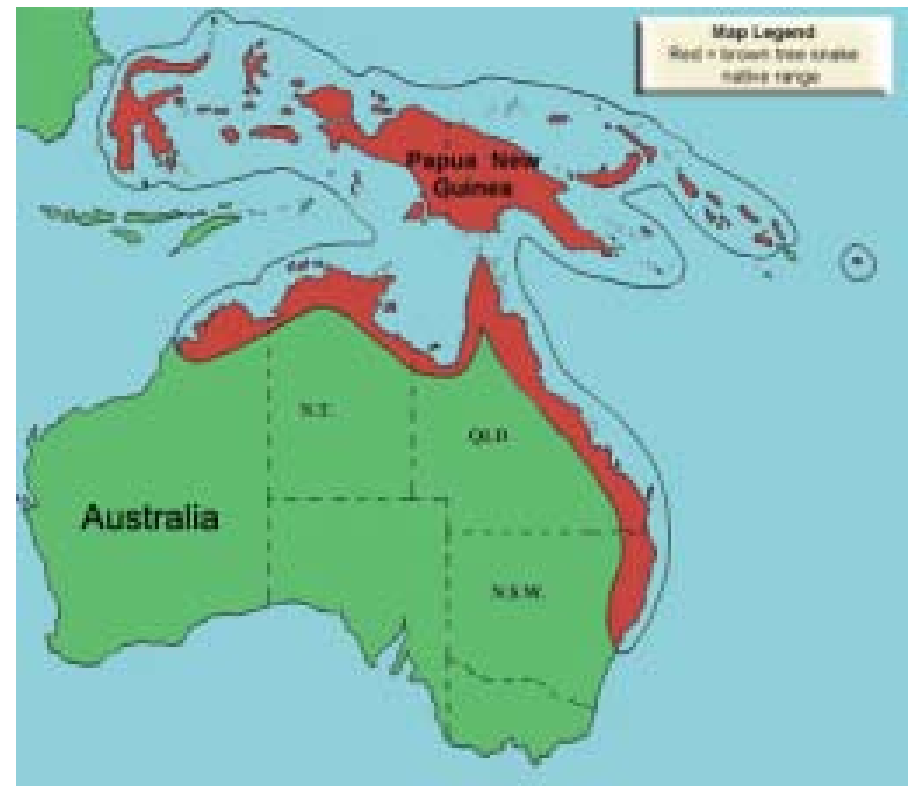

This map from the U.S. Geological Survey shows the native range of the Brown Tree Snake in red/dark gray. 


\section{Procedure:}

1. Provide each group with 200 small squares (or native bird cut-outs) and 50 large squares (or snake cut-outs). Snake cut-outs should be 4-5 times larger than the bird cut-outs.

2. Have students clear their lab table. The table will represent their environment. The table will need to be approximately two feet by five feet long. If using desks, bring four together to make approximately the same amount of space.

3. Students should place 80 of their "birds" on the desk.

4. N ext, have students place their "snake" on the desk trying to touch at least three birds. If the snake touches three birds, it successfully survived this round. Remove the birds that the snake touched before the next round.

5. If at least one snake survives, add another snake for the next round. If no snakes survive, reshuffle the birds and add one snake (a new invader moved in!). For the bird population, add one bird for every two that survived.

6. After each round, students should record the number of snakes and birds in their environment in the data table.

7. Repeat this process until no birds remain or ten rounds are complete.

8. Graph the native bird population over time on the graph provided. 


$$
\begin{aligned}
& 2_{2} \\
& 2_{2}
\end{aligned}
$$




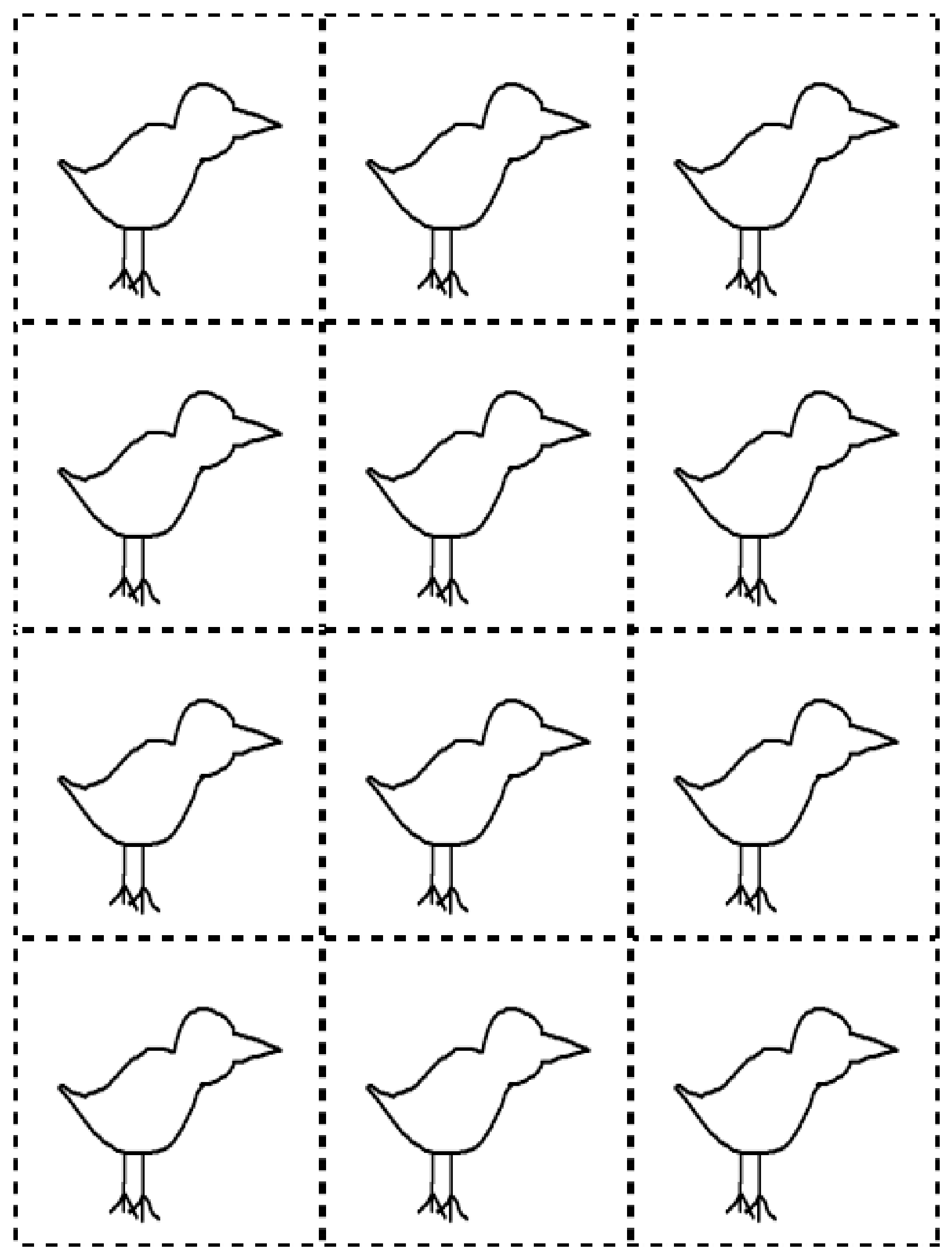

Bird cut-outs 


\section{DATA TABLE}

\begin{tabular}{|c|c|c|}
\hline & Snakes & Birds \\
\hline Snakes \& Birds at start & 1 & 80 \\
\hline Snakes "eating" < 3 birds \& Birds "eaten" & & \\
\hline Surviving snakes $\&$ birds after Round 1 & & \\
\hline Additional Snakes \& Birds for Round 2 & & \\
\hline Snakes \& Birds for Round 2 & & \\
\hline Snakes "eating" < 3 birds \& Birds "eaten" & & \\
\hline Surviving snakes $\&$ birds after Round 2 & & \\
\hline Additional Snakes $\&$ Birds for Round 3 & & \\
\hline Snakes \& Birds for Round 3 & & \\
\hline Snakes "eating" < 3 birds \& Birds "eaten" & & \\
\hline Surviving snakes \& birds after Round 3 & & \\
\hline Additional Snakes $\&$ Birds for Round 4 & & \\
\hline Snakes \& Birds for Round 4 & & \\
\hline Snakes "eating" < 3 birds \& Birds "eaten" & & \\
\hline Surviving snakes $\&$ birds after Round 4 & & \\
\hline Additional Snakes \& Birds for Round 5 & & \\
\hline Snakes \& Birds for Round 5 & & \\
\hline Snakes "eating" < 3 birds \& Birds "eaten" & & \\
\hline Surviving snakes $\&$ birds after Round 5 & & \\
\hline Additional Snakes \& Birds for Round 6 & & \\
\hline Snakes \& Birds for Round 6 & & \\
\hline Snakes "eating" < 3 birds \& Birds "eaten" & & \\
\hline Surviving snakes $\&$ birds after Round 6 & & \\
\hline Additional Snakes \& Birds for Round 7 & & \\
\hline Snakes \& Birds for Round 7 & & \\
\hline Snakes "eating" < 3 birds \& Birds "eaten" & & \\
\hline Surviving snakes $\&$ birds after Round 7 & & \\
\hline Additional Snakes \& Birds for Round 8 & & \\
\hline Snakes \& Birds for Round 8 & & \\
\hline Snakes "eating" < 3 birds \& Birds "eaten" & & \\
\hline Surviving snakes $\&$ birds after Round 8 & & \\
\hline Additional Snakes \& Birds for Round 9 & & \\
\hline Snakes \& Birds for Round 9 & & \\
\hline Snakes "eating" < 3 birds \& Birds "eaten" & & \\
\hline Surviving snakes $\&$ birds after Round 9 & & \\
\hline Additional Snakes \& Birds for Round 10 & & \\
\hline Snakes \& Birds for Round 10 & & \\
\hline Snakes "eating" < 3 birds \& Birds "eaten" & & \\
\hline Surviving snakes \& birds after Round 10 & & \\
\hline
\end{tabular}

Surviving snakes = Snakes - Snakes "eating" $<3$ birds

Surviving birds = Birds - Birds "eaten"

Additional snakes $=1$ snake if any survived

Additional birds = $1 / 2$ (Surviving birds); round "half" birds up 


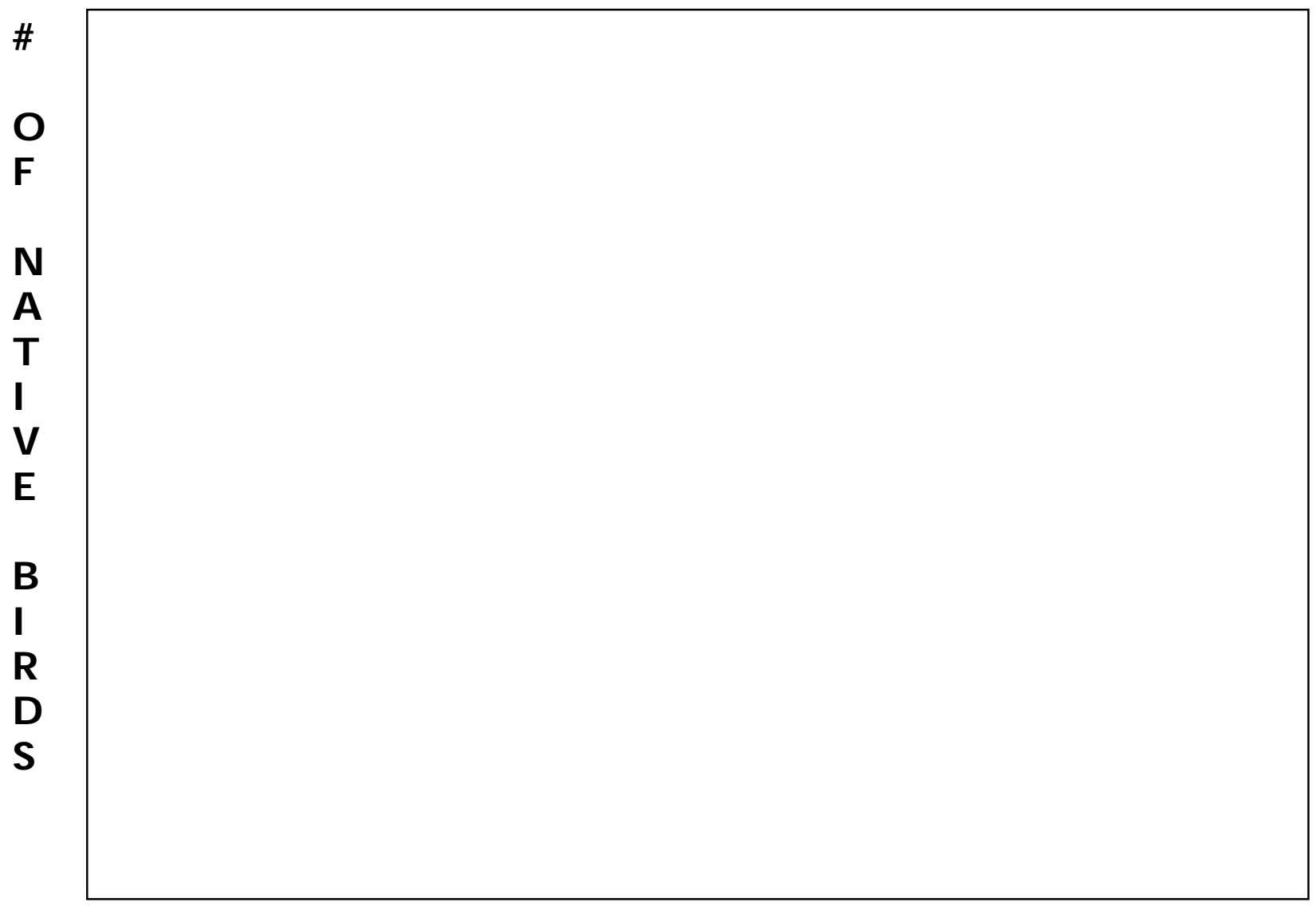

TIME (\# OF ROUNDS) 


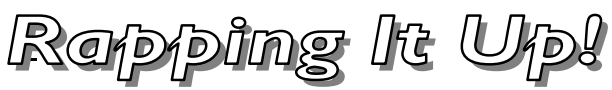

1. After one round, was there a significant effect on the population of native birds? After which round was at least $50 \%$ of the native bird population removed?

2. Using the results from your activity, summarize how the introduction of brown tree snakes impacts native species over time.

3. How do you think an abundance of brown tree snakes here in Florida would affect the native wildlife? 


\section{Glossary:}

Eradicate - Eliminate, exterminate, remove.

Invader/Invasive species- A plant or animal that is not native and causes harm, including disrupting natural ecosystems.

Native species - A plant or animal species that originated in a certain place. A species occurring in its natural range. Species that were present in Florida at the time the first Spanish settlers arrived.

Non-native species - A species introduced to a region intentionally or accidentally. 
This page was intentionally left blank. 


\section{Invasive Species \\ Series
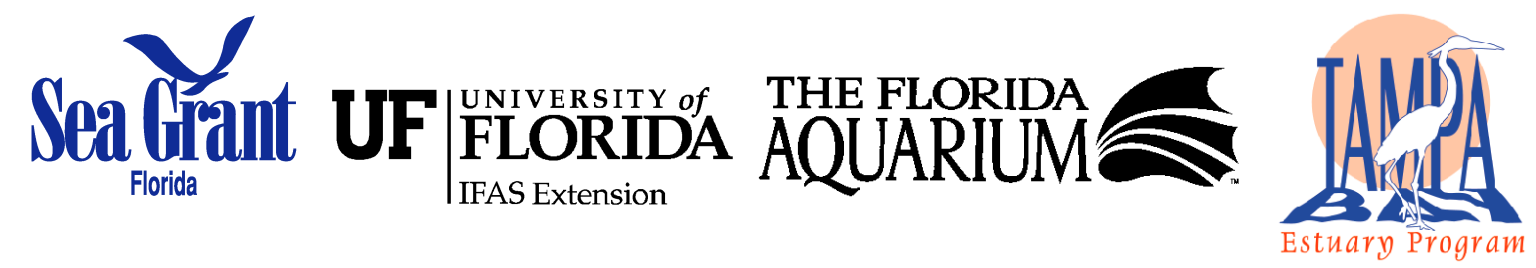 \\ The Green Machine}

\section{Sne ak Pe e K \\ Students will be introduced to Green $\mathcal{T}$ ide, a non-native underwater alga affecting Florida reefs. They will explore two methods to sample coral reefs: quadrat and point transect. Students will calculate the amount of Green $\mathcal{T}$ ide, coral and fish found on a "reef" in the classroom. This activity incorporates math skills and data gathering, recording and analysis.}

Aligned with the following $S$ unshine State Standards and $\mathcal{F C A T}$ Benchmarks for grades $6 \cdot 8:$

SC.D.2.3.2 $\mathcal{A} \mathcal{A} \quad S C . G .2 .3 .4 \quad \mathcal{A} \mathcal{A}$ SC.F.1.3.7 CS SC.H.2.2.1 CS $S C . G .2 .3 .3 \mathrm{CS}$

$\mathcal{A} \mathcal{A}=$ annually assessed

CS = content sampled

\section{Objectives:}

Students will:

- Be able to identify two sampling methods used in reef research.

- Be able to explain which sampling methods most accurately represent the reef as a whole.

- Be able to explain why different methods are appropriate for different studies.

- Be introduced to Green Tide, Caulerpa brachypus, an invasive algae affecting coastal Florida.

\section{Materials:}

- Large open area (open classroom size or larger)

- 10 - 15 whole pieces of construction paper.

- Approximately 60 cup lids or Tupperware lids and 25 - 35 paperclips.

- Two metric tape measures.

- $1 \times 1$ meter quadrat of PVC pipe with ten $10 \mathrm{~cm} \times 10 \mathrm{~cm}$ squares formed by string.

- Calculators.

\section{Background:}

Increasing in numbers, spreading, or occupying space are common characteristics of an invasive species, that is a non-native species that can cause harm. Measuring changes in abundance, the number of organisms in an area, or cover, the space covered by plants or animals, becomes important to scientists that attempt to study effects and impacts of an invasive species. Green Tide on a coral reef provides an example of how scientists accomplish this critical task. 


\section{H ow can coral reef scientists determine how many plants or animals live in an area?}

W orking underwater to determine how many living things are there can be tricky. Sampling is one way to determine how many plants or animals, including coral, are on a reef. Sampling focuses on counting living things in a few small sections of the reef, and the results are used to estimate quantities for the whole reef.

Green Tide, or Caulerpa brachypus, is a non-native alga that is spreading along the East Coast of southern Florida. It smothers and kills corals, forcing fish and invertebrates to find other places for food and shelter. Determining how much $\mathrm{G}$ reen Tide is on reefs represents an important step in understanding and potentially stopping its spread.

\section{What are two common sampling methods?}

Q uadrats are survey grids of a fixed size and shape. In one of the most common forms of sampling, these grids are randomly placed in the study area (not only in the most or least diverse sections). O nce the quadrat is placed on the reef surface, plants and animals within the grid can be counted or the area covered by plants and animals can be estimated (e.g. coral covering more than $50 \%$ of the grid).

Point Transects use a tape measure anchored at a randomly chosen point and stretched to a predetermined length. In this method, the presence of coral, rock, algae or any plant or animal of interest at predetermined intervals (e.g. every $10 \mathrm{~cm}$ ) is recorded.

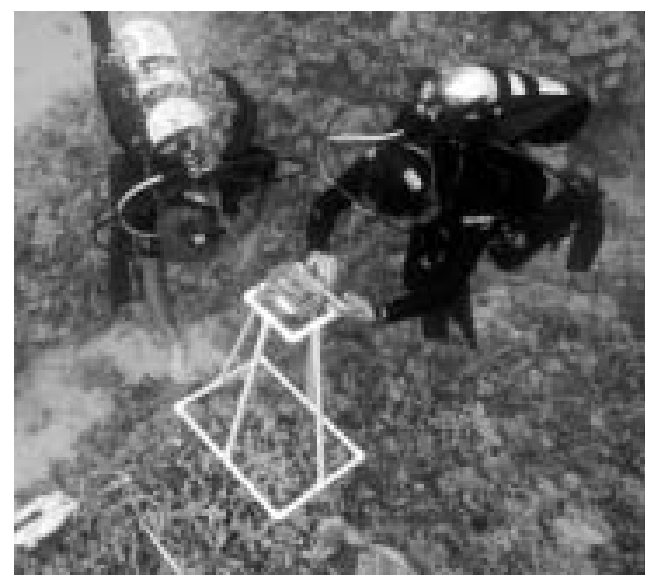

Divers using quadrat equipped with a camera to measure coral cover.

(C ourtesy of U niversity of Hawaii Botany department:

http://www.hawaii.edu/reefalgae/publications/methodsmanual/photoquadratsurvey.htm) 


\section{Procedure:}

1. Before class, place five pieces of construction paper in each of 2-3 patches to represent coral reefs on sand (make the total area of sand and coral to be sampled at least $3 \times 3$ meters). Scatter lids and paper clips around the reefs. The lids represent Green Tide and the paper clips are fish. Do not place paper clips on top of the lids.

2. Count the fish and measure the area covered by coral (construction paper) and Green Tide (lids).

3. Split students into at least three groups. Each group will perform both sampling methods and record their data.

a. For the quadrat method, have students randomly place the quadrat within the area to be sampled. Classify the area under each $10 \mathrm{~cm}$-squared part of the grid as coral, sand or G reen Tide based on whichever covers more than $50 \%$ of the area. Have the students count the number of fish in their quadrat. Repeat this several times. Instruct students to select the random areas by using criteria such as paces in predetermined directions.

b. For the point transect method, place one end of the tape measure randomly on the reef. Stretch the tape measure out to 1.5 meters in any direction. Have students record what is directly under the tape every $10 \mathrm{~cm}$.

6. Use the worksheet to determine the total percentage cover of coral and $\mathrm{G}$ reen Tide and fish density for each method. 


\section{THE GREEN MACHINE WORKSHEET}

NAME

DATE

\section{QUADRAT METHOD}

\begin{tabular}{|l|c|c|c|}
\cline { 2 - 4 } \multicolumn{1}{c|}{} & $\begin{array}{c}\text { TOTAL \# OF } \\
\text { GRIDS IN } \\
\text { QUADRAT }\end{array}$ & $\begin{array}{c}\text { \# OF GRIDS CONTAINING 50\% } \\
\text { OR MORE CORAL OR GREEN } \\
\text { TIDE }\end{array}$ & $\begin{array}{c}\text { \% COVER OF CORAL OR GREEN TIDE } \\
\text { ( OF GRIDS CONTAINING CORAL OR } \\
\text { GREEN TIDE / TOTAL \# OF GRIDS) }\end{array}$ \\
\hline CORAL & & & \\
\hline $\begin{array}{l}\text { GREEN } \\
\text { TIDE }\end{array}$ & & & \\
\hline
\end{tabular}

\begin{tabular}{|c|c|c|c|}
\cline { 2 - 4 } \multicolumn{1}{c|}{} & $\begin{array}{c}\text { TOTAL QUADRAT } \\
\text { AREA }\end{array}$ & $\begin{array}{c}\text { \# OF FISH IN } \\
\text { QUADRAT }\end{array}$ & $\begin{array}{c}\text { FISH DENSITY } \\
\text { (\# OF FISH / TOTAL QUADRAT AREA) }\end{array}$ \\
\hline \multirow{2}{*}{ FISH } & & & \\
\hline
\end{tabular}

\section{POINT TRANSECT METHOD}

\begin{tabular}{|l|c|c|c|}
\cline { 2 - 4 } \multicolumn{1}{c|}{} & $\begin{array}{c}\text { TOTAL \# OF } \\
\text { POINTS SAMPLED }\end{array}$ & $\begin{array}{c}\text { \# OF POINTS DIRECTLY } \\
\text { OVER CORAL OR GREEN } \\
\text { TIDE }\end{array}$ & $\begin{array}{c}\text { \% COVER OF CORAL OR GREEN TIDE } \\
\text { (\# OF POINTS OVER CORAL OR } \\
\text { GREEN TIDE / TOTAL \# OF POINTS) }\end{array}$ \\
\hline CORAL & & & \\
\hline $\begin{array}{l}\text { GREEN } \\
\text { TIDE }\end{array}$ & & & \\
\hline
\end{tabular}

\begin{tabular}{|c|c|c|c|c|c|}
\cline { 2 - 6 } \multicolumn{1}{c|}{} & $\begin{array}{c}\text { TOTAL\# OF } \\
\text { POINTS } \\
\text { SAMPLED }\end{array}$ & $\begin{array}{c}\text { \# OF POINTS } \\
\text { DIRECTLY } \\
\text { OVER FISH }\end{array}$ & $\begin{array}{c}\text { WIDTH } \\
\text { OF } \\
\text { TAPE }\end{array}$ & $\begin{array}{c}\text { TOTAL AREA } \\
\text { SAMPLED (TOTAL \# } \\
\text { OF POINTS X WIDTH } \\
\text { OF TAPE) }\end{array}$ & $\begin{array}{c}\text { FISH DENSITY } \\
\text { (\# OF POINTS DIRECTLY } \\
\text { OVER FISH / TOTAL AREA } \\
\text { SAMPLED) }\end{array}$ \\
\hline FISH & & & & \\
\hline
\end{tabular}




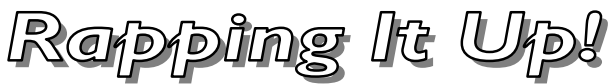

1. W hich method was the hardest to do and why? W hich method was the easiest to do and why?

2. Pick one of the sampling methods and explain why your estimates of fish, coral or Green Tide differ from what is actually on your "classroom reef."

3. If you were a scientist studying $\mathrm{G}$ reen Tide, which method would you use and why?

4. Using what you learned in this experiment, why do you think Green Tide poses a problem for corals and fish? 


\section{Glossary:}

Invader/Invasive Species - A plant or animal that is not native and causes harm, including disrupting natural ecosystems.

Non-native species - A species introduced to a region intentionally or accidentally.

Quadrats - Survey grids of a fixed size and shape.

Point transect - A series of points surveyed along a tape measure anchored at a random point and stretched to a predetermined length. 


\section{Air Potato}

Dioscorea bulbifera

Order: Liliales

Family: Dioscoreaceae

Description: Air potato is an invasive vine in Florida, consisting of large, green, heart-shaped leaves. It can quickly grow 60-70 feet in length, which is long enough to blanket even the tallest trees like those found in hardwood hammocks. As a member of the yam family, air potato produces large numbers of aerial tubers (potato-like growths attached to the stem) that will grow into new stems. Air potato is a prohibited plant in Florida.

\section{Special Features:}

- Medicine - Dioscorea varieties contain the steroid diosgenin, which is a principle material used in the manufacture of birth control pills.

- Food for Thought - Air potato is cultivated in West Africa for their edible underground tubers. Uncultivated forms, such as in Florida, are reported to be bitter and even poisonous.

- Growth - Air potato has a winter dormant period in which stems die back to the ground. After dormancy, the underground tubers give rise to new stems, which grow very quickly often reaching 70 feet by the end of the growing season.

Similar Species: Dioscorea alata and Dioscorea sansibarensis are two other members of the yam family that are similar to the air potato. D. alata is easily distinguished from the other two species because it twines to the right instead of the left. $D$. sansibarensis twines left like the air potato, but is further characterized by its small, purplish bulbs.

Range and Habitat: The origin of air potato is uncertain, however some believe the plant is native to both Africa and Asia. Others believe it was originally native to Asia and subsequently introduced into 
Reproduction:

\begin{abstract}
Africa. Air potato often grows in hardwood forests and invades thickets, disturbed areas and tropical hammocks. It is rarely found along disturbed edges of pinelands, and because it is not salt tolerant, air potato is seldom found in marine areas as well.

Dioscorea species are dioecious, meaning they have male reproductive organs in one individual and female in the other. In Florida, flowers occur during the summer months (but not every year). The inconspicuous flowers are pleasant smelling and green to white in color. Seeds are wind-dispersed although fruit set in Florida occurs only occasionally.
\end{abstract}

\title{
Notes:
}

- History - Air potato was probably introduced into Florida as an ornamental and a food plant in about 1905 . By the early 1970 s it was already recognized as a pest plant throughout the state.

- Ecology - Potato vine is a serious weed in central and southern Florida. Vines grow as rapidly as 7 inches per day, quickly spiraling up to tree tops. The vines form dense masses that shade out trees and may eventually kill them.

- Preventative Measures - Vines grow rapidly in areas of direct sunlight so efforts to remove the plant should be concentrated in these areas first. 


\section{Armored Suckermouth Catfish}

Hypostomus plecostomus (This may not be the species in Florida.)

Additional Genera in Florida:

Pterygoplichthys sp.- Sailfin Catfish

Order: Siluriformes

Family: Loricariidae

Description: Suckermouth catfish are brownish in color and appear to have many darker spots. There are approximately 116 Hypostomus species, making identification difficult. All of the species in the Loricariidae family have large sucker mouths, and the suckermouth catfish may grow up to $18^{\prime \prime}$ in length, making it one of the largest home aquarium fish.

\section{Special Features:}

- Tolerance - Suckermouth catfishes occur in fresh running waters and brackish waters. They appear to tolerate both cold and oxygenpoor waters.

- Size - Males are smaller than females.

Range and Habitat: This species naturally occurs in tropical America, including South and Central America from Uruguay north to Panama. Their range has increased in peninsular Florida to include rivers leading to Tampa Bay and southward to the canals of southeast Miami-Dade County. Adult suckermouth catfishes are typically found in rocky streams, whereas juveniles are more common in areas rich in vegetation. Adults spend most of their time hidden and attached to the underside of logs or large rocks.

Wild Diet:

Reproduction:
Algae and detritus constitute their main food items.

Suckermouth catfish do not typically breed in captivity. In the wild, ripe males develop barbel-like appendages about their mouth, 
whereas females have a tendency to develop swollen abdomens. Eggs are spawned on the surface of substrates, such as stones or logs, or in holes. Males care for the eggs, which hatch in 3-5 days.

\section{Notes:}

- Interest to Fisheries - Suckermouth catfish are of little or no value as a food fish, although they are at least occasionally consumed in their native range.

- How Did They Get Here? - The populations established throughout Florida are believed to have been introduced through escapes from tropical fish farms and releases by aquarium hobbyists.

- Feeding - Some species are more carnivorous than others, but the species established in Florida mainly eat algae and detritus.

- Potential Impacts - The plecos' broad salinity and temperature tolerance improves their chances of expanding their range and increasing their abundance in the Gulf region.

- Additional Research - Plecos may not be a significant factor limiting nesting success of cichlids and native sunfishes. The fact is there has been no research on the subject. 


\section{Asian Swamp Eel}

Monopterus sp.

Order: Synbranchiformes

Family: Synbranchidae

Description: Asian swamp eels are often confused with a number of native animals, including the native American eel. The swamp eel has an elongate (snake-like) body with no noticeable scales or fins. The head is relatively short and the teeth are small and not easily seen. The body and head are dark, sometimes dark olive or brown above, but lighter, often light orange below. Some individuals are brightly colored with yellow, black, and gold spots over a light tan or almost-white background.

\section{Special Features:}

- Skin - The skin produces a thick mucous layer making the eels difficult to catch and hold.

- Breathing - They breathe air and can achieve up to $25 \%$ of respiration cutaneously (through the skin).

- Food Needs - They can survive for weeks without food.

- Male or Female? - The swamp eel changes from female to male as it grows older and larger. Therefore, all larger individuals are males.

- Parental Care - Large males construct bubble nests at the mouth of burrows and guard the eggs and young. A high degree of parental care is given probably assuring improved reproductive success.

Similar Species: The swamp eel introduced to the United States belongs to the genus Monopterus. There may be more than one species. Until recently scientists have used the name Monopterus albus for all U.S. populations.

Range and Habitat: Swamp eels and its relatives are native to tropical and temperate Central and South America, Africa, Australia, and India to eastern Asia (including much of China). In Asia, swamp eels are widespread 
and commonly sold live in markets as food for human consumption.

Wild Diet:

Reproduction:
Crayfish, shrimp, worms, frogs, tadpoles, and other fishes

Eggs are laid into a bubble nest in shallow water. The nest is typically not attached to vegetation but floats freely at the surface. Eggs and young are guarded by one or both parents.

\section{Notes:}

- Common Names - In addition to the name "swamp eel," other English names used for members of this group of fish include rice eel, rice-paddy eel and belut.

- What is it? - Although swamp eels are fish, they are not closely related to other eel-like fishes. Unlike the native American eel (Anguilla rostrata), swamp eels do not migrate to the ocean to spawn. More than a dozen species are included in the eel family.

- Invasion - Swamp eels were first introduced to the United States in Hawaii some time around 1900. They were first identified in the continental United States in 1994 based on specimens collected in ponds at the Chattahoochee Nature Center north of Atlanta, Georgia. The eels were first found in Florida in 1997.

- Ecology - At present, scientists are concerned about the effects that swamp eel predation can have on native fish. Some recent research indicates that swamp eels do not feed heavily on tropical fish in aquaculture ponds, so predictions of impacts remain uncertain. 


\section{Australian Pine}

Casuarina equisetifolia

Order: Casuarinaceae

Family: Casuarinales

Description: The Australian Pine is not a pine tree at all. In fact, it is not even related to the pines. A straight, up-right tree capable of reaching 70 to 90 feet or more in height, the Australian pine has escaped cultivation and become naturalized. Propagating itself on barrier beaches, road sides, and in woods as if wild, the Australian pine tree is now outlawed in many parts of Florida due to its invasive nature and rapid growth rate.

\section{Special Features:}

- Leaves - The Australian Pine appears to have long, soft, graygreen needles, but these needles are actually multi-jointed branchlets. The true leaves are small, inconspicuous, tooth-like scales whorled at joints on the tree's slender, drooping branches. Branchlet length ranges from 4-8 inches.

- Fruit - The fruit is tiny, one-seeded and forms in woody conelike clusters.

- Bark - The wood is reddish brown to gray, rough and peeling.

- Flowers - Flowers are unisexual and inconspicuous, with female flowers in small axillary clusters and male flowers in small terminal spikes.

Similar Species:

Range and Habitat:
There are 45 species of the genus Casuarina, variously known as Australian pine, beefwood, forest oak, horsetail tree and iron wood. All are large evergreen trees resembling conifers, with a thin crown of drooping branches and leaves reduced to scales.

Originating in Australia, South Pacific Islands and Southeast Asia, the Australian pine was introduced to Florida in the late 1800s. By the early 1900s, it was planted extensively in the southern half of the USA. It can also be found in the West Indies, Mexico and 
elsewhere in tropical America. In particular, the Australian pine flourishes in the warmest areas in South Florida on pine land and along exposed shores.

Reproduction:

The Australian pine reproduces with seeds, as many as 300,000 per pound, which are dispersed by birds, wind and water. Flowers are unisexual and inconspicuous with female flowers in small axillary clusters and male flowers in small terminal terminal spikes.

\section{Notes:}

- Ecological Significance - With rapid growth, dense shade, dense accumulation of plant litter, and other competitive advantages, the Australian pine is displacing and extremely destructive to native vegetation.

- Erosion - Originally planted extensively in the Southern United States to provide shade and protect against wind and erosion, the Australian pine can encourage beach erosion by displacing deep-rooted native vegetation.

- Endangered Species - Interferes with nesting of endangered sea turtles and the American crocodile.

- Life History - Not freeze tolerant; sensitive to fire. The Australian pine loses branches easily and topples in high winds because of its shallow roots. It can colonize nutrient-poor soils easily by using nitrogen-fixing microbial associations.

- Allelopathy (suppression of growth of one plant species by another due to the release of toxic substances) - The Australian pine produces compounds that inhibit the growth of native vegetation.

- Related Exotics - May be confused with other related exotics including C. glauca, which has 10-17 leaf scales per whorl, and C. cunninghamiana, which has 8-10 scales per whorl (the Australian pine has 6-8 scales per whorl). 


\section{Brazilian Pepper}

Schinus terebinthifolius

Order: Sapindales

Family: Anacardiaceae

Description: Known as the Florida holly, the Brazilian pepper is a shrub or small tree easily recognized by its dark green leaves and clusters of red berries. It is related to poison ivy and is toxic to some people. Brazilian pepper is an introduced species that can crowd out native plants, necessitating its removal in many areas.

\section{Special Features:}

- Leaves - Bright green and non-leathery in texture, the leaves are compound, meaning there are several leaflets arranged opposite each other around one stem. When crushed, the leaves smell like turpentine.

- Size - The Brazilian pepper is a multi-trunk shrub that can grow as tall as 40 feet and have a diameter of more than a foot.

- Flowers and Fruits - A female Brazilian pepper produces sprays of small yellowish-white flowers and clusters of small red berries.

- Allelopathy (suppression of growth of one plant species by another due to the release of toxic substances) - The Brazilian pepper produces compounds that inhibit the growth of native vegetation.

- Medical Uses - Virtually all parts of the Brazilian pepper have been used medicinally throughout the tropics including its leaves, bark, fruit, seeds and resin. They may be used as a topical antiseptic, aid in treating anything from a toothache to depression, respiratory infections and urinary infections.

\section{Similar Species: $\quad$ Schinus molle and Schinus aroeira}

Range and habitat: Indigenous to South and Central America, the Brazilian pepper is found in semi-tropical and tropical parts of the United States. It can grow in wet or dry soil and is salt tolerant. In addition, it appears to survive flooding, fire and drought. Widely distributed in Florida, the 
Brazilian pepper is sensitive to cold temperatures and therefore limited to protected areas in central Florida. It is an aggressive invader of disturbed habitats, and can successfully colonize several native plant communities including hammocks, pinelands and mangrove forests.

\section{Reproduction:}

Each sex occurs on a separate plant. Male flowers last only 1 day. Female flowers last up to 6 days and are insect pollinated. Fruits are usually mature by December. Birds and mammals are the chief means of dispersal. Seedlings have a high rate of survival and some can be found all year. Reproduction can occur 3 years after germination. Some trees can live for about 35 years.

\section{Notes:}

- History - The Brazilian pepper has been found in ancient religious artifacts and idols, but was brought to Florida in the 1840 s for use as an ornamental shrub.

- Status - What was once a favorite shrub now dominates 700,000 acres from North central to South Florida. It is on the state of Florida's prohibited plant list and is therefore illegal to cultivate, sell or transport.

- Ecology - The Brazilian pepper damages the shoreline by disturbing natural fish habitat. It crowds out valuable mangroves, and its shallow roots allow erosion. Brazilian pepper destroys valuable wildlife habitats in freshwater wetlands and upland pine forests, and it produces many seeds that can sprout years later.

- Growth - Winter flocks of birds love the berries, and they are credited with helping to spread Brazilian pepper. The plants resprout when burned or cut, and must be killed with with herbicides. 


\section{Brazilian Waterweed}

Egeria densa

Order: Hydrocharitales

Family: Hydrocharitaceae

Description: The slender stems of Egeria are usually a foot or two long, but can be much longer. The small leaves are strap-shaped, about one inch long and 1/4 inch wide. The leaf margins have very fine saw teeth that require a magnifying lens to see. Leaves occur in whorls of three to six around the stem. The flowers are on short stalks about one inch above the water. Flowers have three white petals and are about 3/4 inch across.

\section{Special Features:}

- Flowers - Flowers are produced in late spring and again in the fall. The intensity of flowering varies from year to year.

- Invasive Properties - Brazilian waterweed forms dense stands that restrict water movement, trap sediment, and cause fluctuations in water quality. Dense beds interfere with the recreational uses of a waterbody by interfering with navigation, fishing, swimming and water skiing.

- Propagation - A few pieces or cuttings can cause spread: aquarium dumping serves as an additional means of introduction for this invasive.

- Ideal Situation - In drought years, Brazilian waterweed appears to grow more quickly, while in years with heavy precipitation it appears to grow more slowly.

Similar Species: Brazilian waterweed may be confused with hydrilla (Hydrilla verticillata). Similar in appearance and growth, Brazilian waterweed is easily recognizable by whorled leaves exceeding $2 \mathrm{~cm}$ and by fresh plants being smooth to the touch.

Range and Habitat: Brazilian waterweed is a submerged, freshwater perennial herb, generally rooted on the bottom in depths up to 20 feet or drifting. 
It is found in both still and flowing waters, in lakes, ponds, pools, ditches, and quiet streams. It tends to form dense stands that can cover hundreds of acres and can persist until it dies back in the fall. It is found in about 30 states.

Reproduction:

Once introduced, Brazilian waterweed reproduces through the spread of plant fragments. Because all the Brazilian waterweed plants in the United States are male, no seeds are produced. Branches sprout from "double nodes" located at about eight inch intervals along the stems. If a Brazilian waterweed fragment does not have a "double node", it can not grow into a new plant.

\section{Notes:}

- Invaders! - Found in streams, ponds and lakes, this submerged plant is native to South America but was imported to North America for the aquarium trade.

- History - The earliest report of Brazilian waterweed in the United States was from Millneck on Long Island in New York, where the plant was collected in 1893. It was offered for sale in the United States in 1915, where it was recommended as a good "oxygenator" plant.

- Male or Female? - Seeds and/or female flowers have never been reported from Brazilian waterweed populations established in the United States.

- Growth - The plants initiate growth when water temperatures reach 10 degrees centigrade ( $\left.50^{\circ} \mathrm{F}\right)$. Two major growth flushes occur in spring and fall. Each of these flushes is followed by periods of die off/biomass loss.

- Nicknames - Brazilian waterweed is also commonly called Brazilian elodea. 


\section{Brown Anole}

Anolis sagrei

Order: Squamata

Family: Polychrotidae

Description: $5-8$ " long. Extensible throat fan is yellow to red-orange, with a central white line. Enlarged toe pads and short snout. Back is tan to dark brown, with dark-bordered, interconnected light diamonds or stripe. Prominent crest on males' tails, no crest on back.

\section{Special Features:}

- Color - Pattern on back may fade to a uniform tan in mature males.

- Behavior - Males vigilantly protect territories, with intense headbobs or push-ups and colorful displays of throat fans.

- Habitat Use - Although frequently found on trees and shrubs, the Brown Anole is a ground-dweller. It never ventures far from the ground, and it rests head down so that it can flee earthward when threatened.

- Activity - Diurnal

Similar Species: $\quad$ Five; two in our range. The Cuban Anole and the Bahaman Anole.

Range and Habitat: Native to Jamaica, Cuba, and the Bahamas and introduced into peninsular Florida. Lives on trees, shrubs, fences, walls, lumber stacks, and rock piles. Usually within $6^{\prime}$ of the ground.

Wild Diet:

Reproduction:

Predators:
Spiders, ants, beetles, grasshoppers, and other insects are caught by swift dashes.

Mates in spring and summer, with single eggs, laid every couple of weeks from June to September. Eggs hatch in 30 days. Courtship involves colorful displays and visual signals.

Birds, larger lizards, and snakes, as well as house pets (dogs and cats). 
This page was intentionally left blank. 


\section{Cuban Treefrog}

Osteopilus septentrionalis

Order: Anura

Family: Hylidae

Description: Largest treefrog in North America. Skin is green, bronze, or gray and warty. Enormous toe pads as large as external ear. Skin on top of head is fused to skull.

\section{Special Features:}

- Activity - Nocturnal

- Feeding - Eats almost anything it can catch and swallow.

- Habitat Use - The Cuban treefrog is most abundant around ornamental fishponds and well-lighted patios. They also hide among the timbers of highway billboards during the day and feed on insects attracted to the lights at night.

- Introduction - This species was probably introduced by accident into Key West on vegetable produce brought from Cuba early in the century. It continues to spread on the Florida mainland by hitchhiking on crates and transplanted shrubs.

- Call - A variable pitched, slightly rasping or grating snore.

Range and Habitat: Introduced into south Florida from Cuba. Can be found in moist and shady places in trees and shrubs or around houses.

Wild Diet:

Reproduction:

Predators:
Insects and native frogs

Eggs deposited in the water in lakes and ponds, drainage ditches, swimming pools, and cisterns from May to October. Males clasp females behind the forelimbs for amplexus or a mating embrace.

Birds, snakes, larger lizards and house pets (cats and dogs).

\section{Notes:}

- A treefrog's pupils are horizontal, and its toe tips expand into sticky adhesive pads used in climbing.

- The Cuban treefrog is extremely invasive and tends to drive native frogs (e.g. the green treefrog) out of their natural habitat. 
This page was intentionally left blank. 


\section{Formosan Subterranean Termite}

Coptotermes formosanus

Order: Isoptera

Family: Rhinotermitidae

Description: Termites live in social colonies that have three castes. The three castes of termites include the Workers, Soldiers and Reproductives. Workers are small, white, blind and quick moving. They perform most of the tasks required to maintain a colony. The majority of individuals in a colony are workers. Soldiers have hard, brown heads with jaws that look like pincers. These jaws are strictly for fighting and are so specialized that they cannot be used to chew food. Some reproductives fly in swarms and start new colonies while others take over reproduction when the primary king or queen dies or becomes separated from the main colony.

\section{Special Features:}

- Foraging Tubes - When these termites invade a house aboveground, foraging tubes of 0.25 to 0.5 inch diameter may be found connecting soil tubes and the infested house.

- Swarming - Swarming is the primary way termites naturally spread after they have been transported to a new area. Three elements are needed for swarming to be effective: 1 ) proper food resources (cellulose or wood), 2) moisture, and 3) a place to colonize.

Similar Species:

The genus Coptotermes contains the largest number of termite pests ( 28 species) among the $>2,500$ termite species worldwide. The Formosan subterranean termite (FST) is the most widely distributed.

Range and Habitat: Native to Asia, the distribution of FST in the United States in the year 2000, included Alabama, California (an isolated infestation in San Diego County), Florida, Georgia, Hawaii, Louisiana, Mississippi, North and South 
Carolina, Tennessee, and Texas. FST nest in the soil to obtain moisture, but they also nest in wood that is often wet. They easily attack any wood in contact with the ground, and if the wood does not contact the soil, they can build mud tunnels or tubes to reach wood several feet above the ground.

\section{Reproduction:}

A single colony may produce over 70,000 reproductive alates. After a brief flight, reproductive alates shed their wings. Females immediately search for nesting sites with males following closely behind. When the pair find a moist crevice with wooden materials, they form the royal chamber and lay approximately 15 to 30 eggs. Within two to four weeks, young termites hatch from the eggs. The reproductives nurse the first group of young termites. One to two months later, the queen lays the second batch of eggs, which will eventually be nursed by termites from the first egg batch.

\section{Notes:}

- How Many?! - A single colony of FST may contain several million termites (versus several hundred thousand termites for native subterranean termite species) that forage up to $300 \mathrm{ft}$ in soil.

- Damage - A single individual of the FST doesn't consume more wood than a single native subterranean termite, however because of its large population size, a FST colony can cause more structural damage in a shorter time.

- Plants - Studies also found that FST attack many species of living plants. The FST attacks structural lumbers and living plants because they are sources of cellulose.

- Pest Status - Control and repair costs due to FST is estimated at $\$ 300$ million annually in New Orleans alone. 


\section{Green Iguana}

Iguana iguana

Order: Squamata

Family: Iguanidae

Description: Full grown usually between 4-6 feet long, although have been known to grow up to 7 feet long. This includes the tail, which can make up about half the body length and has black stripes in addition to its green color. The body is green in color, but can be many different shades ranging from bright green, to a dull, grayish-green or brownish. Their skin is rough, with a set of pointy scales along the iguana's back. They have long fingers and claws to help them climb and grasp.

\section{Special Features:}

- Senses - Green iguanas have excellent senses of smell, hearing and vision.

- Defense - Long, sharp tail is used as a defense mechanism when snapped in the air. The tail can break off if caught by a predator, but grows back without permanent damage, even though this can cause extreme stress to the animal. Skin is very water resistant and tough enough to prevent cuts and scratches. The coloring of the skin helps camouflage the iguana.

- Behavior - Male iguanas have a special flap of skin called the dewlap. Male iguanas can extend their dewlap to appear bigger than they really are in order to intimidate predators or rivals or to impress females.

- Physiology - Both males and females can store fat under their jaws and their necks for times when there is not enough food available.

- Activity - Iguanas are diurnal, awake during the day. Being cold-blooded animals, they bask in the sun, often lying on warm rocks as they soak up the sun's heat. 
Range and Habitat: The green iguana is found over a large geographic area, from Mexico to southern Brazil and Paraguay, as well as on the Caribbean Islands. Iguanas live in tropical rainforest areas, generally in lower altitudes in areas near water sources, such as rivers or streams. They spend most of their time high in the forest canopy, about 40-50 feet above the ground. Have been introduced to South Florida as a result of escaped or released pets, accidental releases in the commercial pet trade, or some other means of invasion.

Wild Diet:

Reproduction:

Predators:
Green iguanas are herbivorous. They eat a variety of leaves and fruits. Sometimes green iguanas (especially young ones) will eat eggs, insects, and small vertebrates.

Iguanas lay many eggs at a time (about 50 ) in holes in the ground called burrows. They also dig burrows without eggs to confuse predators. After the females lay the eggs, they leave them and do not return. Only about 3-10 babies actually survive to adulthood. The egg takes about 8-10 weeks to hatch, then juveniles take about 2 years to become a mature adult.

Snakes, birds, people

\section{Notes:}

- Like many tropical species, the green iguana is also threatened by habitat destruction in its native range.

- The green iguana is a victim of the pet industry. Although many pet iguanas are now being raised on iguana farms, capture from the wild has lowered their numbers.

- Some people in South America hunt the green iguana for food, known as "bamboo chicken".

- These iguanas can dive from trees into water, and swim well. They are quite sturdy and can fall 40-50 feet to the ground without getting hurt.

- Tend to live alone, but occasionally seen in groups in sunny basking spots. 


\section{Green Mussel}

Perna viridis

Order: Mytiloida

Family: Mytilidae

Description: The Green Mussel is a bivalve that can grow to 6 or 7 inches. Shell length is approximately twice the height. Young mussels are a brilliant green and adults are darker green to brown.

\section{Special Features:}

- Size - Florida's native mussels are nearly as large as green mussels, but none of them act as fouling organisms like the green mussel.

- Density - It is not uncommon to find as many as 1,000 adult green mussels per square foot.

- Distinguishing Characteristics - The green mussel can be distinguished from other mussels because it has both a green lip on the inside of the shell and an indented curve on the bottom edge of the shell.

Similar Species: Green lipped mussel and brown edible mussel

Range and Habitat: The green mussel is native to the tropical marine and estuarine waters of the Indo-Pacific region of Asia, from the Persian Gulf to the South China Sea. They live in waters where the salinity ranges from 27-33 PSU, and their optimal temperature range is $26-32^{\circ} \mathrm{C}$ $\left(78.8^{\circ} \mathrm{F}\right.$ to $\left.89.6^{\circ} \mathrm{F}\right)$. The first known occurrence of the green mussel in the United States was in Tampa Bay, Florida, in the summer of 1999, where they were discovered clogging the inside of cooling water intake tunnels at a local power plant.

Wild Diet:

Phytoplankton, zooplankton and detritus filtered from the water 
Reproduction:

Predators:
Sexes in this species are separate and fertilization is external. Spawning generally occurs twice a year between early spring and late autumn. Fertilized eggs hatch and larvae remain in the water column for two weeks before settling as juveniles. Larvae attach to hard surfaces, such as rocks, pilings and boat hulls using strong threads. Sexual maturity occurs after occurs after 2-3 months. Life span typically ranges from $2-3$ years.

Crustaceans, fish, sea stars and molluscs like octopus

\section{Notes:}

- Introduction - Possible methods of introduction include ballast water dumping from ocean-going vessels carrying planktonic larvae, ship hull fouling, aquaculture farms and intentional release.

- Negative Impacts - Competition with the oyster fishery, displacement of native mussels, and carriers of diseases and parasites harmful to native species.

- Control - To date, there has been no successful eradication of marine invertebrates in the United States. To eliminate the source of many introductions, antifouling paints and ballast water management are being researched.

- Food For Thought - Commercial harvesting may be the best way to control green mussel populations. Researchers caution against eating green mussels collected in the wild because little is known about their safety from a human health standpoint, and many Florida waters are closed to shellfish harvesting because of bacterial contamination. Research will determine if green mussels in Florida waters accumulate toxins or harbor parasites. 


\section{House Mouse}

Mus musculus

Order: Rodentia

Family: Muridae

Description: Slightly less than 7 inches long including their tail (tail is about 3 inches long). Color of fur ranges from brown to gray to white. Pointed snout with long whiskers, round ears and thin tails.

\section{Special Features:}

- Life Span - Mice in captivity live as long as 6 years.

- Activity - The house mouse is a nocturnal animal or mainly active at night.

- Mating - Most mice build nests in protected nooks, but some build burrows in the ground.

- Behavior - Teeth continue to grow throughout their lifetime; therefore, they must gnaw on hard things to keep wearing their teeth down.

Range and Habitat: Native to the Indian subcontinent, the house mouse has accompanied humans and colonized, tropical, temperate, semi-desert, desert, and sub-Antarctic regions throughout the world. Lives and breeds in and around buildings.

Wild Diet:

Reproduction:

Predators:
Omnivorous, they eat grain, seeds, grasses, fruit, roots, and stems, and sometimes insects.

Breeds every 10-17 weeks throughout the year. An average of 5-10 young per litter.

Cats, dogs, hawks, owls, weasels, raccoons, snakes, skinks, and people. 


\section{Notes:}

- They are a host to a range of diseases and parasites infectious to humans, the most serious being the bubonic plague.

- A relative of the white mouse; white mice are raised for scientific experimentation.

- House mice are major economic pests, consuming and despoiling crops and foodstuffs, and they have also been implicated in extirpations and/or extinctions of indigenous species in ecosystems they have invaded and colonized that are outside their natural range.

- The house mouse probably has a world distribution more extensive than any other mammal apart from humans. A mouse is extremely adaptable to any domestic environment. 


\section{Hydrilla}

Hydrilla verticallata

Order: Hydrocharitales

Family: Hydrocharitaceae

Description: Sometimes called "water thyme," Hydrilla is a submerged plant found in all types of freshwater. It can grow to the surface and form dense mats. Hydrilla stems are slender and branched. Its small leaves are strap-like, pointed and grow in whorls of four to eight around the stem. Tiny white flowers are visible on long stalks, and potato-like tubers form along the roots that are found in the mud. Hydrilla is a prohibited plant in Florida.

\section{Special Features:}

- Leaves - Hydrilla leaves are small, pointed and arranged in whorls of 4 to 8 . They have serrated margins and one or more sharp teeth under the midrib. Development of the leaves may vary with location, age and water quality.

- Growth Rate - Hydrilla can grow extremely rapidly, up to one inch per day, until it reaches the surface of the water and forms a thick mat that effectively shades any plants below it.

- Length - Plants have been known to reach lengths of up to 50 feet and produce a biomass of more than 130 tons per acre.

Range and Habitat: Historical reports indicate Hydrilla may have originated on the island of Sri Lanka, and DNA analysis points to India's southern mainland. Hydrilla can grow in almost any fresh water including springs, lakes, marshes, rivers and tidal zones of over 20 states.

\section{Reproduction:} Hydrilla reproduces mainly by regrowth of stem fragments, but also by means of axillary buds and subterranean tubers. Tubers can remain viable for more than 4 years and a single tuber can produce as many as 6,000 new tubers $/ \mathrm{m}^{2}$. 


\section{Notes:}

- How did it get here? - The dioecious (having male reproductive parts in one individual and female in another) strain was imported to the U.S. in the 1950s for use in aquariums. It entered Florida's inland water system after plants were discarded into canals in Tampa and Miami. The monecious (having both male and female flowers on the same plant) strain was a separate introduction, first found decades later in the Potomac Basin.

- Distribution of Populations - Southern populations are predominantly dioecious female (plants having only female flowers) that overwinter as perennials. Populations north of South Carolina are essentially monoecious.

- Stats - The most abundant aquatic plant in Florida public waters, $70 \%$ of Florida's freshwater drainage basins contain water bodies infested with Hydrilla.

- Limiting Factors - Very few factors limit Hydrilla because it can grow in shallow and deep water, high and low nutrient concentrations, low or very intense sunlight, and it can withstand cool temperatures.

- Why the Concern - Intakes for drinking water, power generation and irrigation are easily clogged. Shoreline access and boating traffic can be restricted.

- Impacts - Hydrilla grows aggressively and competitively forming thick mats that block sunlight penetration to native plants. It has been shown to alter the chemical and physical components of lakes. Stratification of the water column, decreased oxygen levels, and fish kills have all been documented.

- Money - Florida officials estimate they will spend $\$ 100$ million in a decade to control Hydrilla and water hyacinth. 


\section{Jack Dempsey}

Cichlosoma octofasciatum

Order: Perciformes

Family: Cichlidae

Description: Jack Dempsey are very aggressive cichlid fish found in many colors depending on age and mood, and ranging from a light yellowish-tan with turquoise speckles to a dark brown-blackish color with blue spots. All Dempsey have a thin reddish line along the top edge of their dorsal fin, which is more prominent in males than in females. Young fish are lightly colored with two golden spots along each side and dark stripes along the body. Males are normally larger and more brightly colored than females.

\section{Special Features:}

- Feeding - Jack Dempsey are omnivorous

- Complex Breeding Behaviors - Eggs are laid on the bottom by the female, and then the male or female will fan them with their fins in order to increase the flow of oxygen. When the eggs hatch, one of the adults nearly always remains to defend the young for the first weeks.

- Size - They grow to approximately 8-10 inches.

Similar Species: Similar species include the Rio Grande cichlid, Cichlasoma cyanoguttatum, the Convict cichlid, Cichlasoma nigrofasciatum and the Mayan cichlid, Cichlasoma urophthalmus.

Range and Habitat: Jack Dempsey are native to the Atlantic slope of Central America, from Rio Chachalacas and Rio Paso San Juan, Mexico, to Rio Ulua, Honduras. Jack Dempsey are established in the Gulf of Mexico region only in Florida, where they 
remain uncommon. The recorded populations probably represented several independent introductions. Jack Dempsey are typically found in canals with mud and sand bottoms and drainage ditches rich in aquatic vegetation.

Reproduction:

Jack Dempsey are substrate spawners. Both males and females are extremely aggressive toward other fish when guarding the clutch and the fry that hatch. Approximately 500-800 eggs are spawned per clutch.

\section{Notes:}

- Introduction - They were introduced through intentional or accidental releases from fish farms and recreational aquaria. The recorded populations probably represent several independent introductions.

- Potential Impacts - Given their limited range and population size, Jack Dempsey do not presently constitute a serious threat to the Gulf of Mexico ecosystem. It is uncertain whether the established populations will persist.

- Limitations - As is the case with other cichlids, Jack Dempsey are very resourceful. They are omnivorous and can be found in a great variety of habitats. In addition, they can tolerate relatively cold waters and very low oxygen concentrations. 


\section{Knight Anole}

Anoles equestris

Order: Squamata

Family: Polychrotidae

Description: 13-19" long. Larger lizard with wrinkled bony head, pale pink extensible throat fan, and enlarged toe pads. Snout long and wedge-shaped. Bright green; can change to brown. Yellow or white stripe under eye and over shoulder. Tail slightly compressed. Low crest, most pronounced on neck and shoulders.

\section{Special Features:}

- Behavior - This lizard becomes fiercely defensive when a snake, or anything resembling a snake, such as a stick or a garden hose, gets too close. It turns broadside to the threat, extends the throat fan, raises the back crest, and gapes menacingly. Knight Anoles are relatively slow and can be easily caught by hand, but their strong jaws and sharp teeth should give collectors pause.

- Habitat Use - Arboreal. Under shady canopies of large trees.

- Activity - Diurnal

Range and Habitat: Introduced into Miami-Dade and Broward counties, Florida. Native to Cuba.

Wild Diet: $\quad$ Insects, smaller lizards, and frogs.

Predators: $\quad$ Snakes, large birds, dogs and cats.

\section{Notes:}

- In Florida, this species does not seem to survive cold winters in great number.

- Reproduces in summer. 
This page was intentionally left blank. 


\section{Kudzu}

Pueraria montana variety lobata

Order: Fabales

Family: Fabaceae

Description: Kudzu is a vigorously growing perennial vine in the pea family. Dark green leaves, starchy fibrous roots and elongated purple flowers with a fragrance reminiscent of grapes readily identify this aggressive vine.

\section{Special Features:}

- Growth - Kudzu plants grow rapidly, extending up to or over 60 feet per season at a rate of about one foot per day.

- Leaves - Kudzu leaves are large and compound with three leaflets. Each leaflet has one to three lobes and the two lateral leaflets often are lobed on only one side, whereas the center leaflet has lobes on both sides.

- Roots - Kudzu roots are fleshy, with massive tap roots 7 inches or more in diameter, 6 feet or more in length, and weighing as much as 400 pounds.

- Vines - This vigorous vine may extend 32-100 feet in length, with stems $1 / 2-4$ inches in diameter. As many as thirty vines may grow from a single root crown.

- Flowers - Individual flowers, about a $1 / 2$-inch long, are purple, highly fragrant and borne in long hanging clusters. Flowering occurs in late summer and is soon followed by production of brown, hairy, flattened, seed pods, each of which contains three to 10 hard seeds.

Similar Species: Three-lobed leaves, purple flowers and aggressive growth make Kudzu easy to identify. Similar invasive vines include air potato, which has heart-shaped leaves and fleshy tubers on the tendrils, and skunk vine which has narrow arrow-shaped leaves and smells like skunk.

Range and Habitat: A native of Asia, Kudzu is now common throughout most of the southeastern U.S. and can be found as far north as Pennsylvania. It 
grows well under a wide range of conditions and in most soil types. Preferred habitats are forest edges, abandoned fields, roadsides, and disturbed areas, where sunlight is abundant. Kudzu grows best where winters are mild, summer temperatures are above 80 degrees Fahrenheit, and annual rainfall is 40 inches or more.

Reproduction:

Predators:
The spread of kudzu in the U.S. is primarily due to vegetative expansion by roots and vines. Kudzu also spreads somewhat through seeds, which are contained in pods and mature in the fall. Only one or two viable seeds are produced per cluster of pods and these hard-coated seeds may not germinate for several years.

Kudzu was originally planted all over the South by farmers who hoped to use it as cattle feed. However it grew much faster than the cattle could eat it.

\section{Notes:}

- Background - Kudzu was introduced into the U.S. in 1876 at the Philadelphia Centennial Exposition, where it was promoted for use in erosion control, as a forage crop and as an ornamental plant. Recognized as a pest weed by the U.S. Department of Agriculture in 1953, it was removed from the list of permissible cover plants.

- Management - For successful long-term control of kudzu, the extensive root system must be destroyed.

- Ecological Threat - Kudzu kills or degrades other plants by smothering them under a blanket of leaves, by girdling woody stems and tree trunks, and by breaking branches or uprooting entire trees and shrubs through the sheer force of its weight.

- Miscellaneous Uses - Vines are used to make baskets, leaves are used in cooking and in tea, and a drug extracted from kudzu root may help in the treatment of alcoholism. 


\section{Lionfish}

Pterois sp.

Order: Scorpaeniformes

Family: Scorpaenidae

Size: May reach 14-17 inches.

Description: Lionfish are easily recognized by their elongated venomous dorsal spines and bright stripes. Appendages on the head and around the eyes mask the mouth and eyes. Lionfish appear to hover in the water column. They have been observed hanging motionless at the crest of a reef or ledge waiting for prey to approach.

Range and Habitat: Temperate and tropical Indo-Pacific Ocean. Commonly seen in openings of coral or around pilings in harbors and bays.

Wild Diet:

Crustaceans, worms, smaller fish. Usually prefers live prey.

\section{Notes:}

- There are more than 300 species in the Scorpaenidae family.

- Due to their striking appearance and venomous sting, lionfish are also known as dragonfish, turkeyfish, zebrafish, scorpionfish and firefish.

- $\quad$ Lionfish are primarily nocturnal hunters. These voracious feeders will try to swallow anything they can get into their mouths.

- Lionfish often use their large pectoral fins to trap and corner smaller fish. When feeding on benthic (bottom-dwelling) prey, these fins spread like a net to trap prey.

- The venomous dorsal spines of lionfish are used as a defense mechanism. Lionfish often point these spines toward a predator.

- The sting of a lionfish can be painful, but it is rarely fatal to humans unless multiple stings are inflicted and help is not sought immediately. For immediate treatment, apply very hot water to the afflicted area. 
This page was intentionally left blank. 


\title{
Marine Toad
}

\author{
Bufo marinus
}

Order: Anura (or Salienta)

Family: Bufonidae

Description: Known as the cane or giant toad, marine toads have flat heads. Typically, 4-6 inches long but can reach 9 inches - female is usually larger. Dry skin that is brown with lighter spots and a cream underbelly. Very large eyes and large, triangular parotoid glands. Known to live 40 years in captivity. Nocturnal.

\section{Special Features:}

- Warts - Collections of poison glands. When the toad is attacked, warts exude milky fluid that irritates the attacker's mucus membranes (snakes and birds don't appear to be affected).

- Parotoid Glands - Two sets of poisonous glands behind each eye and extending along the body. When stressed, a marine toad can release enough toxin (milky white fluid) to kill a large dog.

- Tympanic Membranes - In addition to their use in hearing, these membranes, found on just behind the eyes, have been correlated with the ability of the toad to produce sound.

- Call - The Peterson Field Guide (Reptiles and Amphibians, 1991) describes the call of the marine toad as a slow, low-pitched trill, like the exhaust noise of a distant tractor. The mating call is produced by pumping air back and forth over vocal chords.

\section{Similar Species:}

Range and Habitat:

Wild Diet:
Large size and distinctive appearance distinguishes adults from other toads.

Diverse. Native from northern South America to Central America and Texas. Introduced to Haiti, Hawaii, the Philippines, Puerto Rico and Australia for pest control. However, occurrence in southern Florida is the result of accidental releases at Miami International Airport and further sales as pets. Prefers open, damp, leaf-littered fields where insect food is plentiful. Able to flourish in conditions from arid to tropical rainforests.

Having large appetites and being voracious feeders, they will eat just about anything they can catch and fit in their mouths. Use 
persistence, energy and speed to catch prey.

They often feed on worms and insects.

Reproduction:

In early spring, toads move to a breeding pond where males attract females with their calls. Males call while pushing themselves up on their front legs in shallow water. The male clasps the female behind the arms and the pair swims together (referred to as "amplexus") typically until the female comes into contact with some water weed. The female extrudes eggs as a long string while the male ejects sperm over them. This continues for several hours. The female then swims around so the long string of eggs (which is usually 7-10 ft. long) gets wrapped around the water weed. The female can lay up to 35,000 eggs. The tadpoles hatch after 12 days. Time to maturity varies with temperature, usually taking about 3 months.

Predators:

Dogs, snakes, larger frogs and toads, and birds. Dragonfly nymphs and other water insects feed on toad larvae. A small percentage of babies actually reach maturity due to predation.

\section{Notes:}

- Class Amphibia (from the Greek for "both lives") - Along with frogs and salamanders, toads are classified as amphibians.

- Frogs vs. Toads - Frogs usually have moist, smooth skin and are good leapers. Toads have dry, warty skin and usually hop.

- Invasive Species? - Introduced to certain areas, marine toads are beginning to out-compete native species.

- Movie Stars - A documentary about the marine toads' introduction and success in Australia is called Cane Toads: An Unnatural History. Be sure to rent it.

- "Toad Licking" - The secretions of this toad can be made into a hallucinogenic drug. Improper preparation of this drug, including "toad licking," has resulted in deaths.

- NOTE - A person does not get warts from touching toads, but their skin-gland secretions can be irritating to mucus membranes. After handling, remember to keep your fingers away from your eyes and mouth until you wash your hands. 


\section{Midas Cichlid}

Cichlasoma citrinellum

Order: Perciformes

Family: Cichlidae

Description: Midas cichlids can have 6 dusky to black bars on their flanks, a large black blotch on their midside, and a smaller black blotch on their tail fin. Two different color morphs of this species occur. The "typical" morph is gray with a series of markings along its flanks, which vary from bars to large spots. This is the most common morph over the natural range of the Midas cichlid. The second morph may be bright orange to red in color, which is the most common variety found in Florida.

\section{Special Features:}

- Coloration - This species exhibits two basic color morphs, gray and orange. The color varies between the introduced and and native ranges.

- Size - The Midas cichlid often reaches lengths of 9 inches.

Similar Species: There are two species similar to the midas cichlid: the convict cichlid, Cichlasoma nigrofasciatum, and the black acara, Cichlasoma bimaculatum.

Range and Habitat: Over their native range, Midas cichlids are most abundant in lakes with sufficient cover. They thrive in areas rich in macrophytes, sunken bushes and trees, and they frequently inhabit crevices in or between rocks. They have been known to dig burrows under rocks and sunken logs, which they use as cover or for sleeping.

Midas cichlids are native to the Atlantic slope drainages of Central America, from Nicaragua south to Costa Rica. In Florida, they are etablished in Black Creek canal and adjoining canals northeast of Homestead, Miami-Dade County. 
Specimens have also been collected from Broward County and Hillsborough County. This species has not been found in other parts of the Gulf of Mexico ecosystem; however, there is an established population slowly expanding its range on the Atlantic coast of Florida.

Reproduction:

Over its native range this species typically builds nests in caves, crevices among rock piles, or less frequently digs a pit in an open area adjacent to a hard vertical structure. Eggs are deposited on the walls of caves and crevices, or if pits are dug, on the hard vertical structure adjacent to the nest. Males and females care for the eggs.

\section{Notes:}

- Common Names - Frequently called Mojarra; Heros erythraeus and Cichlasoma erythraeum are listed as possible synonyms.

- Means of Introduction - Introductions into Florida were via aquarium or fish farm releases. In other states, introductions most likely represent aquarium releases.

- Importance to Fisheries - Over its native range, the Midas cichlid is among the most popular of food fishes.

- Ecology - The impact of the Midas cichlid is currently unknown.

- Feeding - Midas cichlids frequently feed by sifting through substrates, straining out edible materials, and then spitting the remaining substrate from their mouths. They scrape and pick off food items from rocks and plants. Midas cichlids feed mostly on benthic items, such as snails, other molluscs, algae and insects.

- Life Span - The Midas cichlid may live up to 15 years. 


\section{Nutria}

Myocastor coypus

Order: Rodentia

Family: Myocastoridae

Description: Nutria are large semi-aquatic rodents, smaller than a beaver but larger than a muskrat. Unlike beavers or muskrats, they have round, scaly tails with some hair. The muzzle and chin are white and the ears and eyes are small. The incisors are large and dark orange, protruding beyond the lips. The four inner toes of the hind feet are webbed. Nutrias may be 3 feet long and weigh up to 35 pounds.

Range and Habitat: Nutria are native to South America. Their original range includes Argentina, Chile, Bolivia, Uruguay, Paraguay and southern Brazil, where they are called coypu. After escaping from captivity in the U.S. and elsewhere, they now inhabit a much greater area. Nutria were first imported into the United States between 1899 and 1930 in an attempt to establish a fur farm industry. Many of the fur farms failed in the late 1940 s because fur prices fell and nutria did not reproduce well in captivity. Many nutria were released into the wild. Nutria are now reported throughout the Chesapeake Bay system and in every Gulf state, including Florida. They have caused widespread damage to wetlands in Texas, Louisiana and the Chesapeake. In Florida, possession of nutria requires a license.

Nutria spend their lives in or near water, especially marshes and ponds.

Wild Diet:

Reproduction:
Favorite foods include rushes, reeds, cattails, arrowhead and sawgrass. They will also eat sugarcane.

Nutria breed year-round and are extremely prolific. Males reach sexual maturity at 
4-9 months, and females are sexually mature at 3-9 months. With a gestation period of only 130 days, in one year, an adult nutria can produce two litters and be pregnant with a third! The number of young in a litter ranges from 1-13. Females can breed within a day of having a litter. At birth, young nutria are fully furred and the eyes are open. Newborn nutria feed on vegetation within hours, and they will nurse for 7-8 weeks.

\section{Special Features:}

- Life Span - A nutria's lifespan is about 6 years.

- Behavior - Nutria feed on the roots of plants, severely damaging wetlands by digging underneath and overturning plants to feed on the root mat. Nutria are excellent swimmers, and typically swim with their food to a feeding platform for eating.

- Habitat Use - Although they are generally found in freshwater habitats, some populations inhabit brackish and salt waters.

- Nutritious Nutria? - Although Louisiana officials have attempted to market nutria as a restaurant entrée, it hasn't yet caught on as a popular dinner item. 


\section{Oscar}

Astronotus ocellatus

(Astronotus - marked with star on back; ocellatus - spotted with little eyes)

Order: Perciformes

Family: Cichlidae

Description: Coloration is usually very dark, olive-brown to deep blue-black with pale yellow or orange markings. The base of the caudal fin has a large spot or ocellus bordered with red. Fin coloration varies, usually they are very dark, and occasionally they have ocelli (eyelike colored spots). Eyes are red.

\section{Special Features:}

- Eye Spot - The eyespot on the tail is a common feature among Oscars. The spot is believed to provide a diversion to misdirect the attack of a potential predator toward the tail.

- Growth - Oscars grow very rapidly in a short period of time, and can reach lengths of 14 inches.

Range and Habitat: Over its native range this species is found in the Amazon, Orinoco and La Plata River systems in South America. Due to temperature limitations, their range in Florida is as far north as Tampa Bay. High densities of Oscars are associated with extensive marsh-type and modified habitats (e.g. Everglades basin).

\section{Reproduction:}

Oscars are sexually mature once they reach a length of approximately 5 inches. Fish pair off and often stay together to breed several times. Females lay up to 2000 eggs, which hatch in just a few days. In Florida, spawning occurs from June to October. 


\section{Notes:}

- Introduction - This South American cichlid has been established in Florida waters since the late 1950s when it was first released from a fish farm and spread by anglers who released them in new sites.

- Limitations - Oscars do not tolerate cold temperatures.

- Feeding Habits - Oscars are mainly carnivorous, but they are known to eat plant matter as well. The main components of their diet include fish and insects, with other items such as reptiles taken opportunistically.

- Interest to Fisheries - Oscars are frequently taken by sport fishermen, and they are presently one of the most popular sport fish in southern Florida. In the early 1980s, there was an unexplained increase in numbers, especially in the water conservation areas of the Everglades. With this increase, Oscars grew in popularity as a sport fish. In 1991-1992 the number of Oscars harvested in Everglades water conservation areas was about 53,286.

- Potential Impacts - The impact of this species on native fishes is unclear. There is no concrete evidence of displacement of native fishes by Oscars. However, this species is renowned for its aggressiveness. It may have a significant impact on native fishes through direct predation and competition for breeding areas. 


\section{Peacock Bass}

Cichla ocellaris (This may not be the species in Florida.)

Order: Perciformes

Family: Cichlidae

Description: The peacock bass derives its name from the large conspicuous, black mark (outlined in gold) on its tail. This ocellus resembles the "eye" on the plume of a peacock's tail. Hence the name, "peacock." It generally has a dark greenish-black or bronze back and a light, white belly with the underside being golden, yellow, light chartreuse, pink or blood red. The main body can be green, yellow, gold or dark black, with dusky, black, vertical bars along the sides.

\section{Special Features:}

- Feeding - Peacock bass are exceptionally adaptable because they are voracious predators and will often pursue prey larger than themselves.

- False Eye - The prominent "false eye" on the tail is actually a deceptive target for predators.

- Coloration - The irregular patterns and vivid shades of green, blue, orange and gold obscure the actual eye and detract from its prominence.

- Weight - In their native range, some species grow to a maximum size of $35 \mathrm{lbs}$, whereas other species average 2-4 lbs.

Similar Species:

The taxonomy of peacock bass species is uncertain, and several possible species, including the five prominent ones, have not been thoroughly identified and described.

Range and Habitat: A native of the Amazon and other South American rivers, the peacock bass is an exotic freshwater cichlid in Florida. In its native range, it inhabits marginal lagoons during the dry season and flooded forests during the the rainy season. In the lagoons, it swims in the early morning and at the end of the day. When the 
sun is at its height, peacock bass go to the middle of the lagoons. In rivers without lagoons, it protects itself from currents by remaining behind rocks and sticks. It is not keen on fast-flowing water.

Reproduction:

The peacock bass is a substrate spawner, with approximately 2000-3000 eggs per brood. Breeding pairs guard their clutch for approximately nine weeks, at which time the fry move from open waters to areas rich in vegetation along banks. As is the case with most cichlids, breeding pairs are highly territorial and aggressive.

\section{Notes:}

- Common Names - Tucunare or Pavon

- To Be or Not to Be a Bass? - The peacock bass resembles the black bass, but it is not a member of the same family. It is just one of the 1,600 plus members of the family of fish called cichlids.

- Introduction - Peacock bass are probably the only species of cichlid deliberately introduced into the United States out of the 13 species found here. Released in 1984 by the Florida Game and Freshwater Fish Commission, they were the first exotic species legally introduced into Florida waters. The Florida Game and Fresh Water Fish Commission obtained the breeding stock from several regions of South America. The progeny were released into open waters primarily as a sport fish, but there was also a hope that peacock bass would prey on and control other introduced cichlids. 


\section{Pike Killifish}

Belonesox belizanus

Order: Cyprinofontiformes

Family: Poeciliidae

Description: Pike killifish can easily be identified by their long jaws and large teeth. The origin of the dorsal fin is posterior to the origin of the anal fin. Dorsally, they appear dark olive in color, fading to white at the belly. Several rows of black spots are present on their sides and a black spot is present on the tail fin.

\section{Special Features:}

- Feeding - Pike killifish are ambush predators; they lurk behind plants, roots, and rocks until they strike violently at their prey. Within one day of their birth, young begin feeding on small crustaceans and newborn fish.

- Size - Pike killifish are the largest fish in the family Poeciliidae, and they grow to about 8 inches total length in Florida.

Range and Habitat: Native to Central America, pike killifish were introduced into a canal in Dade County, Florida in November of 1957, after termination of a research project. Over their native range, pike killifish are found along the banks and in the upper water levels of slow moving fresh water streams, in the brackish waters of mangrove and reed swamps, and around inlets of salty bays. In Florida, pike killifish are typically found in shallow waters rich in vegetation or in mangrove swamps. They are seldom present in open waters.

Reproduction:

Pike killifish are live-bearers that breed throughout the year. They are capable of storing sperm for at least 47-56 days, and may produce one brood about every 40 days. Gestation takes between 30 and 50 days. 
Among mature fish, females are larger than males and significantly more numerous.

\section{Notes:}

- Potential Impacts - Pike killifish exert strong pressure on small native fish through direct predation.

- Mosquitoes - Pike killifish like to eat the native eastern mosquitofish, which are predators on mosquito larvae.

- Interest to Fisheries - Pike killifish are of no value as a food fish.

- Predator or Prey? - Due to its torpedo-shaped body and preference for swimming near the surface, the pike killifish is often a preferred prey for larger fish. 


\section{Red-eared Slider}

Trachemys scripta elegans

Order: Testudines

Family: Emydidae

Description: The top of this turtle's shell (carapace) is smooth and gently curved, and it is olive to black with yellow stripes and bars. This medium-sized turtle is best identified by a red or sometimes yellow patch that is found just behind its eye.

\section{Special Features:}

- Habitat Use - Almost exclusively aquatic, red-eared sliders rarely venture far from water except to lay eggs or to migrate to a new water body.

- Activity - Sliders are active at any time of the day; however, feeding usually occurs in the early morning or late afternoon. At night, sliders sleep underwater.

Range and Habitat: The red-eared slider is at home in quiet, freshwater systems that have muddy bottoms and abundant aquatic vegetation. They range from Indiana to New Mexico and down through Texas to the Gulf of Mexico. The slider is commonly seen basking in the sun, on logs or masses of vegetation. Primarily from west of the Mississippi River, they are now common in Florida and other parts of the world, probably due to people releasing their pets.

Wild Diet:

Sliders are omnivorous. Hatchlings and juveniles are more carnivorous, preferring animal matter. As they age, they gradually consume more plant matter. When adult, they show no preference for plants or animals and will eat almost any available food. Prey include insects, crayfish, shrimp, worms, snails, amphibians, and small fish. Algae and 
duckweed are two of the aquatic plants eaten by red-eared sliders.

Reproduction:

Predators:
Mating and courtship usually occur in the spring, but pairs have also been seen in the summer and early fall. Sliders have an elaborate courtship. A male tries to get in front of a female and face her, then he stretches out his front feet and vibrates his claws against the her head and neck. Mating usually takes about 15 minutes, then the female digs a nest outside of the water and lays about 5-20 eggs that take 65-75 days to hatch.

Raccoons, otters, alligators, gars, crows, mink, and muskrats prey on sliders. Occasionally they are caught and eaten by humans.

\section{Notes:}

- These turtles are very popular in the pet trade. 


\section{Tilapia}

- Blackchin tilapia: Sarotherodon melanotheron

- Spotted tilapia: Tilapia mariae

- Blue tilapia: Oreochromis aureus

- Mozambique tilapia: Oreochromis mossambicus

Order: Perciformes

Family: Cichlidae

Description: Females and non-breeding males generally have black dorsal blotches. Breeding males often have a distinct coloration with patches of color on their heads and on the margins of the dorsal and caudal fins. The Mozambique tilapia has 14-20 gill rakers, while Blue tilapia can be distinguished by its higher gill raker count (18-26) in the lower branch of the gill arch. Blackchin tilapia can be distinguished by the black coloration on the underside of the chin and the gold coloration on the operculum. The dorsal fin of spotted tilapia has 16 spines.

\section{Special Features:}

- Adaptations - They quickly grow accustomed to new habitats, and their resistance is absolutely incredible. Because of their ability to adapt to different habitats and, above all, their food value, tilapia have been introduced into many areas both purposefully and accidentally. In Florida, possession of tilapia is regulated.

- Size - Tilapia can reach up to 18 inches in length and weigh well over 1 pound.

Similar Species:

The common name "tilapia" refers to several genera of fishes of the family Cichlidae, order Perciformes, originating in Africa and southwest Asia.

Range and Habitat: Native to Africa and southwest Asia, tilapia are found in lakes, ponds, rivers, streams and canals throughout the tropical and sub-tropical regions of the world. 
Reproduction:

Some species such as the Mozambique tilapia are mouth brooders. Tilapia will excavate a nest on gravel and defend the site against predators. As with many cichlid species, both parents may protect the nest or young. Blue and Mozambique tilapia may become quite aggressive and will chase trespassers 20 or 30 feet from the nest before returning. During breeding season, tilapia build nests in the shallow areas along shorelines. Spawning begins when water temperatures reach $20^{\circ} \mathrm{C}\left(68^{\circ} \mathrm{F}\right)$.

\section{Notes:}

- Aquaculture - Tilapia are one of the major groups of farmraised fish in the world.

- Consumption - Tilapia farming and consumption are rapidly increasing in the US. In fact, in every year since 1995, retail sales of tilapia surpassed those of trout.

- Fisheries Impacts - In Everglades National Park, blue tilapia compete with largemouth bass for nesting sites. Since the largemouth bass fishery represents over $\$ 50$ million annually to the state economy, state officials take this competition seriously.

- Ecological Effects - Tilapia are not generally considered predatory, however in large numbers they are capable of drastically altering habitat and competing for resources. They are capable of reproducing under a wide range of conditions and are known to reach "plague proportions" in some areas.

- Feeding - Tilapia at all sizes feed primarily on phytoplankton and zooplankton, as well as some invertebrates.

- Growth Rate - Tilapia grow fast and may reach sexual maturity at 6 months. Given the resulting fecundity, and their adaptability, it is not surprising that tilapia are abundant. 


\section{Tokay gecko}

Gekko gecko

Order: Squamata

Family: Gekkonidae

Description: About 10-12 inches long. Greenish gray color with gray and orange-brown spots covering the body. The body is slender, topped by a large head. The eyes are prominent in all species and the gecko's vision is excellent. Broad fleshy toes with inner folds.

\section{Special Features:}

- Senses - Just like snakes, they can also use their tongue to smell. They have a special organ on the roof of their mouth called a Jacobson's organ, which takes scent particles from the tongue and relays messages about the surroundings to the brain.

- Call - Common name comes from the sound of their loud call.

- Life Span - Life span is an average of 10 years, but they can live for 20 years in captivity.

- Behavior - Solitary lifestyle, with territories protected by males.

- Activity - Nocturnal

- Reproduction - Oviparous or egg laying

Range and Habitat: From Southeast Asia and Malayan Isles. Live in tropical and subtropical environments. Found among vegetation in rainforests, on mountainsides, on rocky outcrops, and in deserts. Likes to live in bushes, trees and on or around rocks. Now thrives in South Florida, the Caribbean, and Hawaii.

Wild Diet:

Reproduction:
Tokays will eat anything they can catch and chew; crickets, insects, baby mice, baby birds, and small lizards.

Oviparous. Eggs are deposited on the underside of a rock or piece of bark. Females lay 2 or more eggs at a time. Hatchlings are 
about 2-3" long. When hatched they eat their outer covering of skin. They become sexually mature at a year old.

Predators: $\quad$ Snakes, dogs, cats and people

\section{Notes:}

- Tokays do not like to be handled, and they readily bite the hand that feeds them. Therefore, Tokay geckos only make good pets for those who enjoy watching their pets and not handling them. Also, Tokay geckos can be really noisy pets.

- Many Tokay geckos have escaped or been "set free" by their unhappy owners. Now they are an established, invasive species in South Florida.

- Most common around buildings, but also threatens native species in the Everglades.

- Florida now has more non-indigenous species of lizards than indigenous ones.

- The Tokay gecko arrived in Florida through multiple releases. 


\section{Walking Catfish}

Clarias batrachus

Order: Siluriformes

Family: Clariidae

Description: Walking catfish may appear dark brown, gray, or olive with white specks on the latter half of the flanks. Fins are gray-green and there may be red borders on the median fins and some yellow on the dorsal fin. Although all Florida imports were originally albinos (which are tinted yellow at the outer margins of dorsal fins), albinos in the wild are now rare and descendants have reverted to the dominant, dark-color phase, probably a result of natural selection by predators.

\section{Special Features:}

- Locomotion - Snakelike

- Breathing - The gills of the walking catfish are stiffened to prevent collapse while out of water. On land, they keep their gills closed and in the water the gills remain open. On land, they breathe most efficiently using a special part of the gill chamber consisting of spongy organs that grow from the upper ends of the gill arches. These organs are well supplied with blood vessels and operate efficiently on land as well as in low oxygen waters.

- Barbels - Walking catfish possess 4 pairs of barbels: one pair of nasal, one pair of maxillary and two pairs of mandibular barbels.

- Male or Female? - The male of this species is usually more colorful than the female. The most distinguishing feature however, is a dark spot on the rear of the male's dorsal fin.

Range and Habitat: The native range of the walking catfish spans Southeast Asia and includes eastern India, Sri Lanka, Bangladesh, Burma, Indonesia, Singapore and Borneo. They are commonly found in freshwater and brackish water. They can exist in cloudy, low-oxygen waters. 
Wild Diet:

Reproduction:
Omnivore. Walking catfish are mainly active at night and prey on items such as insect larvae, fish eggs, fish and occasionally plant material.

It is reported that walking catfish engage in mass spawning migrations in late spring and early summer. Adhesive eggs are laid in a nest or in submerged vegetation and the males guard the eggs. Juveniles appear in late summer and sexual maturity is attained by the end of the first year.

\section{Notes:}

- Introduction - In the early 1960 s, walking catfish were imported to Florida from Thailand for the aquarium trade.

- Movement - In Florida, dispersal apparently has occurred by way of the interconnected network of canals. However, spread was accelerated by overland migration, typically during rainy nights.

- Impact of Introduction - Largely unknown. In Florida, walking catfish are known to invade aquaculture farms, entering ponds where these predators prey on fish stocks. In response, fish farmers erect fences to protect ponds, though they are inefficient in floods.

- Threats - Cold weather is believed to be the major threat in the introduced range.

- Status - In 1967, the importation or possession of the walking catfish without a permit was outlawed in the state of Florida. 


\section{Water Hyacinth}

Eichhornia crassipes

Order: Liliidae

Family: Pontederiaceae

Description: Known as one of the "world's worst aquatic weeds," the attractive water hyacinth is very deceiving. Large purple flowers once made this plant a popular ornamental species for fish ponds, but it is now illegal in Florida and some other states. Florida officials estimate they will spend $\$ 100$ million in a decade to control water hyacinth and another invasive, Hydrilla.

\section{Special Features:}

- Leaves - This plant only has basal leaves (formed at the base of the stem) that reach up to 6 inches in length. Each leaf is generally rounded, and many of the petioles (the stalks or stems of the leaves) have inflated bases that keep the plant extremely buoyant.

- Flowers - Each flower has 6, bluish-purple petals joined at the base to form a short tube. One petal has a yellow spot. Blooms first appear in late spring, and they continue into late summer, with each plant producing a single spike comprised of 8-15 flowers.

- Fruit - The fruit is a three-celled capsule containing many minute, ribbed seeds.

- Roots - Water hyacinth obtains its nutrients directly from the water, and it is used in wastewater treatment facilities to extract pollutants. Its large root masses make it an efficient water filter.

Range and Habitat: This South American native was introduced into Florida in the 1880 s, and it covered more than 125,000 acres of public lakes and navigable rivers by the early 1960 s. Water hyacinth has become the worst floating, aquatic weed in many tropical and sub-tropical parts of the Americas, Asia, Australia, and Africa. In Africa, it infests every major river and nearly every major freshwater lake. In the United States, it 
flourishes in hundreds of bodies of water in Hawaii, California and throughout the south from Texas to the Carolinas.

Reproduction:

Water hyacinth reproduces sexually by seeds and vegetatively by budding. The seeds can germinate in a few days or remain dormant for 15-20 years. They usually sink and remain dormant during periods of stress (drought). Upon reflooding, the seeds germinate and renew the growth cycle.

\section{Notes:}

- Growth Rates - The growth rate of water hyacinth is among the highest of any plant. In Florida, water hyacinth populations can double in as little as 6-18 days by sending off short runner stems, which develop new plants.

- Effects - Water hyacinth blocks waterways and limits boat traffic, recreation, flood control and wildlife use. By shading and crowding out native aquatic plants, this exotic species reduces biological diversity in aquatic ecosystems.

- Fish - Large water hyacinth populations can adversely affect fish populations. As vegetation continually falls to the bottom, it decays and consumes oxygen. Certain species of fish cannot tolerate low levels of oxygen. One acre of water hyacinth can deposit approximately 200 tons of decaying plant material on the bottom of a water body each year. The nutrients in these decaying plants are released back into the water to support growth of more water hyacinth.

- Methods of Control - 1) herbicides, 2) direct harvesting and 3 ) biological control, including the use of two weevil species (Neochetina spp.) and a moth (Sameodes albiguttalis). 